\title{
Quercetin and its methylated metabolites : the chemical basis of activity
}

Citation for published version (APA):

Moalin, M. (2014). Quercetin and its methylated metabolites : the chemical basis of activity. [Doctoral Thesis, Maastricht University]. Maastricht University. https://doi.org/10.26481/dis.20140611 mm

Document status and date:

Published: 01/01/2014

DOI:

10.26481/dis.20140611mm

Document Version:

Publisher's PDF, also known as Version of record

\section{Please check the document version of this publication:}

- A submitted manuscript is the version of the article upon submission and before peer-review. There can be important differences between the submitted version and the official published version of record.

People interested in the research are advised to contact the author for the final version of the publication, or visit the DOI to the publisher's website.

- The final author version and the galley proof are versions of the publication after peer review.

- The final published version features the final layout of the paper including the volume, issue and page numbers.

Link to publication

\footnotetext{
General rights rights.

- You may freely distribute the URL identifying the publication in the public portal. please follow below link for the End User Agreement:

www.umlib.nl/taverne-license

Take down policy

If you believe that this document breaches copyright please contact us at:

repository@maastrichtuniversity.nl

providing details and we will investigate your claim.
}

Copyright and moral rights for the publications made accessible in the public portal are retained by the authors and/or other copyright owners and it is a condition of accessing publications that users recognise and abide by the legal requirements associated with these

- Users may download and print one copy of any publication from the public portal for the purpose of private study or research.

- You may not further distribute the material or use it for any profit-making activity or commercial gain

If the publication is distributed under the terms of Article $25 \mathrm{fa}$ of the Dutch Copyright Act, indicated by the "Taverne" license above, 


\section{Quercetin and its methylated metabolites:}

The chemical basis of activity

Mohamed Moalin 
(C) Mohamed Moalin, Maastricht 2014

\section{ISBN}

NUR

Cover design: Mohamed Moalin and Erik Ruijters

Lay-out: Mohamed Moalin
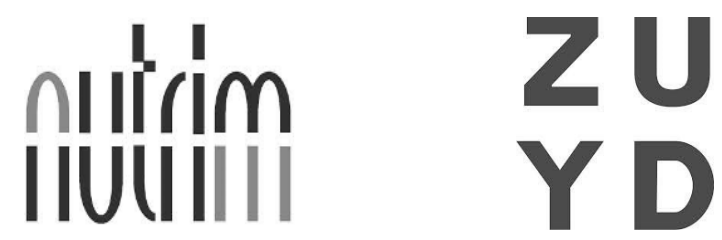

The work in this thesis was financially supported by the dr.ir. J.H.J. van de Laar foundation. The studies presented in this thesis were performed at the University of Maastricht in the Department of Toxicology, at Zuyd University of Applied Sciences in Heerlen in the Research Centre for Material Sciences, and in Chemelot Innovation and Learning Labs (CHILL) at the Chemelot Campus in Geleen. 


\title{
Quercetin and its methylated metabolites: \\ The chemical basis of activity
}

\author{
PROEFSCHRIFT \\ ter verkrijging van de graad van doctor \\ aan de Universiteit Maastricht, \\ op gezag van de Rector Magnificus, Prof.dr. L.L.G. Soete, \\ volgens het besluit van het College van Decanen, \\ in het openbaar te verdedigen \\ op woensdag 11 juni 2014 om 12.00 uur \\ door
}

\section{Mohamed Moalin}

geboren te Mogadishu (Somalia) op 18 april 1983 


\section{Promotor}

Prof.dr. A. Bast

\section{Copromotors}

Dr. G.R.M.M. Haenen

Dr. G.P.F. van Strijdonck (Zuyd Hogeschool Heerlen)

\section{Beoordelingscommissie}

Prof.dr. H.A.J. Struijker-Boudier (voorzitter)

Prof.dr. T.M. Hackeng

Prof.dr. R. Lesyk (Danylo Halytsky Lviv National Medical University, Ukraine)

Prof.dr. R.J.M. Nolte (Radboud University Nijmegen)

Prof.dr. W.J.F. van der Vijgh 


\section{Table of contents}

Preface

Chapter 1

Chapter 2

Quercetin metabolites in humans

A planar conformation and the hydroxyl groups in the $\mathrm{B}$ and $\mathrm{C}$ rings play a pivotal role in the antioxidant capacity of quercetin and quercetin derivatives

Chapter 3

Protection of the catechol moiety of quercetin through micro-reactor technology

Chapter 4 Quercetin radical's unpaired electron is delocalized in conjugated $\pi$-system of its B-ring

Chapter 5

Peroxynitrite scavenging of quercetin and structural analogues: The AC-ring of quercetin donates the first electron, the B-ring scavenges the AC-ring and safely cages the unpaired electron in the quercetin radical

Chapter 6 Competition between ascorbate and glutathione for the oxidized form of methylated quercetin metabolites and analogues: Tamarixetin, 4'Omethylquercetin, has the lowest thiol reactivity

Chapter 6 Supplemental information

Summary

Conclusions and implications

Samenvatting

Conclusie en relevantie

Acknowledgements

Curriculum vitae

List of publications 

Preface 


\section{Preface}

\section{Preface}

Toxicology is the study of effect, mode of action, detection and treatment of poisonings, especially the poisoning of humans. In the $16^{\text {th }}$ century, Paracelsus paved the path for toxicology by stating: "Alle Dinge sind Gift und nichts ist ohne Gift; allein die Dosis macht, dass ein Ding kein Gift ist." This roughly translates as; "All substances are toxic, provided the dose is high enough". This statement forms the fundament for toxicology, namely: the risk of toxicity is a function of the hazard of a substance and its exposure.

Molecular oxygen $\left(\mathrm{O}_{2}\right)$ is a hazardous compound that naturally occurs as a diradical $\left(\mathrm{O}_{2}^{2 \bullet}\right) \cdot \mathrm{O}_{2}^{2 \bullet}$ has by far the greatest exposure level of any hazardous compound to humans, making it the number one cause of human mortality. Unfortunately, reducing exposure is not an option because $\mathrm{O}_{2}^{2 \bullet}$ is, paradoxically, essential for sustaining human life. In the body, it is used to release energy from food that also leads to other types of reactive oxygen species (ROS) as byproducts. These ROS are even more hazardous and these toxic 'metabolites' of molecular oxygen are thought to actually initiate oxygen toxicity. ROS can cause oxidative stress in vivo and severely damage tissues. Fortunately, the body can utilize anti-oxidants from food to circumvent damage from ROS.

The definition of an anti-oxidant is subject to change. Initially, it was thought that an anti-oxidant was only needed to rapidly react with radicals to prevent radical toxicity. Halliwell \& Gutteridge [1] coined a more accurate but rather pragmatic definition by stating that an anti-oxidant is a substance that, when present at low concentrations compared with that of an oxidizable substrate, inhibits oxidation of the substrate. In this definition, the mechanism of action is not specified. Focusing on free radical scavenging as mode of action, an antioxidant can be defined as a catalyst that channels the dangerous reactivity of ROS safely into the anti-oxidant network of the body. This also puts an emphasis on the cooperation between anti-oxidants, which is well documented for the interplay between vitamin $\mathrm{E}$ and vitamin $\mathrm{C}$. From this concept, three important criteria can be deduced that make up a good scavenging anti-oxidant: (i) the antioxidant should be able to react relatively fast with radicals, (ii) it should form a 
relatively stable product when it has neutralized a ROS and finally (iii) the oxidized anti-oxidant should be safely regenerated in the anti-oxidant network of the body.

Flavonoids are a family of polyphenols, ubiquitously found in plants, which contain many compounds that might fulfill the three criteria needed for a good anti-oxidant. As a group, they are implicated in the health benefits of fruit and vegetable consumption. The most prominent dietary flavonoid found in the Western diet is quercetin $(\mathbf{Q})$ that has been shown to have one of the highest anti-oxidant capacity. However, in vivo, the hydroxyl groups of $\mathbf{Q}$ are readily metabolized into $O$-methylated, $O$-glucuronidated and $O$-sulfated derivatives. These $O$-conjugated metabolites, $\mathbf{Q}$ and $\mathbf{Q}$-glycosides can be extensively metabolized and catabolized by the complex indigenous microflora into smaller phenolics. Chapter 1, which reviews the metabolism and metabolites of $\mathbf{Q}$, describes this in more details.

In this thesis the focus is not only on $\mathbf{Q}$ itself but also on the methylated derivatives of $\mathbf{Q}$. First of all, methylation is a relatively subtle change in the chemical structure of $\mathrm{Q}$ and the methylated derivaties are known to display antioxidant activity. Relating the effect of this subtle structural change with the change in activity is an elegant strategy to elucidate the molecular mechanism of action of the compounds. In addition, methylation of $\mathbf{Q}$ might even lead to improved cellular uptake, metabolic stability and lower toxicity.

It is important to note that, the biological effect of an anti-oxidant is just the sum of the chemical reactions and interactions with the components (e.g. free radicals and the anti-oxidant network) in the cellular environment. $\mathbf{Q}$ can protect cells by donating electrons to free radicals, leading to the oxidation of the anti-oxidant (Scheme 1). The oxidation can occur in several steps and follow several paths.

In this thesis, we determine the effect of methylation of $\mathbf{Q}$ on each step of the anti-oxidant process to get a more profound understanding of the molecular mechanism. More specifically, our aim is to elucidate which structural elements are pivotal in each of the three stages involved in the mode of action of Q, i.e. (i) to quickly pick up the radical (ii) to temporarily store the radical and (iii) to 


\section{Preface}

safely shuttle this reactivity into the anti-oxidant network. This will help to understand its biological effect and will provide a rational for the use of this antioxidant. The next goal is to rationally design more potent anti-oxidants in order to further optimize the treatment of oxygen toxicity.

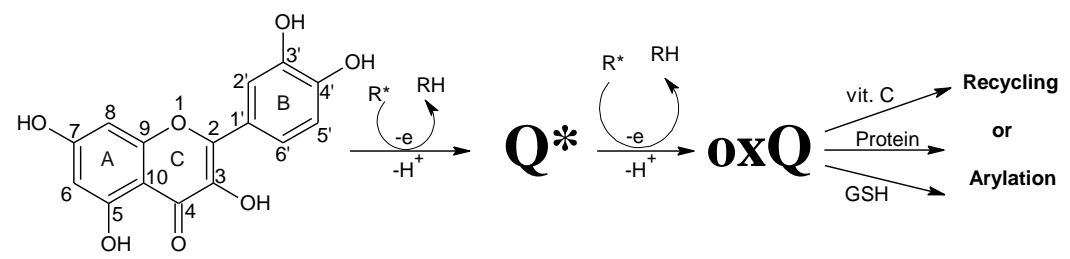

Scheme 1. Schematic representation of the different steps involved in the scavenging activity of quercetin $(\boldsymbol{Q})$.

In Chapter 2, we investigate the possibility of using flow chemistry to synthesize $O$-methylated derivatives of $\mathbf{Q}$ in a highly controlled and well-defined micro-reactor. The advantage of this "micro-reactor" is the reproducibility and the relative ease to optimize and up-scale synthesis to a "Kilo-Flow". In Chapter 3, the "regular lab" synthesis and the effect of methylation on the anti-oxidant capacity of $\mathbf{Q}$ is established. In Chapter $\mathbf{4}$, the structure of $\mathbf{Q}$ radical, the roles of its different rings (i.e. A, B and C-rings) and the effect of $O$-methylation on the radical species are demonstrated. In Chapter 5, the effect of methylation on the peroxynitrite (PON) scavenging potency of $\mathbf{Q}$ is determined. In addition, we discuss which of the two pharmacophores, i.e. the AC-ring or the B-ring, of $\mathbf{Q}$ is more prone to donating an electron to a free radical such as peroxynitrite (PON). In Chapter 6, the interaction of oxidized $\mathbf{Q}$ and its oxidized methyl derivatives with the anti-oxidant network (i.e. vitamin $\mathrm{C}$ and GSH) are described. Finally, Chapter 7 summarizes the results of this thesis and elucidates the chemical basis of the anti-oxidant activities of $\mathbf{Q}$ and its methylated derivatives, by expanding and completing the chemistry depicted in Scheme 1. 
Preface

\section{References}

1. Halliwell, B.; Gutteridge, J. M. C. Free radicals in biology and medicine. Oxford: Oxford University Press; 2007. 



\section{Chapter 1}

\section{Quercetin metabolites in humans}

Mohamed Moalin, Geja Hageman, Gino P.F. van Strijdonck, Aalt Bast and Guido R.M.M. Haenen 


\title{
Chapter 1
}

\begin{abstract}
Flavonols, especially quercetin $(\mathbf{Q})$, represent a substantial amount of the chemical constituents in fruits and vegetables consumed in the Western diet. In addition, a flavonol rich diet has been associated with health benefits. However, flavonols are mainly found as metabolites in vivo, gradually shifting the focus of anti-oxidant research to the metabolites of $\mathbf{Q}$. There is a growing awareness that it might actually be the metabolites that are responsible for the health benefits associated with $\mathbf{Q}$. Therefore, this review provides an inventory of $\mathbf{Q}$ metabolites that have been identified in literature. Special attention is given to the methylated derivatives of $\mathbf{Q}$ that have several advantages, such as relatively low toxicity, relatively high metabolic stability and improved absorption combined with a direct health promoting effect.
\end{abstract}




\section{Introduction}

Many studies have associated a high intake of fruit and vegetables with a decreased risk of human malignancies, including colon, pancreatic, bladder, stomach, breast, lung, laryngeal, oesophageal, and oral cancers [1-3]. Although food plants consist of many compounds that can provide chemo-protective effects, one class of compounds that has gained much interest is the flavonoids. Flavonoids occur in most plant species and can account for a significant percentage of the chemical constituents in vegetables, fruits, and beverages such as tea and red wine [4,5]. Contemporary interest in flavonoids focuses on their anti-oxidant and anti-inflammatory properties. The total group of flavonoids, which comprise more than 8000 compounds, is too diverse to be covered in a single review. Therefore, the focus will be put on the most potent anti-oxidant subgroup, the flavonols. The predominant flavonols found in the Western diet are glycosides of $\mathbf{Q}$ with onions (200-650 mg/kg), apples (36 mg/ kg), and broccoli $(6-30 \mathrm{mg} / \mathrm{kg})$ as their major sources [4,6,7]. Although $\mathbf{Q}$ is mainly found as metabolites in vivo, the majority of in vitro investigations have focussed on the parent compound (Figure 1).<smiles>O=c1c(O)c(-c2ccccc2)oc2cc(O)cc(O)c12</smiles>

Figure 1. Quercetin aglycone with the carbon atom numbering system generally used.

The awareness that it is actually the flavonol metabolites that account for most of the beneficial health effects is growing. Therefore, the objective of this review is to survey the literature for known flavonol metabolites in humans, especially those from $\mathbf{Q}$, with regard to the site and mechanism of metabolism. 


\section{Chapter 1}

\section{Absorption and metabolism}

In flavonoid research, it is often forgotten that flavonoids are food components that must be bio-available in some form to exert a systemic biological effect. In general, most of the ingested Q-glycosides can barely be detected and plasma levels of $\mathbf{Q}$ rarely exceed $1 \mu \mathrm{M}$ in humans, when the average dietary intake (ca. $16 \mathrm{mg} /$ day) is not exceeded [4,5,8,9]. The primary and major site of absorption of Q-glycosides is the small intestine [8,10-12] and it appears that the sugar moiety of the glycoside is an important determinant in the absorption process $[13,14]$. For example; onion glycosides, Q4'-glucoside and Q3,4'-diglucoside, appear to be absorbed better than either tea flavonol glycosides, apple flavonol glycosides or Q3-rutinoside (rutin) from a supplement [8]. Q-monosaccharides, such as Q3glucoside and Q4'-glucoside, are absorbed in the small intestine as the Qaglycone. In contrast, glycosides which contain one sugar other than glucose (such as hyperoside) or disaccharides/oligosaccharides (such as rutin) are absorbed in the large intestine as $\mathbf{Q}$-aglycone, after deconjugation caused by the activity of enterobacteria [15]. These findings indicate that the sugar moiety determines the place of absorption in the intestine (Figure 3). To date, the absorption of Q- glycosides is thought to involve epithelial brush border membrane transporters, such as sodium-dependent glucose transporter-1 (SGLT1), followed by deglycosylation [14,16,17]. However, phenolic glycosides might also inhibit the SGLT-1 without being transported across the membrane [18]. For example, in Caco2 cell line, $\mathbf{Q}$ was easily absorbed but $\mathbf{Q 4}$ '-glucoside and Q3,4'-glucoside were not, despite the presence of SGLT-1 [19]. The lack of absorption is attributed to an effective efflux by the multidrug resistance protein 2 (MRP-2) transporter [20]. Only when MRP-2 was inhibited, the transport of Q4'-glucoside by SGLT-1 across the apical membrane of enterocytes was observed [21]. These findings suggest an active multi-transport system for flavonol glycosides in the small intestine. Other studies indicate that flavonoids may also be absorbed after deglycosylation by hydrolases (e.g. lactose-phlorizin hydrolase or $\beta$-glucosidase) located at the intestinal brush border membrane [2224]. In either case, absorption is immediately followed by phase II conjugation 
due to the action of uridine-5'-diphosphate glucuronosyltransferase (UDP-GT), catechol- $O$-methyl transferases (COMT) and sulfotransferases. This leads to the formation of numerous glucuronidated, methylated and sulphated conjugates prior to reaching systemic circulation [25-28].

\section{Glucuronidation}

Glucuronide conjugation is regarded as the major conjugation reaction involved in flavonoid metabolism [29-33]. There are three explanations that can be given for the widespread utilisation of the glucuronidation pathway. Firstly, glucuronic acid is derived directly from glucose and its store, glycogen, and is therefore readily available. Secondly, $O$-glucuronidation (linkage through an oxygen atom) is the most common form of glucuronide conjugation, making the poly hydroxylated flavonoids prime targets [34]. Thirdly, glucuronidation reaction is catalysed by UDP-GT which is found in high concentrations in the liver, intestine and kidneys. Even though the liver has the greatest capacity for glucuronidation $[35,36]$, most evidence point toward the intestine as being the initial and principal site for flavonoid glucuronidation in humans following typical dietary consumption $[32,37,38]$. However, glucuronides formed in the intestine tend to enter the systemic circulation directly and are not readily available for biliary excretion (Figure 2). In contrast, glucuronides newly formed in the liver are predominantly excreted into the bile entering the enterohepatic circulation (EHC). EHC prolongs the residence of a xenobiotic in the body by reducing its faecal excretion. It was suggested that a compound will have a longer plasma elimination half-life, if it is available to the systemic circulation while undergoing EHC [39]. EHC is suggested to be responsible for the flavonoids low but consistent levels in the circulation long after their time to reach maximum concentration is achieved [40]. As a consequence, the accumulation of the aglycone and its metabolites in plasma could be achieved with repeated intakes [41]. However, compounds undergoing EHC may also undergo further sulfation in the intestine or hepatocyte. This would divert them from biliary excretion toward eventual urinary elimination, as enteral 


\section{Chapter 1}

reabsorption of strongly polar compounds is negligible. This indicates that glucuronidation in the intestinal cells facilitates the loss of flavonoids from the EHC towards the systemic circulation [40].

In general, flavonol glucuronides are recognized as biologically less active or inactive than the aglycone. However, glucuronides can be readily deconjugated in case of inflammation by neutrophiles, which possess substantial levels of $\beta$ glucuronidase activity [42]. This would mean that the relatively more potent aglycone can be released locally from its glucuronide form when needed.

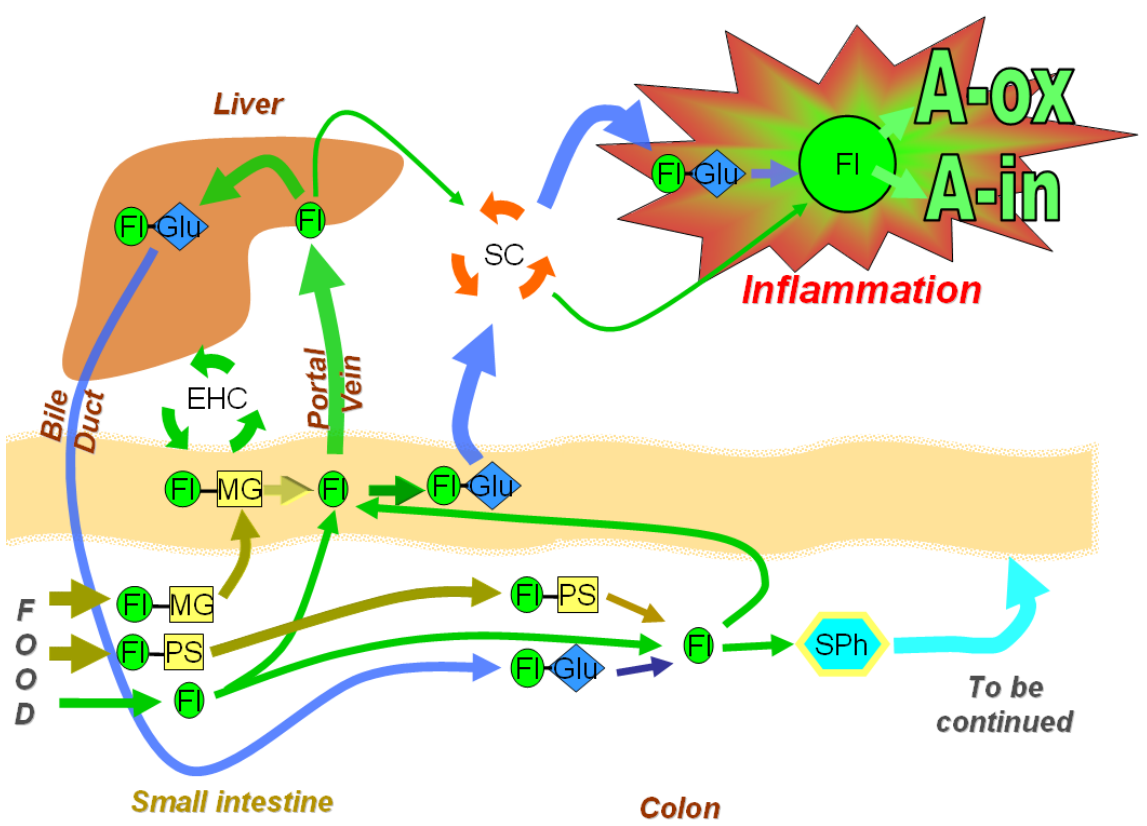

Figure 2. Schematic representation of the human metabolism of flavonols with emphasis on glucuronidation. The arrows show the potential route for flavonol circulation. $F l=$ flavonol, $F l-M G=$ monoglucosides, $F L-P S=$ polysaccharides, $F l$ Glu=glucuronides, SPh=small phenolics, SC=systemic circulation, $E H C=$ enterohepatic circulation, $A-O x=$ anti-oxidation, $A-I n=$ anti-inflammation.

\section{Methylation}

Methylation appears to be the second most significant conjugation reaction involving flavonoids [31,43]. Methylation is driven by methyltransferases that 
are found in many tissues, including the liver and intestine [44]. The most common methylation reaction associated with the metabolism of $\mathbf{Q}$ is $O$ methylation of the catechol moiety. The methylation is catalysed by COMT, with S-adenosyl methionine as a cofactor. The liver has the highest COMT activity and is the main organ responsible for methylation [45].

Unlike glucuronidation and sulfation, methylation actually increases the uptake in cells by making the aglycone more lipophilic. It has been demonstrated that isorhamnetin (Q3'-OMe) and tamarixetin (Q4'-OMe) both showed protection against peroxide-induced damage of normal human dermal fibroblasts, while Q7-glucuronide did not [46]. In addition, both methylated derivatives of $\mathbf{Q}$ were less toxic than $\mathbf{Q}$ when concentrations above $10 \mathrm{uM}$ were used. Intriguingly, there were small but measurable levels of $\mathbf{Q}$ detected in the lysates from cells exposed to both methylated derivatives of $\mathbf{Q}$, after 12 and 18 hours. This suggests that some cells can regenerate $\mathbf{Q}$ from its methylderivatives. 


\section{Chapter 1}

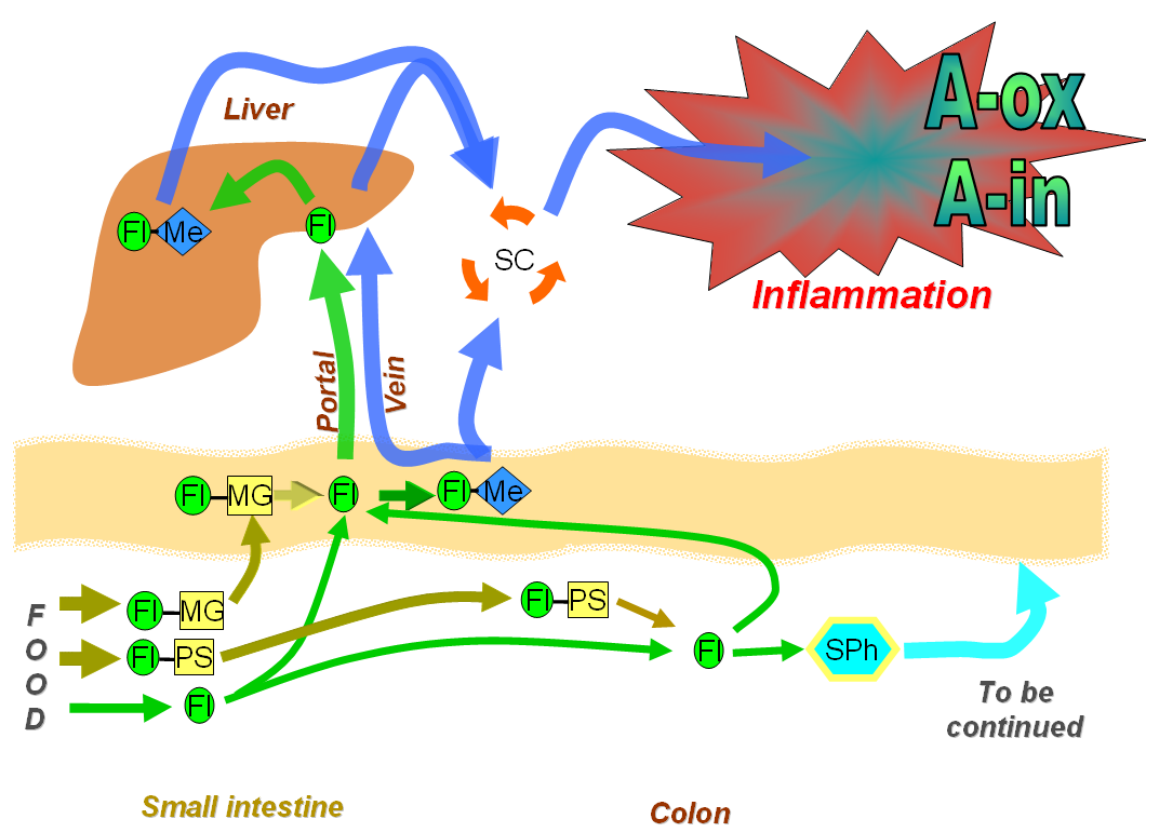

Figure 3. Schematic representation of the human metabolism of flavonol with emphasis on methylation. The arrows show the potential route for flavonol circulation. $F l=$ flavonol, $F l-M G=$ monoglucosides, $F L-P S=$ polysaccharides, $F l$ Glu=glucuronides, SPh=small phenolics, SC=systemic circulation, EHC=enterohepatic circulation, $A-O x=$ anti-oxidation, $A-I n=$ anti-inflammation.

\section{Sulfation}

Sulfation is a conjugation reaction of flavonoids, which predominates at relatively low dose. The reaction is catalysed by sulfotransferases, which are a small group of cytosolic enzymes widely distributed throughout the body [40]. Sulfotransferases utilise phosphoadenosine-5'-phosphosulphate as a cofactor $[34,47]$. It has been reported that sulfated derivatives of $\mathbf{Q}$ appeared to be the major metabolite in human plasma within 30 minutes (time to peak concentration, $\mathrm{t}_{\max }<1$ hour) after ingestion of onions [48]. The small $\mathrm{t}_{\max }$, indicates that sulfation probably occurs in the enterocyte before reaching the systemic circulation [49]. In addition, it has been demonstrated that fisetin and $\mathbf{Q}$ 
are not sulphated but only methylated in human liver [50,51]. Sulfation, as a conjugation reaction, is relatively costly in ATP and has a relatively limited capacity [34].

\section{Small phenolics}

The majority of flavonoids ingested can also reach the colon without metabolism, depending on the individual (Figure 4). The complex indigenous microflora in the colon is able to cleave the glycoside bond from flavonoid glycosides and use the sugar moiety for catabolism, while the resulting aglycone can be absorbed through the intestinal wall [52-54]. Additionally, the colonic bacteria is also able to extensively metabolize flavonoids producing a range of small phenolics, which then can be absorbed [41,55-57]. The degree of degradation is significantly dependant on the variations of the species and genera composing the colonic microflora of the individual. Although these metabolites are mostly returned to the digestive tract via MRP-2, some are transported through the portal vein into the liver where they undergo secondary metabolism [15]. In addition, the lymphatic system can also contribute to the transport of flavonoid metabolites around the body [58]. 


\section{Chapter 1}

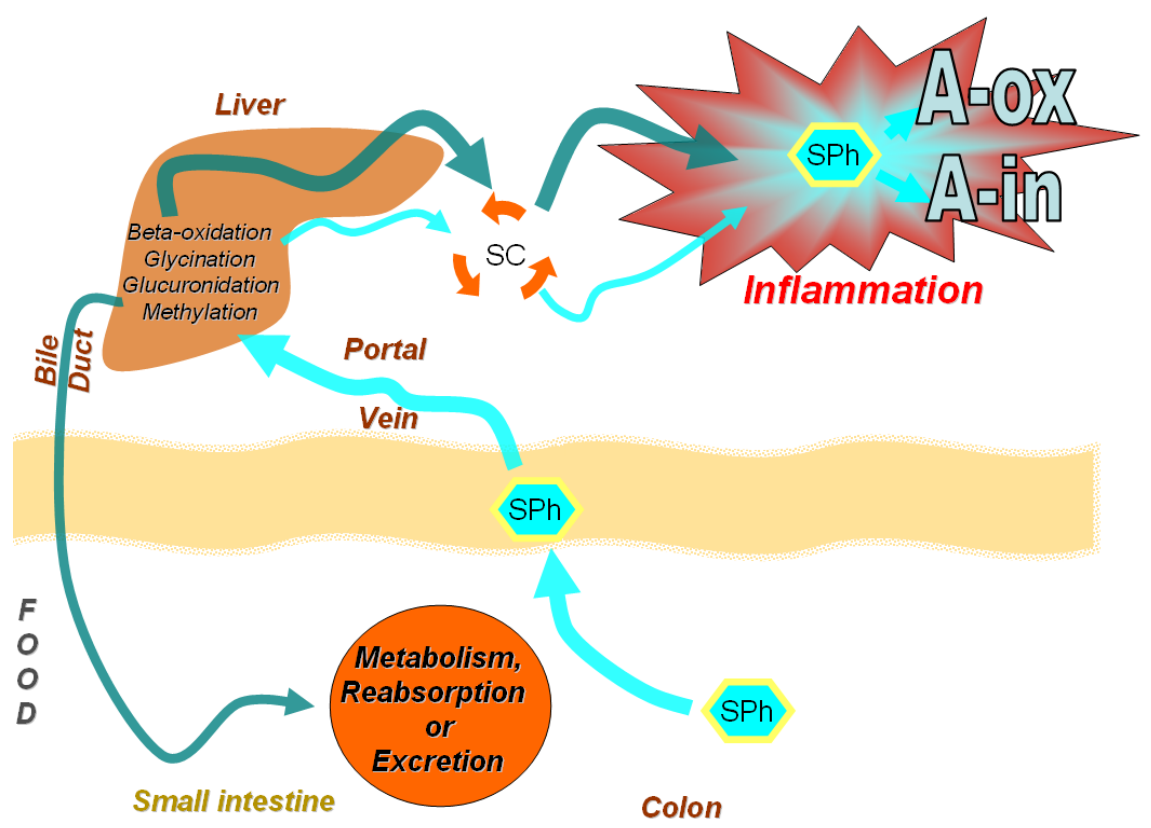

Figure 4. The circulation and possible metabolism of the small phenolics. SPh=small phenolics, SC=systemic circulation, A-Ox=anti-oxidation, AIn=anti-inflammation. See also Figure 11 in "Metabolites" for more details.

\section{Site of elimination}

Apart from the gastrointestinal tract and the liver, the kidneys can also form glucuronidated, sulphated, and methylated conjugates of flavonols before excretion in the urine [40]. Varying proportions of the aglycone and its metabolites will also pass through the gastrointestinal tract unabsorbed and be eliminated in the faeces [59]. Walle et al. radio-labelled the carbonylgroup of $\mathbf{Q}$ and reported, after both oral and iv doses in humans, that 23.0 to $81.1 \%$ was exhaled as ${ }^{14} \mathrm{CO}_{2}$, making the lung an additional site for elimination of the carbonylgroup of $\mathbf{Q}[60]$. 


\section{Metabolites}

\section{Glycosides}

Besides flavonol aglycones, there are also studies that have demonstrated the presence of relatively low levels of flavonol glycosides in plasma [33,61-63] indicating that few glycosides escape cleavage of the sugar moiety (Figure 5). Aziz et al. reported that isorhamnetin-4'-glucoside and Q4'-glucoside accumulated in plasma after the consumption of onion [61]. Mauri et al. found rutin in the plasma of healthy volunteers after the consumption of tomato extracts [62]. Oliveira et al. tentatively identified two flavonol glycosides in human plasma after the consumption of capsules of Ginkgo biloba, a plant rich in flavonoid glycosides [33]. Mullen et al. found sulfated and glucuronidated derivatives of $\mathbf{Q}$-monoglucosides in the urine after the ingestion of onions, which are rich in Q4'-glucoside and Q3,4'-diglucoside [64].

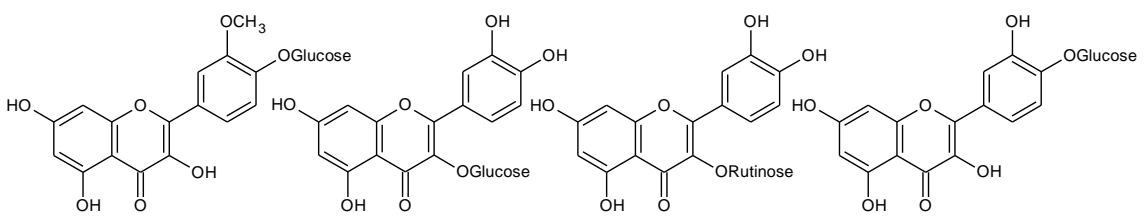

Figure 5. Flavonol glycosides detected in humans and characterized in the literature scope of this review.

\section{O-conjugated flavonols}

Even though small amount of ingested flavonol glycosides can escape metabolism, the majority of the glycosides are metabolized extensively and can only be found as metabolites. For example, the high pressure liquid chromatography (HPLC) of human urine, after the consumption of cooked onions, indicated that there are around 30 peaks representing possible flavonol metabolites and their isomers in urine; only 20 of those peaks could be identified by electrospray ionization-tandem mass spectrometry LC/ESI-MS/MS [65]. In total, seven different metabolites of $\mathbf{Q}$ were identified, including $\mathbf{Q}$ monoglucuronides, methylated Q-monoglucuronides, sulphated Q-glucuronide, Q- diglucuronides, methylated Q-diglucuronides, sulphated Q-glucoside, and 


\section{Chapter 1}

methylated Q. Q-monoglucuronides and methylated Q-monoglucuronides predominate followed by $\mathbf{Q}$-diglucuronides and one sulphated $\mathbf{Q}$-monoglucoside. When isomeric forms are taken into account, a total of 16 metabolites of $\mathbf{Q}$ were identified by the difference in the composition and intensities of minor ions and their LC retention times. In addition, all 4 isomers of kaempherol monoglucuronides were also detected (Figure 6). Kaempferol is the second most abundant flavonol in onions with concentrations of $0.89 \mathrm{mg} / 100 \mathrm{~g}$ of raw onion [65]. Hong and Mitchell, however, emphasized the necessity for synthesized forms of the flavonol metabolites to unambiguously identify the structure of the different isomers.<smiles>COc1ccc(-c2oc3cc(Oc4ccc(O)c(-c5oc6cc(Oc7ccc(O)cc7)cc(O)c6c(=O)c5O)c4)cc(O)c3c(=O)c2O)cc1</smiles>

Figure 6. Kaempferol O-glucuronides in humans that were identified in the literature scope of this review. OGlu=glucuronide.

In another study, three major Q-monoglucuronides were characterized (conjugation on the 3,4 ', 3' position) in human urine and plasma after the consumption of red onions [64]. Day et al. detected Q-monoglucuronides, methylated $\mathbf{Q}$-glucuronide and a sulphated derivative of $\mathbf{Q}$ in the plasma of humans fed with onions (Figure 7). The derivatives were identified as Q3'glucuronide, Q4'-glucuronide, Q3-glucuronide, isorhamnetin-4'-glucuronide, isorhamnetin-3-glucuronide and Q3'-sulphate [25]. Oliveira and Watson investigated the in vitro glucuronidation of $\mathbf{Q}$ and kaempherol by human UGT1A9 microsomes, and detected four monoglucuronides for $\mathbf{Q}$ and two for kaempherol [66]. Additionally, Day et al. demonstrated the presence of four Qmonoglucuronide isomers in human liver cell-free extracts [67]. The conjugational positions $\left(3,7,3^{\prime}\right.$ and 4' position) of these four isomers have been described and confirmed by UV absorption spectral shift assays [33] and more unambiguously by LC-MS and ${ }^{1} \mathrm{H}-\mathrm{NMR}$ analysis [68]. In a very recent study, the 
oxidation of monoHER, with horseradish peroxidase $/ \mathrm{H}_{2} \mathrm{O}_{2}$ was investigated in the presence of GSH. Jacobs et al. identified the only formed conjugate as the 2'glutathionyl-monoHER. Intriguingly, Jacobs et al. also detected the same glutathione conjugate in the bile fluid of a healthy volunteer after intravenous administration (iv) of monoHER [69].<smiles></smiles><smiles>COc1cc(-c2c(-c3ccc(OC)c(OC)c3)oc3cc(O)cc(O)c3c2=O)ccc1O</smiles>

Figure 7. Quercetin O-conjugates in humans that were characterized in the literature scope of this review. OGlu=glucuronide.

\section{Small phenolics}

The metabolites described so far have maintained their original aglycone skeleton and were even expanded with a functional group by metabolism in the body. However, there are several studies that report heterocyclic cleavage of flavonols (Figure 8) by colon bacteria leading to smaller phenolic compounds like dihydroxybenzoic acid, dihydroxyphenylacetic acid, dihydroxyphenylpropionic acid and caffeic acid [70,71]. 


\section{Chapter 1}

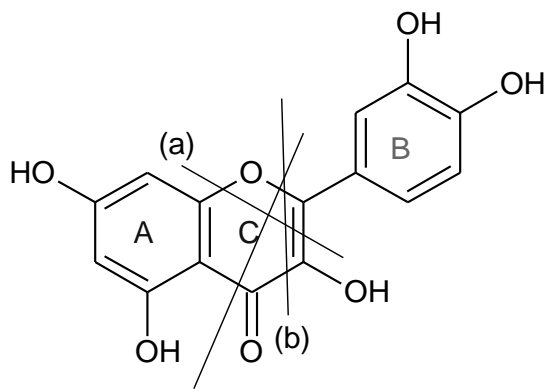

(c) \& (d)

(a)<smiles>O=C(O)c1ccc(O)c(O)c1</smiles>

(b)<smiles>O=C(O)Cc1ccc(O)c(O)c1</smiles><smiles>C=C(O)CCc1ccc(O)c(O)c1</smiles><smiles>O=C(O)/C=C/c1ccc(O)c(O)c1</smiles>

Figure 8. On top is the structure of quercetin aglycone, with the lines indicating the various modes of ring fission of the flavonol C-ring. On the bottom are some of the structures derived from the ring cleavage of quercetin by colonic bacteria: (a) 3,4-dihydroxybenzoic acid, (b) 3,4-dihydroxyphenyl acetic acid, (c) 3-,4dihydroxyphenylpropionic acid and (d) 3,4-dihydroxycinnamic acid [70-72].

Several gluthatione-related metabolites of $\mathbf{Q}$ have also been identified in the human urine as mercapturic acids, i.e. 3-,4-dihydroxytoluene, 3-,4dihydroxybenzaldehyde, 3-,4-dihydroxyphenylacetic acid, caffeic acid and 3-,4dihydroxyphenylpropionic acid, of common hydroxyphenylacetic acids generated by the microbial degradation of $\mathbf{Q}$ in the gut (Figure 9). The mass spectra of dihydroxyphenylacetic acid and dihydroxycinnamic acid demonstrated that the mercapturates are present as isomers [70]. Due to the low concentration of the individual phenolics, synthetic strategies are required to obtain enough compounds for NMR to unambiguously identify their structures. In another study on the metabolism of $\mathbf{Q}$ in the gut, hydroxyphenylacetic acids including 3,4dihydroxyphenylacetic acid, 3-hydroxyphenylacetic acid, and 4-hydroxy-3methoxyphenylacetic acid (homovanillic acid) has been reported [73]. In yet another study investigating the urine and plasma of humans fed with an extract 
of Ginko biloba; only the urine samples contained detectable amounts of substituted benzoic acids, such as 4-hydroxybenzoic acid conjugate, 4hydroxyhippuric acid, 3-methoxy-4-hydroxyhippuric acid, 3,4-dihydroxybenzoic acid, 4-hydroxybenzoic acid, hippuric acid and 3-methoxy-4-hydroxybenzoic acid (vanillic acid) [74]. There are also a number of in vitro studies showing the bacterial degradation of rutin and Q3-glucoside to 4-hydroxyphenylacetic acid, 3,4-dihydroxyphenylacetic acid [75,76], 3,4-dihydroxytoluene [72] and 3,4dihydroxybenzaldehyde [53]. All the products of flavonol degradation in the colon, described in the literature scope of this review, have been summarized in Figure 9.<smiles>COc1cc(C(=O)O)ccc1O</smiles><smiles>COc1cc(CC(=O)O)ccc1O</smiles><smiles>O=C(O)CCc1ccc(O)c(O)c1</smiles><smiles>O=C(O)/C=C/c1ccc(O)c(O)c1</smiles><smiles>O=C(O)CNC(=O)c1ccccc1</smiles>

Figure 9. The small phenolics identified in the literature scope of this review. Top: hydroxyl substituted toluene, benzaldehyde and benzoic acids. Top-middle: hydroxyl substituted phenylacetic acids. Bottom-middle: hydroxyl substituted propionic acids. Bottom: hydroxyl substituted hippuric acids.

\section{Final destination}

It has been reported that the increase in total excretion of hippuric acids after a day, in humans fed with a flavonoid-rich meal, exceeded by far all other metabolites (conjugated and small phenolics) together [77]. This was suggested to point out towards the final metabolic fate of the B-ring of most polyphenols. It is generally believed that hippuric acids are derived from the absorption of the 


\section{Chapter 1}

corresponding phenylpropionic acids that followed $\beta$-oxidation to benzoic acids and subsequent glycination in the liver, as shown in Figure 10 [77]. The ${ }^{14} \mathrm{C}$ labelling of the carbonylgroup on the 4 position of $\mathbf{Q}$ by Walle et al. showed that the urinary recovery of total radio-activity ranged from 18.4 to $26.8 \%$ after the iv dose and from 3.3 to $5.7 \%$ after the oral dose. The corresponding faecal recoveries were only $1.5-5.0 \%$ and $1.6-4.6 \%$, respectively. The rest, 23.0 $81.1 \%$, of the labelled carbons were mostly found in the expired air of the volunteers, as ${ }^{14} \mathrm{CO}_{2}$ [60]. These results suggest that the carbons on the 3 and 2 position of $\mathbf{Q}$ will also follow a similar fate to some extent. However, labelling of these carbons is required for the unambiguous determination of their fate. Moreover, in this study [60] a big part of the flavonol that does not have the ${ }^{14} \mathrm{C}$ label was unaccounted for; i.e. the A-ring and phenolic acids derived from the Bring. These unaccounted phenolics are expected to be excreted mainly in the urine. However, a more complete determination of the metabolic fate of $\mathbf{Q}$ would also require the specific labelling of both the A- and the B-ring.

To date, phenolic fragments containing the A-ring (1,3-benzenediol) of $\mathbf{Q}$ have not been identified. However, it was recently reported that free resorcinol (similar to A-ring of $\mathbf{Q}$ ) could only be detected in the blood of rats that drank extreme high dose $(3000 \mathrm{mg} / \mathrm{L})$ of water containing the xenobiotic; no detectable toxic effect could be determined at this dose [78]. These findings are in agreement with metabolic disposition studies, conducted several decades ago, confirming that ${ }^{14} \mathrm{C}$ radio-labelled resorcinol was readily absorbed from the gastrointestinal tract, efficiently metabolized (detoxified) and subsequently excreted [79]. More than $90 \%$ of the dose was excreted in the urine within the first 24 hours after oral administration of resorcinol, indicating little potential for bioaccumulation in animal tissues. The resulting ${ }^{14} \mathrm{C}$-labeled products were predominantly excreted in urine as glucuronides (70\%) and as sulphate conjugates [79]. 


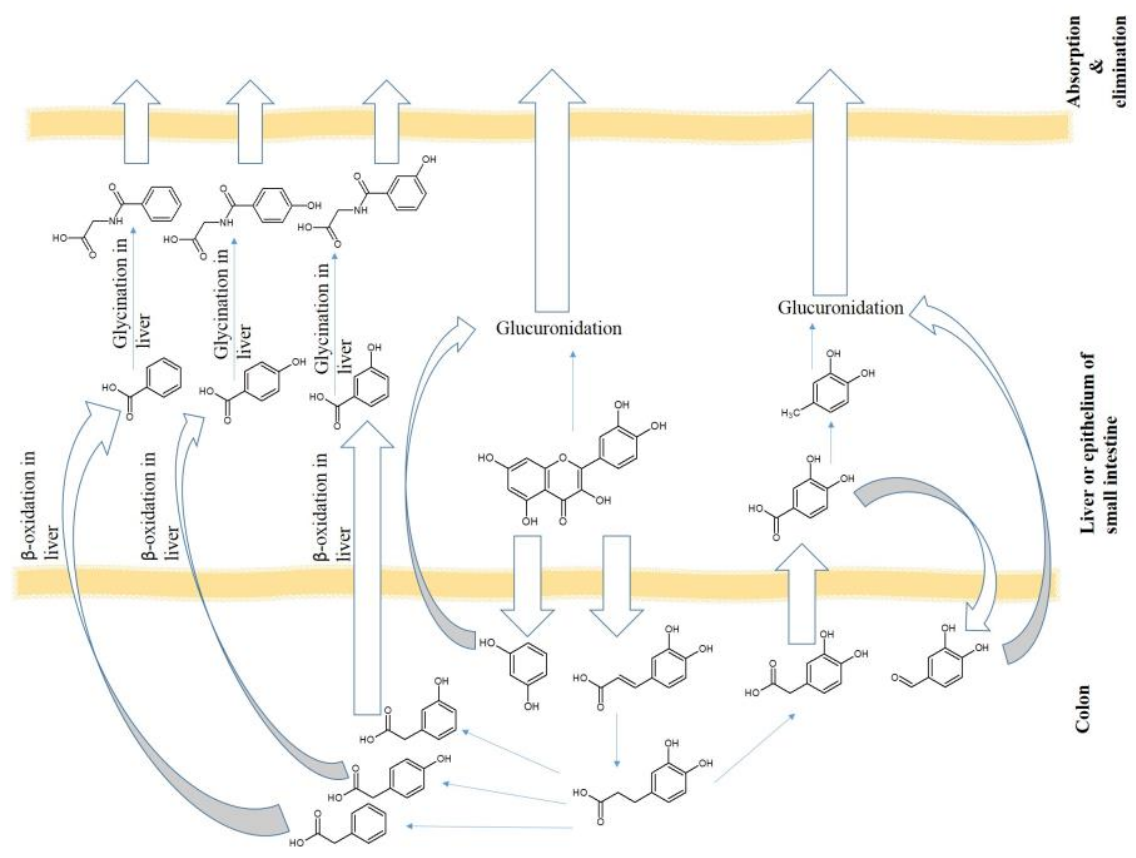

Figure 10. A simplified schematic representation of the suggested metabolism of quercetin to small phenolics [77,80-82].

\section{Conclusion}

There is a growing awareness that flavonol metabolites play an essential role in the health benefits associated with flavonol rich food. The flavonol metabolites that have been identified in literature are summarized in this review with regard to their metabolism. It is clear that flavonols are prime targets for O-conjugation, especially $\mathbf{Q}$, because of their high number of hydroxyl groups. Given that $\mathbf{Q}$ is extensively metabolised in vivo, the biological effects of this food compound should be reassessed incorporating the metabolites. Especially the methylated metabolites of $\mathbf{Q}$ appear to have several advantages, such as relatively low toxicity, relatively high metabolic stability and improved cellular absorption combined with a direct health promoting effect. This puts these methylated derivatives of $\mathbf{Q}$ in the spotlight. 


\section{Chapter 1}

\section{References}

1. Arts, I. C.; Hollman, P. C. Polyphenols and disease risk in epidemiologic studies. Am J Clin Nutr 2005, 81, 317S-325S.

2. Neuhouser, M. L. Dietary flavonoids and cancer risk: evidence from human population studies. Nutr Cancer 2004, 50, 1-7.

3. Ross, J. A.; Kasum, C. M. Dietary flavonoids: bioavailability, metabolic effects, and safety. Annu Rev Nutr 2002, 22, 19-34.

4. Hertog, M. G.; Hollman, P. C.; Katan, M. B. Content of potentially anticarcinogenic flavonoids of 28 vegetables and 9 fruits commonly consumed in The Netherlands. J. Agric. Food Chem. 1992, 40, 23792383.

5. Hertog, M. G.; Hollman, P. C.; van de Putte, B. Content of potentially anticarcinogenic flavonoids of tea infusions, wines, and fruit juices. $J$. Agric. Food Chem. 1993, 41, 1242-1246.

6. Crozier, A.; Lean, M. E.; McDonald, M. S.; Black, C. Quantitative analysis of the flavonoid content of commercial tomatoes, onions, lettuce, and celery. J. Agric. Food Chem. 1997, 45, 590-595.

7. Justesen, U.; Knuthsen, P.; Leth, T. Quantitative analysis of flavonols, flavones, and flavanones in fruits, vegetables and beverages by highperformance liquid chromatography with photo-diode array and mass spectrometric detection. J. Chromatogr. A 1998, 799, 101-110.

8. Hollman, P. C.; van Trijp, J. M.; Buysman, M. N.; van der Gaag, M. S.; Mengelers, M. J.; de Vries, J. H.; Katan, M. B. Relative bioavailability of the antioxidant flavonoid quercetin from various foods in man. FEBS Lett 1997, 418, 152-156.

9. de Vries, J. H.; Janssen, P. L.; Hollman, P. C.; van Staveren, W. A.; Katan, M. B. Consumption of quercetin and kaempferol in free-living subjects eating a variety of diets. Cancer Lett 1997, 114, 141-144.

10. Hollman, P. C.; vd Gaag, M.; Mengelers, M. J.; van Trijp, J. M.; de Vries, J. H.; Katan, M. B. Absorption and disposition kinetics of the 
dietary antioxidant quercetin in man. Free Radic Biol Med 1996, 21, 703-707.

11. Erlund, I.; Kosonen, T.; Alfthan, G.; Maenpaa, J.; Perttunen, K.; Kenraali, J.; Parantainen, J.; Aro, A. Pharmacokinetics of quercetin from quercetin aglycone and rutin in healthy volunteers. Eur J Clin Pharmacol 2000, 56, 545-553.

12. Graefe, E. U.; Wittig, J.; Mueller, S.; Riethling, A. K.; Uehleke, B.; Drewelow, B.; Pforte, H.; Jacobasch, G.; Derendorf, H.; Veit, M. Pharmacokinetics and bioavailability of quercetin glycosides in humans. J Clin Pharmacol 2001, 41, 492-499.

13. Hollman, P. C.; de Vries, J. H.; van Leeuwen, S. D.; Mengelers, M. J.; Katan, M. B. Absorption of dietary quercetin glycosides and quercetin in healthy ileostomy volunteers. Am J Clin Nutr 1995, 62, 1276-1282.

14. Hollman, P. C.; Bijsman, M. N.; van Gameren, Y.; Cnossen, E. P.; de Vries, J. H.; Katan, M. B. The sugar moiety is a major determinant of the absorption of dietary flavonoid glycosides in man. Free Radic Res 1999, 31, 569-573.

15. Murakami, A.; Ashida, H.; Terao, J. Multitargeted cancer prevention by quercetin. Cancer Lett 2008, 269, 315-325.

16. Ader, P.; Block, M.; Pietzsch, S.; Wolffram, S. Interaction of quercetin glucosides with the intestinal sodium/glucose co-transporter (SGLT-1). Cancer Lett 2001, 162, 175-180.

17. Wolffram, S.; Block, M.; Ader, P. Quercetin-3-glucoside is transported by the glucose carrier SGLT1 across the brush border membrane of rat small intestine. J Nutr 2002, 132, 630-635.

18. Lostao, M. P.; Hirayama, B. A.; Loo, D. D.; Wright, E. M. Phenylglucosides and the Na+/glucose cotransporter (SGLT1): analysis of interactions. J Membr Biol 1994, 142, 161-170.

19. Walgren, R. A.; Walle, U. K.; Walle, T. Transport of quercetin and its glucosides across human intestinal epithelial Caco-2 cells. Biochem Pharmacol 1998, 55, 1721-1727. 


\section{Chapter 1}

20. Walgren, R. A.; Karnaky, K. J., Jr.; Lindenmayer, G. E.; Walle, T. Efflux of dietary flavonoid quercetin 4'-beta-glucoside across human intestinal Caco-2 cell monolayers by apical multidrug resistanceassociated protein-2. J Pharmacol Exp Ther 2000, 294, 830-836.

21. Walgren, R. A.; Lin, J. T.; Kinne, R. K.; Walle, T. Cellular uptake of dietary flavonoid quercetin 4'-beta-glucoside by sodium-dependent glucose transporter SGLT1. J Pharmacol Exp Ther 2000, 294, 837-843.

22. Day, A. J.; Canada, F. J.; Diaz, J. C.; Kroon, P. A.; McLauchlan, R.; Faulds, C. B.; Plumb, G. W.; Morgan, M. R.; Williamson, G. Dietary flavonoid and isoflavone glycosides are hydrolysed by the lactase site of lactase phlorizin hydrolase. FEBS Lett 2000, 468, 166-170.

23. Day, A. J.; DuPont, M. S.; Ridley, S.; Rhodes, M.; Rhodes, M. J.; Morgan, M. R.; Williamson, G. Deglycosylation of flavonoid and isoflavonoid glycosides by human small intestine and liver betaglucosidase activity. FEBS Lett 1998, 436, 71-75.

24. Nemeth, K.; Plumb, G. W.; Berrin, J. G.; Juge, N.; Jacob, R.; Naim, H. Y.; Williamson, G.; Swallow, D. M.; Kroon, P. A. Deglycosylation by small intestinal epithelial cell beta-glucosidases is a critical step in the absorption and metabolism of dietary flavonoid glycosides in humans. Eur J Nutr 2003, 42, 29-42.

25. Day, A. J.; Mellon, F.; Barron, D.; Sarrazin, G.; Morgan, M. R.; Williamson, G. Human metabolism of dietary flavonoids: identification of plasma metabolites of quercetin. Free Radic Res 2001, 35, 941-952.

26. Mullen, W.; Graf, B. A.; Caldwell, S. T.; Hartley, R. C.; Duthie, G. G.; Edwards, C. A.; Lean, M. E.; Crozier, A. Determination of flavonol metabolites in plasma and tissues of rats by HPLC-radiocounting and tandem mass spectrometry following oral ingestion of [2(14)C]quercetin-4'-glucoside. J Agric Food Chem 2002, 50, 6902-6909.

27. Nielsen, S. E.; Breinholt, V.; Justesen, U.; Cornett, C.; Dragsted, L. O. In vitro biotransformation of flavonoids by rat liver microsomes. Xenobiotica 1998, 28, 389-401. 
28. Wittig, J.; Herderich, M.; Graefe, E. U.; Veit, M. Identification of quercetin glucuronides in human plasma by high-performance liquid chromatography-tandem mass spectrometry. J Chromatogr B Biomed Sci Appl 2001, 753, 237-243.

29. Shimoi, K.; Okada, H.; Furugori, M.; Goda, T.; Takase, S.; Suzuki, M.; Hara, Y.; Yamamoto, H.; Kinae, N. Intestinal absorption of luteolin and luteolin 7-O-beta-glucoside in rats and humans. FEBS Lett 1998, 438, 220-224.

30. Spencer, J. P.; Chowrimootoo, G.; Choudhury, R.; Debnam, E. S.; Srai, S. K.; Rice-Evans, C. The small intestine can both absorb and glucuronidate luminal flavonoids. FEBS Lett 1999, 458, 224-230.

31. Kuhnle, G.; Spencer, J. P.; Schroeter, H.; Shenoy, B.; Debnam, E. S.; Srai, S. K.; Rice-Evans, C.; Hahn, U. Epicatechin and catechin are Omethylated and glucuronidated in the small intestine. Biochem Biophys Res Commun 2000, 277, 507-512.

32. Donovan, J. L.; Crespy, V.; Manach, C.; Morand, C.; Besson, C.; Scalbert, A.; Remesy, C. Catechin is metabolized by both the small intestine and liver of rats. $J$ Nutr 2001, 131, 1753-1757.

33. Oliveira, E. J.; Watson, D. G.; Grant, M. H. Metabolism of quercetin and kaempferol by rat hepatocytes and the identification of flavonoid glycosides in human plasma. Xenobiotica 2002, 32, 279-287.

34. Dutton, G. Glucuronidation of Drugs and other Compounds. Boca Raton, FL: CRC Press 1980.

35. Mojarrabi, B.; Mackenzie, P. I. Characterization of two UDP glucuronosyltransferases that are predominantly expressed in human colon. Biochem Biophys Res Commun 1998, 247, 704-709.

36. Strassburg, C. P.; Nguyen, N.; Manns, M. P.; Tukey, R. H. Polymorphic expression of the UDP-glucuronosyltransferase UGT1A gene locus in human gastric epithelium. Mol Pharmacol 1998, 54, 647-654. 


\section{Chapter 1}

37. Cheng, Z.; Radominska-Pandya, A.; Tephly, T. R. Studies on the substrate specificity of human intestinal UDP- lucuronosyltransferases 1A8 and 1A10. Drug Metab Dispos 1999, 27, 1165-1170.

38. Crespy, V.; Morand, C.; Manach, C.; Besson, C.; Demigne, C.; Remesy, C. Part of quercetin absorbed in the small intestine is conjugated and further secreted in the intestinal lumen. Am J Physiol 1999, 277, G120126.

39. Gregus, Z.; Klaassen, C. D. Enterohepatic circulation of toxicants. In Gastrointestinal Toxicology, pp. 57-99. Rozman K, Hänninen O, editors. New York: Elsevier Science Ltd; 1986. 630 p.

40. Kay, C. D. Aspects of anthocyanin absorption, metabolism and pharmacokinetics in humans. Nutr. Res. Rev. 2006, 19, 137-146.

41. Manach, C.; Williamson, G.; Morand, C.; Scalbert, A.; Remesy, C. Bioavailability and bioefficacy of polyphenols in humans. I. Review of 97 bioavailability studies. Am J Clin Nutr 2005, 81, 230S-242S.

42. Shimoi, K.; Nakayama, T. Glucuronidase deconjugation in inflammation. Methods Enzymol 2005, 400, 263-272.

43. Williamson, G.; Day, A. J.; Plumb, G. W.; Couteau, D. Human metabolic pathways of dietary flavonoids and cinnamates. Biochem Soc Trans 2000, 28, 16-22.

44. Laitinen, M.; Watkins, J. B. Mucosal biotransformations. In Gastrointestinal Toxicology, pp. 169-192. Rozman K, Hänninen O, editors. New York: Elsevier Science Ltd; 1986.

45. Piskula, M. K.; Terao, J. Accumulation of (-)-epicatechin metabolites in rat plasma after oral administration and distribution of conjugation enzymes in rat tissues. J Nutr 1998, 128, 1172-1178.

46. Spencer, J. P.; Kuhnle, G. G.; Williams, R. J.; Rice-Evans, C. Intracellular metabolism and bioactivity of quercetin and its in vivo metabolites. Biochem. J. 2003, 372, 173-181. 
47. Coughtrie, M. W.; Sharp, S.; Maxwell, K.; Innes, N. P. Biology and function of the reversible sulfation pathway catalysed by human sulfotransferases and sulfatases. Chem Biol Interact 1998, 109, 3-27.

48. Mullen, W.; Edwards, C. A.; Crozier, A. Absorption, excretion and metabolite profiling of methyl-, glucuronyl-, glucosyl- and sulphoconjugates of quercetin in human plasma and urine after ingestion of onions. Br J Nutr 2006, 96, 107-116.

49. Crozier, A.; Del Rio, D.; Clifford, M. N. Bioavailability of dietary flavonoids and phenolic compounds. Mol Aspects Med 2010, 31, 446467.

50. De Santi, C.; Pietrabissa, A.; Spisni, R.; Mosca, F.; Pacifici, G. M. Sulphation of resveratrol, a natural compound present in wine, and its inhibition by natural flavonoids. Xenobiotica 2000, 30, 857-866.

51. Eaton, E. A.; Walle, U. K.; Lewis, A. J.; Hudson, T.; Wilson, A. A.; Walle, T. Flavonoids, potent inhibitors of the human P-form phenolsulfotransferase. Potential role in drug metabolism and chemoprevention. Drug Metab Dispos 1996, 24, 232-237.

52. Boulton, D. W.; Walle, U. K.; Walle, T. Fate of the flavonoid quercetin in human cell lines: chemical instability and metabolism. J Pharm Pharmacol 1999, 51, 353-359.

53. Schneider, H.; Schwiertz, A.; Collins, M. D.; Blaut, M. Anaerobic transformation of quercetin-3-glucoside by bacteria from the human intestinal tract. Arch Microbiol 1999, 171, 81-91.

54. Skibola, C. F.; Smith, M. T. Potential health impacts of excessive flavonoid intake. Free Radic Biol Med 2000, 29, 375-383.

55. Das, N. P.; Sothy, S. P. Studies on flavonoid metabolism. Biliary and urinary excretion of metabolites of $(+)-(\mathrm{U}-14 \mathrm{C})$ catechin. Biochem $J$ 1971, 125, 417-423.

56. Hackett, A. M. The metabolism of flavonoid compounds in mammals. Prog Clin Biol Res 1986, 213, 177-194. 


\section{Chapter 1}

57. Shaw, I. C.; Griffiths, L. A. Identification of the major biliary metabolite of (+)-catechin in the rat. Xenobiotica 1980, 10, 905-911.

58. Murota, K.; Terao, J. Quercetin appears in the lymph of unanesthetized rats as its phase II metabolites after administered into the stomach. FEBS Lett 2005, 579, 5343-5346.

59. Rozman, K. Disposition of xenobiotics: species differences. Toxicol Pathol 1988, 16, 123-129.

60. Walle, T.; Walle, U. K.; Halushka, P. V. Carbon dioxide is the major metabolite of quercetin in humans. J Nutr 2001, 131, 2648-2652.

61. Aziz, A. A.; Edwards, C. A.; Lean, M. E.; Crozier, A. Absorption and excretion of conjugated flavonols, including quercetin-4'-O-betaglucoside and isorhamnetin-4'-O-beta-glucoside by human volunteers after the consumption of onions. Free Radic Res 1998, 29, 257-269.

62. Mauri, P. L.; Iemoli, L.; Gardana, C.; Riso, P.; Simonetti, P.; Porrini, M.; Pietta, P. G. Liquid chromatography/electrospray ionization mass spectrometric characterization of flavonol glycosides in tomato extracts and human plasma. Rapid Commun Mass Spectrom 1999, 13, 924-931.

63. Paganga, G.; Rice-Evans, C. A. The identification of flavonoids as glycosides in human plasma. FEBS Lett 1997, 401, 78-82.

64. Mullen, W.; Boitier, A.; Stewart, A. J.; Crozier, A. Flavonoid metabolites in human plasma and urine after the consumption of red onions: analysis by liquid chromatography with photodiode array and full scan tandem mass spectrometric detection. J Chromatogr A 2004, 1058, 163-168.

65. Hong, Y. J.; Mitchell, A. E. Metabolic profiling of flavonol metabolites in human urine by liquid chromatography and tandem mass spectrometry. J Agric Food Chem 2004, 52, 6794-6801.

66. Oliveira, E. J.; Watson, D. G. In vitro glucuronidation of kaempferol and quercetin by human UGT-1A9 microsomes. FEBS Lett 2000, 471, 1-6. 
67. Day, A. J.; Bao, Y.; Morgan, M. R.; Williamson, G. Conjugation position of quercetin glucuronides and effect on biological activity. Free Radic Biol Med 2000, 29, 1234-1243.

68. van der Woude, H.; Boersma, M. G.; Vervoort, J.; Rietjens, I. M. Identification of 14 quercetin phase II mono- and mixed conjugates and their formation by rat and human phase II in vitro model systems. Chem Res Toxicol 2004, 17, 1520-1530.

69. Jacobs, H.; van der Vijgh, W. J.; Koek, G. H.; Draaisma, G. J.; Moalin, M.; van Strijdonck, G. P.; Bast, A.; Haenen, G. R. Characterization of the glutathione conjugate of the semisynthetic flavonoid monoHER. Free Radic Biol Med 2009, 46, 1567-1573.

70. Hong, Y. J.; Mitchell, A. E. Identification of glutathione-related quercetin metabolites in humans. Chem Res Toxicol 2006, 19, 15251532 .

71. Rechner, A. R.; Smith, M. A.; Kuhnle, G.; Gibson, G. R.; Debnam, E. S.; Srai, S. K.; Moore, K. P.; Rice-Evans, C. A. Colonic metabolism of dietary polyphenols: influence of structure on microbial fermentation products. Free Radic Biol Med 2004, 36, 212-225.

72. Justesen, U.; Arrigoni, E.; Larsen, B. R.; Amaso, R. Degradation of flavonoid glycosides and aglycones during in vitro fermentation with human faecal flora. Lebensm.-Wiss. Techol. 2000, 33, 424-430.

73. Gross, M.; Pfeiffer, M.; Martini, M.; Campbell, D.; Slavin, J.; Potter, J. The quantitation of metabolites of quercetin flavonols in human urine. Cancer Epidemiol Biomarkers Prev 1996, 5, 711-720.

74. Pietta, P. G.; Gardana, C.; Mauri, P. L. Identification of Gingko biloba flavonol metabolites after oral administration to humans. J Chromatogr B Biomed Sci Appl 1997, 693, 249-255.

75. Winter, J.; Moore, L. H.; Dowell, V. R.; Bokkenheuser, V. D. C-ring cleavage of flavonoids by human intestinal bacteria. Appl. Environ. Microbiol. 1989, 55, 1203-1208. 


\section{Chapter 1}

76. Kim, D. H.; Jung, E. A.; Sohng, I. S.; Han, J. A.; Kim, T. H.; Han, M. J. Intestinal bacterial metabolism of flavonoids and its relation to some biological activities. Arch Pharm Res 1998, 21, 17-23.

77. Rechner, A. R.; Kuhnle, G.; Bremner, P.; Hubbard, G. P.; Moore, K. P.; Rice-Evans, C. A. The metabolic fate of dietary polyphenols in humans. Free Radic Biol Med 2002, 33, 220-235.

78. Welsch, F. Routes and modes of administration of resorcinol and their relationship to potential manifestations of thyroid gland toxicity in animals and man. Int J Toxicol 2008, 27, 59-63.

79. Kim, Y. C.; Matthews, H. B. Comparative metabolism and excretion of resorcinol in male and female F344 rats. Fundam Appl Toxicol 1987, 9, 409-414.

80. Scheline, R. R. Metabolism of acids, lactones, and esters. In: Scheline R. R., eds. Handbook of mammalian metabolism of plant compounds, pp.139-196. Scheline RR, editor. Boca Raton, Florida: CRC Press; 1991.

81. Scheline, R. R. Metabolism of oxygen heterocyclic compounds. In: Scheline, R. R., eds. Handbook of mammalian metabolism of plant compounds, pp. 243-305. Boca Raton, Florida: CRC Press; 1991.

82. Anson, N. M.; Selinheimo, E.; Havenaar, R.; Aura, A. M.; Mattila, I.; Lehtinen, P.; Bast, A.; Poutanen, K.; Haenen, G. R. Bioprocessing of wheat bran improves in vitro bioaccessibility and colonic metabolism of phenolic compounds. J Agric Food Chem 2009, 57, 6148-6155. 


\section{Chapter 2}

\section{A planar conformation and the hydroxyl groups in the $B$ and $C$ Rings play a pivotal role in the antioxidant capacity of quercetin and quercetin derivatives}

Mohamed Moalin, Gino P. F. van Strijdonck, Maud Beckers, Geja Hageman, Paul Borm, Aalt Bast and Guido R. M. M. Haenen

Molecules 2011, 16, 9636-50 


\title{
Chapter 2
}

\begin{abstract}
The polyphenol quercetin $(\mathbf{Q})$ that has a high antioxidant capacity is a lead compound in the design of antioxidants. We investigated the possibility of modifying quercetin while retaining its antioxidant capacity as much as possible. To this end, the antioxidant capacities of $\mathbf{Q}$, rutin, monohydroxyethyl rutinoside (monoHER) and a series of synthesized methylated $\mathbf{Q}$ derivatives were determined. The results confirm that the electron donating effect of the hydroxyl groups is essential. It was also found that the relatively planar structure of $\mathbf{Q}$ needs to be conserved. This planar conformation enables the distribution of the electron donating effect through the large conjugated $\pi$-system over the entire molecule. This is essential for the cooperation between the electron donating groups. Based on the activity of the compounds tested, it was concluded that structural modification at the 5 or 7 position is the most optimal to retain most of the antioxidant capacity of $\mathbf{Q}$. This was confirmed by synthesizing and testing Q5OMe $(\mathbf{Q 6})$ and Q7OMe $(\mathbf{Q 7})$ that indeed displayed antioxidant capacities closest to $\mathbf{Q}$.
\end{abstract}




\section{Introduction}

Flavonoids are polyphenolic compounds found in most plants. They account for a significant percentage of the chemical constituents of vegetables, fruits, and beverages such as tea and red wine. As a group they are implicated in the health benefits of fruit and vegetable consumption [1]. Isolated flavonoids have various potent biological effects, and they are used as nutraceuticals [2]. 2-(3,4Dihydroxyphenyl)-3,5,7-trihydroxy-4H-1-benzopyran-4-one or quercetin $(\mathbf{Q})$ is one of the most prominent dietary flavonoids [1,3,4]. It has a high antioxidant capacity, which is implicated in its health effects, and is a lead compound in the design of antioxidants. Chemical modification of quercetin has generated new derivatives with improved biological effect. One of these semi-synthetic antioxidants, i.e., monohydroxyethyl rutinoside (monoHER), efficiently protects against the cardiotoxic effect of doxorubicin in mice [5], although it appeared to be less effective in humans [6]. The chemical modification explored in the present study was O-methylation, since this might improve the cellular uptake and metabolic stability of $\mathbf{Q}$ [7-9]. It is important to note that antioxidants such as $\mathbf{Q}$ can exert their beneficial effects through different mechanisms, e.g. scavenging radicals, metal chelation and interactions with enzymes [10]. This makes profiling antioxidants such as $\mathbf{Q}$ a daunting task with many pitfalls [11]. The essential feature of $\mathbf{Q}$ evaluated in the present study is its free radical scavenging. This was determined using the well-established 2,2'-azino-bis(3ethylbenzthiazoline-6-sulphonic acid) radical (ABTS•) decolorization assay to determine the effect of O-conjugation on the scavenging capacity of $\mathbf{Q}$. We investigated the possibility of modifying quercetin while retaining its antioxidant capacity as much as possible.

\section{Synthesis}

The strategy used for the synthesis of the methylated derivatives of $\mathbf{Q}$ is adopted from Bouktaib et al. [12] and van Acker et al. [13]. The catechol moiety of $\mathbf{Q}$ was protected by the reaction with dichlorodiphenylmethane (Scheme 1) that lead to the formation of $\mathbf{1}$. This reaction proceeds at temperatures above $160{ }^{\circ} \mathrm{C}$. A 


\section{Chapter 2}

major improvement appeared to be the addition of NMP, a solvent with a high boiling point, which increased the overall yield from 10 to $70 \%$. The protected $\mathbf{Q}$ (1) was methylated with methyl iodide (MeI) and 1 equivalent (equiv.) $\mathrm{K}_{2} \mathrm{CO}_{3}$, followed by deprotection of the catechol group. Under these conditions both compounds Q1 and Q2 were formed and they could be readily separated by column chromatography on silica gel. Compounds Q3 and Q4 were synthesized by reacting $\mathbf{Q}$ with $\mathrm{MeI}$ and 3 eq of $\mathrm{K}_{2} \mathrm{CO}_{3}$. Both compounds could be readily separated by silica column chromatography. Methylation of $\mathbf{Q}$ with an excess of MeI and base gives the pentamethylated derivative Q5. I3 Had already been already synthesized for an earlier study by demethylation of Q5 with an excess of $\mathrm{AlCl}_{3}$. All the other synthesized compounds were made according to Bouktaib et al. and van Acker et al. with minimum adjustments. The chemical structures of the tested compounds are depicted in Table 1. 
Scheme 1. Synthesis of the methylated derivatives of quercetin.

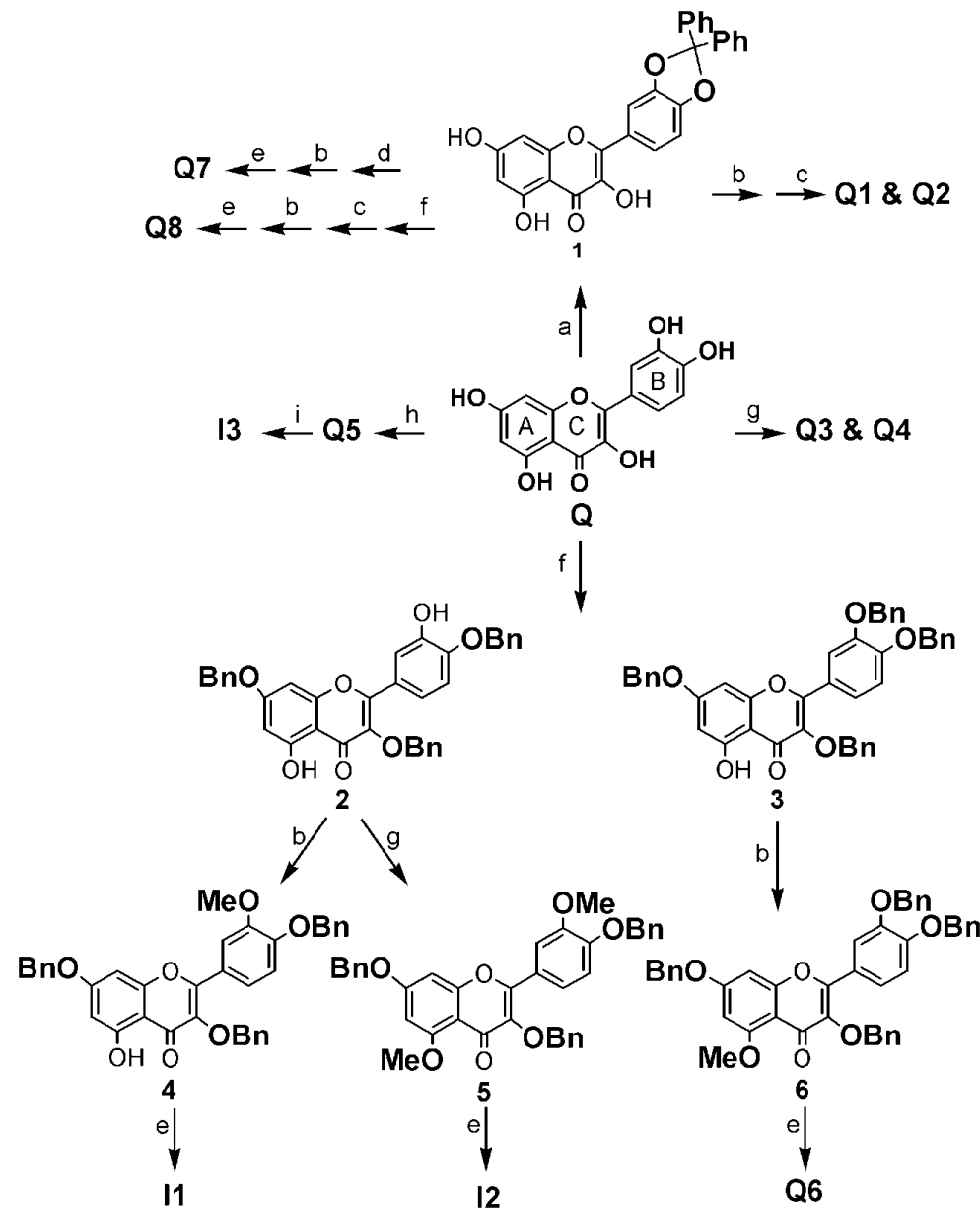

Reagents and conditions: (a) 5 equiv. dichlorodiphenylmethane, NMP, $165^{\circ} \mathrm{C}, 1 \mathrm{~h}$; (b) 1 equiv. $\mathrm{K}_{2} \mathrm{CO}_{3}$, excess MeI, DMF, $3 \mathrm{~h}$; (c) acetic acid/water (80:20, v/v), reflux, 3 h; (d) 1.2 equiv. $\mathrm{NaHCO}_{3}$, excess BnBr, DMF, 3 h; (e) acetic acid/ $\mathrm{HCl}(1: 1$, v/v), reflux, 4 h; (f) 3 equiv. $\mathrm{K}_{2} \mathrm{CO}_{3}$, excess $\mathrm{BnBr}$, DMF, overnight; (g) 3 equiv. $\mathrm{K}_{2} \mathrm{CO}_{3}$, excess MeI, DMF, overnight; (h) 5.5 equiv. $\mathrm{K}_{2} \mathrm{CO}_{3}$, excess MeI, DMF, overnight; (i) 38 eq $\mathrm{AlCl}_{3}$, dry ether, $12 \mathrm{~h}, 60{ }^{\circ} \mathrm{C}$; then acetic $\mathrm{acid} / \mathrm{HCl}(2: 1, \mathrm{v} / \mathrm{v}), 25 \mathrm{~min}$, reflux. 


\section{Chapter 2}

Table 1. The antioxidant capacities of quercetin $(\mathbf{Q})$, isorhamnetin (I1), rutin (R1) and their derivatives. The capacity is expressed as the number of ABTS radicals (ABTS ${ }^{\circ}$ ) that is scavenged by one molecule of the tested compound.

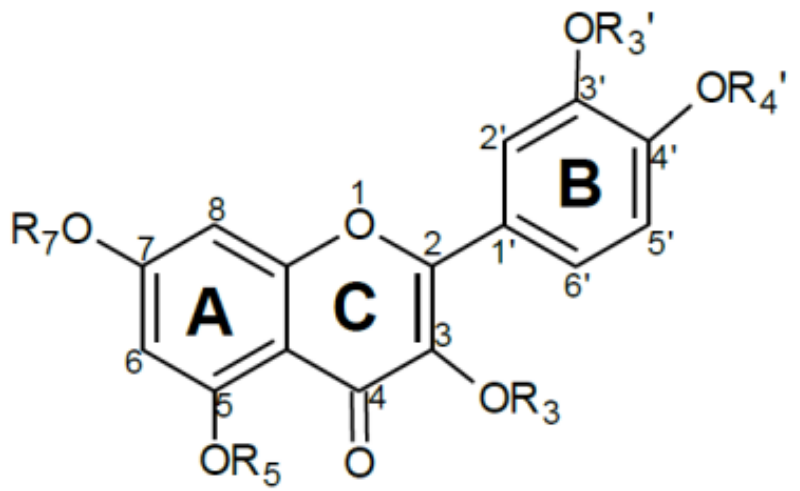

\begin{tabular}{|c|c|c|c|c|c|c|}
\hline Compound & $\overline{\mathrm{R}_{3}}$ & $\overline{\mathrm{R}_{5}}$ & $\overline{\mathrm{R}_{7}}$ & $\overline{\mathrm{R}_{3}}$ & $\overline{\mathrm{R}_{4}}$ & Antioxidant capacity \\
\hline $\mathbf{Q}$ & $\mathrm{H}$ & $\mathrm{H}$ & $\mathrm{H}$ & $\mathrm{H}$ & $\overline{\mathrm{H}}$ & $+8,6$ \\
\hline Q1 & $\mathrm{CH}_{3}$ & $\mathrm{H}$ & $\overline{\mathrm{H}}$ & $\overline{\mathrm{H}}$ & $\overline{\mathrm{H}}$ & 5,8 \\
\hline $\mathbf{Q 2}$ & $\mathrm{CH}_{3}$ & $\mathrm{H}$ & $\mathrm{CH}_{3}$ & $\mathrm{H}$ & $\mathrm{H}$ & 4,0 \\
\hline Q3 & $\mathrm{CH}_{3}$ & $\mathrm{H}$ & $\mathrm{CH}_{3}$ & $\mathrm{H}$ & $\mathrm{CH}_{3}$ & 1,2 \\
\hline Q4 & $\mathrm{CH}_{3}$ & $\mathrm{H}$ & $\mathrm{CH}_{3}$ & $\mathrm{CH}_{3}$ & $\mathrm{CH}_{3}$ & 0,6 \\
\hline Q5 & $\mathrm{CH}_{3}$ & $\mathrm{CH}_{3}$ & $\mathrm{CH}_{3}$ & $\mathrm{CH}_{3}$ & $\mathrm{CH}_{3}$ & 0,0 \\
\hline I1 & $\mathrm{H}$ & $\mathrm{H}$ & $\mathrm{H}$ & $\mathrm{CH}_{3}$ & $\mathrm{H}$ & 4,2 \\
\hline$\overline{12}$ & $\overline{\mathrm{H}}$ & $\overline{\mathrm{CH}_{3}}$ & $\overline{\mathrm{H}}$ & $\mathrm{CH}_{3}$ & $\overline{\mathrm{H}}$ & 72,6 \\
\hline I3 & $\mathrm{H}$ & $\mathrm{CH}_{3}$ & $\mathrm{CH}_{3}$ & $\mathrm{CH}_{3}$ & $\mathrm{CH}_{3}$ & 1,3 \\
\hline R1 & $\mathrm{Ru}^{1}$ & $\mathrm{H}$ & $\overline{\mathrm{H}}$ & $\mathrm{H}$ & $\mathrm{H}$ & 5,1 \\
\hline $\mathbf{R 2}$ & $\mathrm{Ru}{ }^{1}$ & $\mathrm{H}$ & $\mathrm{He}^{2}$ & $\mathrm{H}$ & $\mathrm{H}$ & $+3,8$ \\
\hline Q6 & $\mathrm{H}$ & $\mathrm{CH}_{3}$ & $\mathrm{H}$ & $\mathrm{H}$ & $\mathrm{H}$ & 7,0 \\
\hline Q7 & $\mathrm{H}$ & $\mathrm{H}$ & $\mathrm{CH}_{3}$ & $\mathrm{H}$ & $\mathrm{H}$ & 6,7 \\
\hline Q8 & $\mathrm{H}$ & $\mathrm{H}$ & $\mathrm{H}$ & $\mathrm{H}$ & $\mathrm{CH}_{3}$ & 3,7 \\
\hline
\end{tabular}

${ }^{1} \mathrm{Ru}$ is a rutinosyl group, a disaccharide consisting of glucose and rhamnose

${ }^{2} \mathrm{He}$ is a hydroxyethyl group 


\section{Results and Discussion}

The antioxidant capacity was determined in a decolorization assay using the intensely

colored

2,2'-azino-bis(3-ethylbenzthiazoline-6-sulphonic acid) radical (ABTS*), as described previously [14-19]. In our study, the capacity is expressed as the number of $\mathrm{ABTS}^{\bullet}$ that is scavenged by one molecule of the compound tested (Table 1). In the literature, the capacity of antioxidants is usually related to the capacity of the reference compound trolox and expressed as Trolox Equivalent Antioxidant Capacity (TEAC). These TEAC values have to be multiplied by 1.9, which is the value of Trolox in the assay, to compare TEAC data to our data. In literature, it is reported that $\mathbf{Q}$ can scavenge 5.9 [18], 8.4 [19], 9.0 [14] and 9.3 [17] ABTS ${ }^{*}$. The capacity observed for $\mathbf{Q}$ in the present study is 8.6. In addition, the reported values of rutin (R1) are 4.7 [14] and 5.2 [16], and we observed 5.1. This shows that the values found in the present study are within close proximity of most of the values reported previously.

In accordance with the literature data, $\mathbf{Q}$ has an extraordinarily high antioxidant capacity compared with simpler polyphenols, such as 4-methylcatechol (MC) that has a capacity of 2.5 in our assay. Compared to $\mathbf{M C}, \mathbf{Q}$ contains a large conjugated $\pi$-system. This large conjugated $\pi$-system is one of the main reasons for the high antioxidant potential of $\mathbf{Q}$.

Gradual methylation of the hydroxyl groups, from $\mathbf{Q}$ to Q1, Q2, Q3, Q4 and Q5 decreases the capacity (Table 1). Methylation of all the $\mathrm{OH}$ groups (Q5) reduces the capacity of $\mathbf{Q}$ to zero. This demonstrates that not only the size of the conjugated $\pi$-system determines the antioxidant potential; the free $\mathrm{OH}$ groups play a pivotal role in the antioxidant capacity as well.

It has been suggested that the antioxidant capacity of flavonoids is proportional to the number of $\mathrm{OH}$ groups present in the molecule [20]. However, several derivatives with the same number of $\mathrm{OH}$ groups display a significant difference in capacity. For example, the mono-methylated derivatives Q1 and I1, both containing four $\mathrm{OH}$ groups, show a large difference of 1.6 in capacity (Table 1). In addition, there is also a substantial difference of 1.4 between the two di- 


\section{Chapter 2}

methylated derivatives ( $\mathbf{Q 2}$ and $\mathbf{1 2}$ ) and of 0.7 between the two tetramethylated derivatives (Q4 and I3). This confirms that the number of $\mathrm{OH}$ groups is not the primary factor in the antioxidant capacity of $\mathbf{Q}$ and its derivatives [21-24].

Apparently the contribution of each $\mathrm{OH}$ group to the antioxidant capacity is not equal. Methylation of the $\mathrm{OH}$ groups in the B-ring of $\mathbf{Q}$ reduced the antioxidant capacity the most, followed by methylation of the 3-OH group in the C-ring. Methylation of the 5 or 7 position in the A-ring reduced the antioxidant capacity the least.

The effect of $\mathrm{OH}$ groups on the antioxidant activity of flavones has previously been explained by their strong electron donating effect. Donating electrons to the conjugated $\pi$-system decreases the ionization potential and increases the energy of the highest occupied molecular orbital (HOMO) that is reflected by an increase in the antioxidant potential. The optimum stimulating effect of $\mathrm{OH}$ groups that are attached to $\mathbf{Q}$, is found with an even number of $\mathbf{C}$-atoms between these groups [21]. In addition, adjacent $\mathrm{OH}$ groups can also increase the antioxidant potential by stabilizing the flavone radical through intramolecular $\mathrm{H}$ bonding interaction $[24,25]$. Consequently the $\mathrm{OH}$ groups in $\mathbf{Q}$ cooperate in the scavenging of radicals, and the efficiency of this cooperation depends on their relative position.

Previously, two pharmacophores have been postulated for Q; i.e., the AC-ring and the B-ring [21-23]. The activity of various flavonoids indicated that the $3-\mathrm{OH}$ group was the active centre in the AC-ring, and that its activity is positively influenced by the $\mathrm{OH}$ groups at the 5 and 7 position in the AC-ring [21]. In the present study, two tetramethylated derivatives of $\mathbf{Q}$, i.e., $\mathbf{Q 4}$ and $\mathbf{I 3}$, were tested. Q4 has only one free $\mathrm{OH}$ group at the 5 position, and $\mathbf{I 3}$ has only one free $\mathrm{OH}$ group at the 3 position. The capacity of $\mathbf{I 3}$ (i.e., 1.3) was twice that of Q4 (i.e., 0.6). This confirms that an $\mathrm{OH}$ group at the 3 position is indeed more important for the antioxidant activity than one at the 5 position.

The high activity of the B-ring can be explained by the strong electron-donating effect of its two adjacent phenolic $\mathrm{OH}$ groups and their intramolecular $\mathrm{H}$ bonding interaction $[21,24,25]$. Actually, in our study methylation of the B-ring 
has the most profound effect as demonstrated by the relatively low capacity of I1. I1 is methylated at the 3 '-O position in the B-ring and its capacity is 4.4 lower than $\mathbf{Q}$. For comparison, $\mathbf{Q 1}$ is methylated at the 3-O position in the ACring and this leads to a decrease of 2.8. This confirms the importance of the $\mathrm{OH}$ groups in the B-ring for the antioxidant capacity of $\mathbf{Q}$.

The difference in capacity (i.e., 0.7) between Q1 and R1 (Table 1) indicates that other factors, besides the position and number of the $\mathrm{OH}$ groups, also influence the antioxidant capacity of $\mathbf{Q}$ derivatives. Both compounds are only substituted at the 3-O position. The difference is that $\mathbf{Q 1}$ has a methyl group while $\mathbf{R} 1$ has a rutinosyl group. To examine the effect of substitution at the 3-O position, quantum calculations on the equilibrium geometry of the molecules were performed [24]. The calculations point out that the bulky rutinosyl group at the 3-O position induces a dihedral angle $(\varphi)$ of $38^{\circ}$ between the plane of the ACring and that of the B-ring. The methyl group in Q1 induces a dihedral of $20^{\circ}$, while in $\mathbf{Q}$ the dihedral is only $0.29^{\circ}$ (Table 2 ). The relatively planar structure of $\mathbf{Q}$ allows the conjugated $\pi$-system of the AC-ring and that of the B-ring to efficiently interact. This interaction distributes the electron donating effect of the $\mathrm{OH}$ groups over the whole molecule, enabling the cooperation of electron donors in the different rings. Apparently, the pharmacophores that were postulated for $\mathbf{Q}$, i.e., the AC-ring and the B-ring, can cooperate. However, a bulky substituent at the 3 position, such as a rutinosyl group, forces the B-ring out of the plane of the AC-ring (Figure 1). This steric effect diminishes the efficiency of the large conjugated $\pi$-system found in $\mathbf{Q}$, leading to a relatively low antioxidant capacity. In the design of derivatives of $\mathbf{Q}$ aimed at retaining most of the antioxidant activity, the relatively planar conformation of $\mathbf{Q}$ should be conserved. 


\section{Chapter 2}

Table 2. The antioxidant capacities of $\mathbf{Q}, \mathbf{Q 1}$ and $\mathbf{R} \mathbf{1}$ vs their dihedral angles $(\varphi)$, the angle between the plane of the AC-ring and that of the B-

ring.

\begin{tabular}{ccc}
\hline Compound & Capacity & $\boldsymbol{\varphi}$ \\
\hline $\mathrm{Q}$ & 8.6 & $0.29^{\circ}$ \\
$\mathrm{Q} 1$ & 5.8 & $20^{\circ}$ \\
$\mathrm{R} 1$ & 5.1 & $38^{\circ}$ \\
\hline
\end{tabular}

In vivo, methylation of the $3^{\prime}-\mathrm{O}$ or $4^{\prime}-\mathrm{O}$ in the B-ring by Catechol $O$-Methyl Transferase (COMT) is a major pathway. It has been suggested that these metabolites have a substantial contribution to the biological effects of $\mathbf{Q}$, because their cellular uptake as well as their metabolic stability are superior to those of $\mathbf{Q}[8,9,26]$. However, our data corroborate previous studies $[9,27]$ that demonstrate the relatively low antioxidant capacity of these metabolites.

Our results show that semi-synthetic derivatives that are methylated at the 5 or 7 position display a higher antioxidant capacity than the in vivo metabolites. This was confirmed by synthesizing the 5 and $7 \mathrm{O}$-methylated quercetin derivatives (Q6 and Q7). Moreover, 5 or 7 O-methylation of $\mathbf{Q}$ would not undermine the structural features that are important for metal chelation, i.e., 3-hydroxy-4-keto conformation together with the 2,3-double bond and the catecholic B-ring $[10,24]$. To complete the series of monomethylated derivatives, we also synthesized Q4'OMe (Q8). In line with our theory, Q8 appeared to be the least active, while Q6 and Q7 demonstrate the highest capacity of the O-conjugated derivatives of $\mathbf{Q}$. 


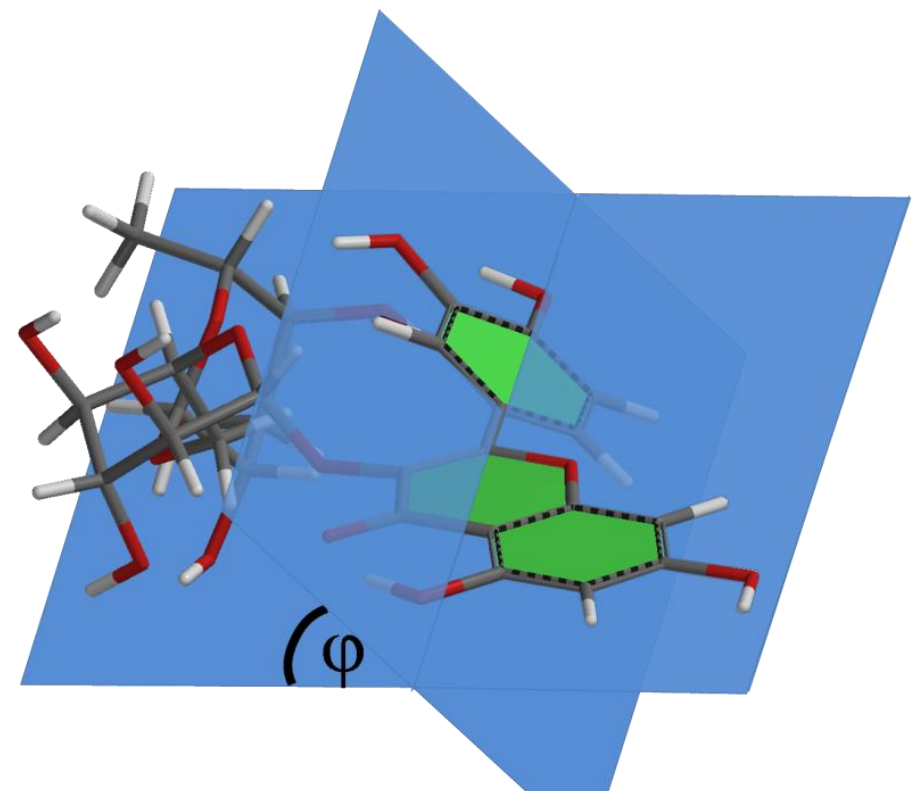

Figure 1. Three dimensional structure of rutin (R1), illustrating the dihedral angle $(\varphi)$ of $38^{\circ}$ between the plane of the AC-ring and that of the $B$-ring.

\section{Conclusions}

To chemically modify quercetin $(\mathbf{Q})$ while retaining most of its antioxidant capacity, substitution at the 5 and $7 \mathrm{OH}$ are the most suitable. This modification will not disturb the planar structure that enables the distribution of the electron donating effect through the $\pi$-system found in $\mathbf{Q}$, and does not compromise $\mathbf{H}$ bond interactions that can be essential for the stabilization of the flavone radical. This opens new avenues for (semi)-synthetic derivatives of $\mathbf{Q}$ that are chemically modified at the 5 or 7 position. 


\section{Chapter 2}

\section{Experimentals}

\section{Antioxidant Capacity}

Chemicals

All chemicals, synthesized or purchased, had a purity of at least $95 \%$ by HPLC. Rutin $3 \mathrm{H}_{2} \mathrm{O}$, ABTS [2,2'-azinobis-(3-ethylbenzothiazoline-6-sulfonic acid)] and ABAP 2,2'-Azobis-(2-amidino-propane) $\cdot \mathrm{HCl}$ ) were purchased from SigmaAldrich and used as received. MonoHER [7-mono-O-( $\beta$-hydroxyethyl)-rutoside] was kindly provided by Novartis Consumer Health (Nyon, Switzerland). Spectrophotometric analysis was performed with a Varian Carry 50 spectrophotometer (Varian, Mulgrave, VIC, Australia).

\section{Scavenging of ABTS Radicals}

All solutions were prepared fresh on the same day of the experiments. To generate the ABTS radicals (ABTS $)$, ABTS $(20 \mathrm{mM})$ was incubated with ABAP (2.5 mM) in $145 \mathrm{mM}$ sodium phosphate buffer ( $\mathrm{pH} \mathrm{7.4)}$ ) for $30 \mathrm{~min}$ at $60{ }^{\circ} \mathrm{C}$. During the experiments, the ABTS ${ }^{\bullet}$ stock solution was protected from light and kept on ice. The antioxidants were dissolved in DMSO to a concentration of 0.4 $\mathrm{mM}$ and further diluted in the phosphate buffer $(\mathrm{pH}$ 7.4) to a final concentration of $4 \mu \mathrm{M}$. In the actual measurement, antioxidant ( $500 \mu \mathrm{L}$ of $4 \mu \mathrm{M}$ solution) was mixed with $\operatorname{ABTS}^{\bullet}\left(500 \mu \mathrm{L}\right.$ of $60 \mu \mathrm{M}$ solution) and incubated at $37{ }^{\circ} \mathrm{C}$. After 5 min the absorbance at $734 \mathrm{~nm}$ was measured. The concentration of the ABTS ${ }^{\bullet}$ was determined by using its molecular extinction coefficient of $1.5 \times 10^{4} \mathrm{M}^{-1} \mathrm{~cm}^{-1}$. Control experiments showed that DMSO and the phosphate buffer did not interfere with the assay. The antioxidant capacity is expressed as the number of $\mathrm{ABTS}^{\bullet}$ that has reacted with one molecule of the antioxidant within the 5 min incubation period. All measurements were performed, at least, in triplicate. Data are expressed as mean \pm standard deviation.

\section{Molecular Quantum Calculations}

The density functional theory (DFT) using the B3LYP hybrid functional with the 6-31G* basis set in Spartan '10 (Wavefunction, Irvine, CA, USA) was utilized 
for calculating the equilibrium geometry, and for determining the dihedrals $(\varphi)$, the angles between the plane of the AC-ring and that of the B-ring, of quercetin $(\mathbf{Q})$, rutin (R1) and quercetin-3-OMe (Q1).

\section{Synthesis}

General

Quercetin $\cdot 2 \mathrm{H}_{2} \mathrm{O}$, dichlorodiphenylmethane, benzyl bromide, iodomethane, potassium carbonate, sodium bicarbonate, $\mathrm{MgSO}_{4}$ and silica-gel $60 \mathrm{~A}(0.060-$ $0.200 \mathrm{~mm}$ ) were purchased from Acros Organics and used as received. All solvents were obtained from Sigma-Aldrich and were of analytical grade. $\mathrm{N}$ Methyl-2-pyrrolidone (NMP) and dimethylformamide (DMF) were distilled at reduced pressure before use. For the ${ }^{1} \mathrm{H}-\mathrm{NMR}$ data, chemical shifts are recorded in ppm downfield from tetramethylsilane. $J$ values are given in $\mathrm{Hz}$. Abbreviations used are s (singlet), d (doublet), dd (double doublet), t (triplet), b (broad) and bm (broad multiplet). Melting points (Mp) were measured on a differential scanning calorimetric apparatus (Mettler DSC 12E) and were not corrected.

Protection of the Catechol Group of Quercetin. Synthesis of 2-(2,2Diphenylbenzo [1,3]dioxol-5-yl)-3,5,7-trihydroxychromen-4-one (1)

To a solution of quercetin (2.0 $\mathrm{g}, 5.9 \mathrm{mmol})$ in NMP $(60 \mathrm{~mL})$, dichlorodiphenylmethane $(5.8 \mathrm{~mL}, 30 \mathrm{mmol})$ was added. The solution was heated to $165{ }^{\circ} \mathrm{C}$, stirred for $1 \mathrm{~h}$ and then cooled to room temperature (RT). The solution was diluted with EtOAc $(150 \mathrm{~mL})$, washed with $0.1 \mathrm{M} \mathrm{HCl}(100 \mathrm{~mL})$ and saturated $\mathrm{NaCl}$ (aq.). The organic layer was dried over $\mathrm{MgSO}_{4}$, the drying agent was filtered and the filtrate was dried in vacuo. The crude product was purified by flash column chromatography using toluene/EtOAc $(9: 1, \mathrm{v} / \mathrm{v})$ as eluent. The eluent was evaporated and compound 1 (2.0 g, $4.3 \mathrm{mmol}, 70 \%)$ was thus isolated. ${ }^{1} \mathrm{H}-\mathrm{NMR}$ ([D3]MeCN, $\left.300 \mathrm{MHz}\right): 6.21\left(\mathrm{~d}, J=2.1 \mathrm{~Hz}, 1 \mathrm{H}, \mathrm{H}_{6}\right.$ ), $6.48\left(\mathrm{~d}, J=2.1 \mathrm{~Hz}, 1 \mathrm{H}, \mathrm{H}_{8}\right), 7.24\left(\mathrm{dd}, J=8.7 \mathrm{~Hz}, 2.0 \mathrm{~Hz}, 1 \mathrm{H}, \mathrm{H}_{5^{\prime}}\right), 7.46-7.61(\mathrm{bm}$, 


\section{Chapter 2}

$10 \mathrm{H}$, diphenyl protons), $7.81\left(\mathrm{~d}, J=2.0 \mathrm{~Hz}, 1 \mathrm{H}, \mathrm{H}_{2^{\prime}}\right), 7.84\left(\mathrm{~b}, 1 \mathrm{H}, \mathrm{H}_{6^{\prime}}\right), 12.39$ (s, $1 \mathrm{H}, 5-\mathrm{OH})$.

\section{Synthesis of Quercetin-3-OMe (Q1) and Quercetin-3,7-OMe (Q2)}

To a solution of 1 ( $0.60 \mathrm{~g}, 1.3 \mathrm{mmol})$ and potassium carbonate $(182 \mathrm{mg}, 1.3 \mathrm{mmol})$ in DMF (12 mL), an excess of iodomethane $(0.20 \mathrm{~mL}, 3.2 \mathrm{mmol})$ was added. The reaction mixture $(\mathrm{RM})$ was stirred at RT overnight for $3 \mathrm{~h}$. The mixture was diluted with $0.1 \mathrm{M} \mathrm{HCl}(30 \mathrm{~mL})$ and extracted with EtOAc $(50 \mathrm{~mL})$. The organic layer was washed with saturated $\mathrm{NaCl}$ (aq.) and dried over $\mathrm{MgSO}_{4}$. The drying agent was filtered and the filtrate was evaporated in vacuo. The resulting residue was refluxed in acetic acid/water $(8: 2,100 \mathrm{~mL})$ for $3 \mathrm{~h}$ and then cooled down to RT. The RM was diluted with water $(100 \mathrm{~mL})$ and extracted with EtOAC (200 $\mathrm{mL})$. The organic layer was washed with saturated $\mathrm{NaHCO}_{3}$ (aq.) $(100 \mathrm{~mL})$, water $(100 \mathrm{~mL})$ and saturated $\mathrm{NaCl}$ (aq.) $(100 \mathrm{~mL})$. The organic layer was dried over $\mathrm{MgSO}_{4}$, the drying agent was filtered and the filtrate was dried in vacuo. The crude product was purified by flash column chromatography using toluene/EtOAc (10:3, v/v) to afford $100 \mathrm{mg}$ of Q1 (0.31 mmol, 24\%) and 150 mg of Q2 (0.45 mmol, 35\%), after removal of the eluents in vacuo.

Quercetin-3-OMe (Q1). ${ }^{1} \mathrm{H}-\mathrm{NMR}$ ([D3]MeCN, $\left.300 \mathrm{MHz}\right): 3.79$ (s, 3H, 3$\left.\mathrm{OCH}_{3}\right), 6.20\left(\mathrm{~d}, J=2.1 \mathrm{~Hz}, 1 \mathrm{H}, \mathrm{H}_{6}\right), 6.42\left(\mathrm{~d}, J=1.8 \mathrm{~Hz}, 1 \mathrm{H}, \mathrm{H}_{8}\right), 6.91(\mathrm{~d}, J=8.4$ $\left.\mathrm{Hz}, 1 \mathrm{H}, \mathrm{H}_{5^{\prime}}\right), 7.46\left(\mathrm{dd}, J=8.4,2.4 \mathrm{~Hz}, 1 \mathrm{H}, \mathrm{H}_{6^{\prime}}\right), 7.56\left(\mathrm{~d}, J=2.4 \mathrm{~Hz}, 1 \mathrm{H}, \mathrm{H}_{2^{\prime}}\right.$ ), 12.72 (s, 1H, 5-OH).

Quercetin-3,7-OMe (Q2). ${ }^{1} \mathrm{H}-\mathrm{NMR}$ ([D3]MeCN, $\left.400 \mathrm{MHz}\right): 3.81$ (s, 3H, 3-OCH 3 ), 3.87 (s, 3H, 7- $\left.\mathrm{OCH}_{3}\right), 6.38$ (b, 1H, H $), 6.73$ (b, 1H, H $), 7.12$ (d, J = 8.8 Hz, 1H, $\left.\mathrm{H}_{5^{\prime}}\right), 7.58$ (b, 2H, $\left.\mathrm{H}_{2^{\prime}}, \mathrm{H}_{6^{\prime}}\right), 9.44$ (s, 1H, 3'-OH), 12.65 (s, 1H, 5-OH).

\section{Synthesis of Quercetin-3,7,4'-OMe (Q3) and Quercetin-3,7,3',4'-OMe (Q4)}

To a solution of quercetin $(0.25 \mathrm{~g}, 0.74 \mathrm{mmol})$ and potassium carbonate $(0.30 \mathrm{~g}$, $2.2 \mathrm{mmol})$ in DMF $(6 \mathrm{~mL})$, iodomethane $(0.20 \mathrm{~mL}, 3.2 \mathrm{mmol})$ was added. The $\mathrm{RM}$ was stirred at RT overnight. The mixture was diluted with $0.2 \mathrm{M} \mathrm{HCl}$ (15 
$\mathrm{mL})$ and extracted with EtOAc $(30 \mathrm{~mL})$. The organic layer was washed with saturated $\mathrm{NaCl}$ (aq.) and dried over $\mathrm{MgSO}_{4}$. The drying agent was filtered and the filtrate was evaporated in vacuo. The resulting residue was purified by flash column chromatography using $\mathrm{CHCl}_{3} / \mathrm{EtOAc}(95: 5$, v/v) as eluent. Two products were isolated. The eluents were concentrated in vacuo and the products were precipitated from iso-hexane. The different precipitates were dried in vacuo to afford $0.13 \mathrm{~g}$ of Q3 (0.39 mmol, 53\%) and $46 \mathrm{mg}$ of Q4 (0.13 mmol, 17\%).

Quercetin-3,7,4'-OMe (Q3). ' ${ }^{1} \mathrm{H}-\mathrm{NMR}([\mathrm{D} 3] \mathrm{MeCN}, 400 \mathrm{MHz}): 3.81$ (s, 3H, 3$\left.\mathrm{OCH}_{3}\right), 3.87$ (s, 6H, 4'-OCH $\left.3,7-\mathrm{OCH}_{3}\right), 6.38\left(\mathrm{~d}, J=2.1 \mathrm{~Hz}, 1 \mathrm{H}, \mathrm{H}_{6}\right), 6.73$ (d, $J=$ $\left.2.0 \mathrm{~Hz}, 1 \mathrm{H}, \mathrm{H}_{8}\right), 7.12$ (d, J = 9.2 Hz, 1H, $\left.\mathrm{H}_{5^{\prime}}\right), 7.58\left(\mathrm{~b}, 2 \mathrm{H}, \mathrm{H}_{2^{\prime}}, \mathrm{H}_{6^{\prime}}\right), 9.44(\mathrm{~s}, 1 \mathrm{H}$, 3'-OH), 12.65 (s, 1H, 5-OH).

Quercetin-3,7,3',4'-OMe (Q4). ${ }^{1} \mathrm{H}-\mathrm{NMR}\left(\mathrm{CDCl}_{3}, 300 \mathrm{MHz}\right): 3.88$ (s, 3H, 3'$\left.\mathrm{OCH}_{3}\right)$,

3- $\left.-\mathrm{OCH}_{3}\right), 3.98$ (s, 3H, 4'- $\left.\mathrm{OCH}_{3}\right), 3.99$ (s, 3H, 7- $\left.-\mathrm{OCH}_{3}\right), 6.37$ (d, J = 2.1 Hz, 1H, $\left.\mathrm{H}_{6}\right), 6.46\left(\mathrm{~d}, J=2.1 \mathrm{~Hz}, 1 \mathrm{H}, \mathrm{H}_{8}\right), 7.00\left(\mathrm{~d}, J=8.4 \mathrm{~Hz}, 1 \mathrm{H}, \mathrm{H}_{5^{\prime}}\right), 7.70(\mathrm{~d}, J=1.8$ $\left.\mathrm{Hz}, 1 \mathrm{H}, \mathrm{H}_{2^{\prime}}\right), 7.75\left(\mathrm{dd}, J=8.4,2.1 \mathrm{~Hz}, 1 \mathrm{H}, \mathrm{H}_{6^{\prime}}\right), 12.65$ (s, 1H, 5-OH).

\section{Synthesis of Quercetin-penta-OMe (Q5)}

To a solution of quercetin $(0.20 \mathrm{~g}, 0.59 \mathrm{mmol})$ and potassium carbonate $(0.45 \mathrm{~g}$, $3.3 \mathrm{mmol})$ in DMF $(5 \mathrm{~mL})$, iodomethane $(0.40 \mathrm{~mL}, 6.4 \mathrm{mmol})$ was added. The $\mathrm{RM}$ was stirred at RT overnight. The mixture was diluted with $0.2 \mathrm{M} \mathrm{HCl}$ (15 $\mathrm{mL})$ and extracted with EtOAc $(30 \mathrm{~mL})$. The organic layer was washed with saturated $\mathrm{NaCl}$ (aq.) and dried over $\mathrm{MgSO}_{4}$. The drying agent was filtered and the filtrate was evaporated in vacuo. The resulting residue was crystallized from EtOAc $(1 \mathrm{~mL})$ and then washed twice with cold EtOAc $(0.5 \mathrm{~mL})$. The crystals were dissolved in DCM, precipitated from iso-hexane and then dried in vacuo to afford Q5 (0.10 g, $0.27 \mathrm{mmol}, 46 \%)$. 


\section{Chapter 2}

Quercetin-penta-OMe (Q5). ${ }^{1} \mathrm{H}-\mathrm{NMR}\left(\mathrm{CDCl}_{3}, 300 \mathrm{MHz}\right): 3.89$ (s, 3H, 3'-- $\left.\mathrm{OCH}_{3}\right)$, 3.92 (s, 3H, 3- $\left.-\mathrm{OCH}_{3}\right), 3.97$ (b, 9H, 5- $\left.\mathrm{OCH}_{3}, 7-\mathrm{OCH}_{3}, 4^{\prime}-\mathrm{OCH}_{3}\right), 6.36$ (d, $J=2.1$ $\left.\mathrm{Hz}, 1 \mathrm{H}, \mathrm{H}_{6}\right), 6.52\left(\mathrm{~d}, J=2.4 \mathrm{~Hz}, 1 \mathrm{H}, \mathrm{H}_{8}\right), 6.99$ (d, $\left.J=9 \mathrm{~Hz}, 1 \mathrm{H}, \mathrm{H}_{5^{\prime}}\right), 7.70$ (d, $J=$ $\left.1.8 \mathrm{~Hz}, 1 \mathrm{H}, \mathrm{H}_{2^{\prime}}\right), 7.73\left(\mathrm{~b}, 1 \mathrm{H}, \mathrm{H}_{6^{\prime}}\right)$.

\section{Synthesis of Quercetin-3, 7,4'-OBn (2) and Quercetin-3, 7,3',4'-OBn (3)}

To a solution of quercetin $(1.0 \mathrm{~g}, 3.0 \mathrm{mmol})$ and potassium carbonate $(1.4 \mathrm{~g}, 10$ mmol) in

DMF

(20 mL), benzyl bromide $(2.2 \mathrm{~mL}, 18 \mathrm{mmol})$ was added. The RM was stirred at RT overnight. The mixture was diluted with $0.3 \mathrm{M} \mathrm{HCl}(60 \mathrm{~mL})$ and extracted with EtOAc $(100 \mathrm{~mL})$. The organic layer was washed with saturated $\mathrm{NaCl}$ (aq.) and dried over $\mathrm{MgSO}_{4}$. The drying agent was filtered and the filtrate was evaporated in vacuo. The resulting residue was purified by flash column chromatography using $\mathrm{CHCl}_{3} / \mathrm{EtOAc}(95: 5, \mathrm{v} / \mathrm{v})$ to afford $0.80 \mathrm{~g}$ of 2 (1.4 mmol, $47 \%)$ and $0.66 \mathrm{~g}$ of 3 (1.0 mmol, 33\%), after removal of the eluents in vacuo. Quercetin-3,7,4'-OBn (2): Mp $150.8{ }^{\circ} \mathrm{C}$ (150-152 $\left.{ }^{\circ} \mathrm{C}\right)$, Quercetin-3,7,3',4'-OBn (3): $\operatorname{Mp~} 145.2{ }^{\circ} \mathrm{C}\left(140-142{ }^{\circ} \mathrm{C}\right)[12]$.

\section{Synthesis of Quercetin-3,7,4'-OBn-3'-OMe (4)}

To a solution of $2(0.20 \mathrm{~g}, 0.35 \mathrm{mmol})$ and potassium carbonate $(50 \mathrm{mg}, 0.36$ $\mathrm{mmol})$ in DMF $(5 \mathrm{~mL})$, an excess of iodomethane $(0.10 \mathrm{~mL}, 1.6 \mathrm{mmol})$ was added. The RM was stirred at RT overnight. The mixture was diluted with $0.3 \mathrm{M}$ $\mathrm{HCl}(15 \mathrm{~mL})$ and extracted with EtOAc $(30 \mathrm{~mL})$. The organic layer was washed with saturated $\mathrm{NaCl}$ (aq.) and dried over $\mathrm{MgSO}_{4}$. The drying agent was filtered and the filtrate was evaporated in vacuo. The residue was purified by flash column chromatography using $\mathrm{CHCl}_{3} / \operatorname{EtOAc}(95: 5$, v/v) as eluent. The eluent was concentrated in vacuo and the residue was precipitated from methanol. The precipitate was dried in vacuo to afford $0.15 \mathrm{~g}(0.26 \mathrm{mmol}, 74 \%)$ of Quercetin3,7,4'-OBn-3'-OMe (4). Mp $141.8^{\circ} \mathrm{C}\left(142-144^{\circ} \mathrm{C}\right)$ [12]. 
Synthesis of Quercetin-3,7,4'-OBn-5,3'-OMe (5)

To a solution of $2(0.20 \mathrm{~g}, 0.35 \mathrm{mmol})$ and potassium carbonate $(0.15 \mathrm{~g}, 1.1$ $\mathrm{mmol})$ in DMF $(5 \mathrm{~mL})$, an excess of iodomethane $(0.10 \mathrm{~mL}, 1.6 \mathrm{mmol})$ was added. The RM was stirred at RT overnight. The mixture was diluted with $0.3 \mathrm{M}$ $\mathrm{HCl}(10 \mathrm{~mL})$ and extracted twice with EtOAc $(30 \mathrm{~mL})$. The combined organic layer was washed with saturated $\mathrm{NaCl}$ (aq.) and dried over $\mathrm{MgSO}_{4}$. The drying agent was filtered and the filtrate was evaporated in vacuo. The product was recrystallized from toluene and dried in vacuo to afford $0.13 \mathrm{~g}(0.22 \mathrm{mmol}, 63 \%)$ of Quercetin-3,7,4'-OBn-5,3'-OMe (5). Mp $139.6{ }^{\circ} \mathrm{C}$.

\section{Synthesis of Quercetin-3,7,3',4'-OBn-5-OMe (6)}

To a solution of $3(0.20 \mathrm{~g}, 0.30 \mathrm{mmol})$ and potassium carbonate $(50 \mathrm{mg}, 0.36$ $\mathrm{mmol})$ in DMF $(5 \mathrm{~mL})$, an excess of iodomethane $(0.10 \mathrm{~mL}, 1.6 \mathrm{mmol})$ was added. The RM was stirred at RT overnight. The mixture was diluted with $0.3 \mathrm{M}$ $\mathrm{HCl}(15 \mathrm{~mL})$ and extracted with EtOAc $(30 \mathrm{~mL})$. The organic layer was washed with saturated $\mathrm{NaCl}$ (aq.) and dried over $\mathrm{MgSO}_{4}$. The drying agent was filtered and the filtrate was evaporated in vacuo. The residue was purified by flash column chromatography using $\mathrm{CHCl}_{3} / \operatorname{EtOAc}(95: 5, \mathrm{v} / \mathrm{v})$ as eluent. The eluent was dried in vacuo to afford $0.18 \mathrm{~g}(0.27 \mathrm{mmol}, 90 \%)$ of Quercetin-3,7,3',4'OBn-5-OMe (6). $\mathrm{Mp} 159.8^{\circ} \mathrm{C}\left(156-158^{\circ} \mathrm{C}\right)[12]$.

Debenzylation of 4, 5 and 6: Synthesis of Quercetin-3'-OMe (I1), Quercetin-5,3'OMe (I2) and Quercetin-5-OMe (Q6), respectively (see section 4.3.17 "General procedure for debenzylation”)

Synthesis of 2-(2,2-Diphenylbenzo [1,3]dioxol-5-yl)-3-benzyloxy-5,7dihydroxychromen-4-one $(2 *)$ and 2-(2,2-Diphenylbenzo [1,3]dioxol-5-yl)-3,7dibenzyloxy-5-hydroxychromen-4-one (3*)

To a solution of $1(0.60 \mathrm{~g}, 1.3 \mathrm{mmol})$ and sodium bicarbonate $(0.13 \mathrm{~g}, 1.5 \mathrm{mmol})$ in DMF (12 mL), an excess of benzyl bromide $(1.0 \mathrm{~mL}, 8.2 \mathrm{mmol})$ was added. The RM was stirred at RT overnight. The mixture was diluted with $0.1 \mathrm{M} \mathrm{HCl}$ (30 


\section{Chapter 2}

$\mathrm{mL})$ and extracted with EtOAc $(50 \mathrm{~mL})$. The organic layer was washed with saturated $\mathrm{NaCl}$ (aq.) and dried over $\mathrm{MgSO}_{4}$. The drying agent was filtered and the filtrate was evaporated in vасио. The resulting residue was purified by flash column chromatography using toluene/EtOAc (100:5, v/v) to afford $0.24 \mathrm{~g}(0.43$ mmol, 33\%) of 2-(2,2-Diphenylbenzo [1,3]dioxol-5-yl)-3-benzyloxy-5,7dihydroxychromen-4-one $\left(2^{*}\right)$ and $0.51 \mathrm{~g}(0.79 \mathrm{mmol}, 61 \%)$ of 2-(2,2Diphenylbenzo [1,3]dioxol-5-yl)-3,7-dibenzyloxy-5-hydroxychromen-4-one (3*).

Monomethylation of 2*: Synthesis of 2-(2,2-Diphenylbenzo [1,3]dioxol-5-yl)-3benzyloxy-5-hydroxy-7-methoxychromen-4-one (4*)

To a solution of $2 *(0.20 \mathrm{~g}, 0.36 \mathrm{mmol})$ and potassium carbonate $(45 \mathrm{mg}, 0.33$ $\mathrm{mmol})$ in DMF $(5 \mathrm{~mL})$, an excess of iodo methane $(0.10 \mathrm{~mL}, 1.6 \mathrm{mmol})$ was added. The RM was stirred at RT overnight. The mixture was diluted with $0.1 \mathrm{M}$ $\mathrm{HCl}(15 \mathrm{~mL})$ and extracted with EtOAc $(30 \mathrm{~mL})$. The organic layer was washed with saturated $\mathrm{NaCl}$ (aq.) and dried over $\mathrm{MgSO}_{4}$. The drying agent was filtered and the filtrate was evaporated in vacuo. The resulting residue was purified by flash column chromatography using toluene/EtOAc (100:5, v/v) to afford $0.16 \mathrm{~g}(0.28$ mmol, 78\%) of 2-(2,2-Diphenylbenzo [1,3]dioxol-5-yl)-3-benzyloxy-5-hydroxy7-methoxychromen-4-one (4*). $\mathrm{Mp} 134.8^{\circ} \mathrm{C}\left(134-136^{\circ} \mathrm{C}\right)$ [12].

Debenzylation of 4*: Synthesis of Quercetin-7-OMe (Q7) (see section 4.3.17 “General procedure for debenzylation”)

Tribenzylation of Compound 1 Followed by Selective Deprotection of the Catechol Moiety: Synthesis of Quercetin-3,7-OBn (5*)

To a solution of $1(0.60 \mathrm{~g}, 1.3 \mathrm{mmol})$ and potassium carbonate $(0.55 \mathrm{~g}, 4.0$ $\mathrm{mmol})$ in DMF (12 mL), an excess of benzyl bromide $(1.0 \mathrm{~mL}, 8.2 \mathrm{mmol})$ was added. The RM was stirred at RT overnight. The mixture was diluted with $0.1 \mathrm{M}$ $\mathrm{HCl}(30 \mathrm{~mL})$ and extracted with EtOAc $(50 \mathrm{~mL})$. The organic layer was washed with saturated $\mathrm{NaCl}$ (aq.) and dried over $\mathrm{MgSO}_{4}$. The drying agent was filtered and the filtrate was evaporated in vacuo. The resulting residue was refluxed in 
acetic acid/water $(8: 2,100 \mathrm{~mL})$ for $3 \mathrm{~h}$ and then cooled down to RT. The reaction mixture $(\mathrm{RM})$ was diluted with water $(100 \mathrm{~mL})$ and extracted with of EtOAc $(200 \mathrm{~mL})$. The organic layer was washed with saturated $\mathrm{NaHCO}_{3}$ (aq.) (100 $\mathrm{mL})$, water $(100 \mathrm{Ml})$ and saturated $\mathrm{NaCl}$ (aq.) $(100 \mathrm{~mL})$. The organic layer was dried over $\mathrm{MgSO}_{4}$, the drying agent was filtered and the filtrate was dried in vacuo. The crude product was purified by flash column chromatography using toluene/EtOAc (10:1, v/v) to afford $0.38 \mathrm{~g}(0.78 \mathrm{mmol}, 60 \%)$ of Quercetin-3,7OBn (5*), after removal of the eluents in vacuo. $\mathrm{Mp} 201.5^{\circ} \mathrm{C}\left(202-204{ }^{\circ} \mathrm{C}\right)$ [12].

Monomethylation of 5*: Synthesis of Compound Quercetin-3,7-OBn-4'-OMe $(6 *)$

To a solution of $5^{*}(0.28 \mathrm{~g}, 0.58 \mathrm{mmol})$ and potassium carbonate $(75 \mathrm{mg}, 0.54$ mmol) in DMF $(7 \mathrm{~mL})$, an excess of iodomethane $(0.10 \mathrm{~mL}, 1.6 \mathrm{mmol})$ was added. The RM was stirred at RT for $3 \mathrm{~h}$. The mixture was diluted with $0.1 \mathrm{M}$ $\mathrm{HCl}(15 \mathrm{~mL})$ and extracted with EtOAc $(30 \mathrm{~mL})$. The organic layer was washed with saturated $\mathrm{NaCl}$ (aq.) and dried over $\mathrm{MgSO}_{4}$. The drying agent was filtered and the filtrate was evaporated in vacuo. The resulting residue was purified by flash column chromatography using toluene/EtOAc (100:5, v/v) to afford $0.20 \mathrm{~g}(0.40$ mmol, 69\%) of Quercetin-3,7-OBn-4'-OMe (6*). Mp $146.8{ }^{\circ} \mathrm{C}\left(144-146{ }^{\circ} \mathrm{C}\right)$ [12].

Debenzylation of 6*: Synthesis of Quercetin-4'-OMe (Q8) (see section 4.3.17 “General procedure for debenzylation”)

General Procedure for Debenzylation: Synthesis of Quercetin-3'-OMe (I1), Quercetin-5,3'-OMe (I2), Quercetin-5-OMe (Q6), Quercetin-7-OMe (Q7) and Quercetin-4'-OMe (Q8)

A suspension of $0.2 \mathrm{mmol}$ of the benzylated product in $\mathrm{HCl}(36 \%, 10 \mathrm{~mL})$ and glacial acid $(10 \mathrm{~mL})$ was refluxed for $4 \mathrm{~h}$ and then cooled down to RT. The reaction mixture $(\mathrm{RM})$ was diluted with water $(100 \mathrm{~mL})$ and extracted with EtOAc $(200 \mathrm{~mL})$. The organic layer was washed with saturated $\mathrm{NaHCO}_{3}$ (aq.) 


\section{Chapter 2}

$(100 \mathrm{~mL})$, water $(100 \mathrm{~mL})$ and saturated $\mathrm{NaCl}$ (aq.) $(100 \mathrm{~mL})$. . The organic layer was dried over $\mathrm{MgSO}_{4}$, the drying agent was filtered and the filtrate was concentrated in vacuo. The products were precipitated from iso-hexane and the precipitates were dried in vacuo.

Quercetin-3'-OMe (I1). (60 mg, 0.19 mmol, 95\%). ${ }^{1} \mathrm{H}-\mathrm{NMR}$ ([D6]DMSO, 300 MHz): 3.86 (s, 3H, 3'-OCH $\left.{ }_{3}\right), 6.21$ (d, $\left.J=2.1 \mathrm{~Hz}, 1 \mathrm{H}, \mathrm{H}_{6}\right), 6.49$ (d, $J=2.1 \mathrm{~Hz}$, $\left.1 \mathrm{H}, \mathrm{H}_{8}\right), 6.95\left(\mathrm{~d}, J=8.4 \mathrm{~Hz}, 1 \mathrm{H}, \mathrm{H}_{5^{\prime}}\right), 7.70\left(\mathrm{dd}, J=8.4,2.1 \mathrm{~Hz}, 1 \mathrm{H}, \mathrm{H}_{6^{\prime}}\right), 7.77(\mathrm{~d}$, $J=2.1 \mathrm{~Hz}, 1 \mathrm{H}, \mathrm{H}_{2^{\prime}}$ ), 9.45 (b, 1H, 3-OH), 9.75 (b, 1H, 4'-OH), 10.79 (b, 1H, 7$\mathrm{OH}), 12.48$ (s, 1H, 5-OH).

Quercetin-5,3'-OMe (I2). (63 mg, 0.19 mmol, 95\%). ${ }^{1} \mathrm{H}-\mathrm{NMR}$ ([D6]DMSO, 300 $\mathrm{MHz}): 3.84$ (s, 3H, 3'- $\left.\mathrm{OCH}_{3}\right), 3.85$ (s, 3H, 5- $\left.\mathrm{OCH}_{3}\right), 6.37$ (d, J=2.1 Hz, 1H, $\mathrm{H}_{6}$ ), $6.54\left(\mathrm{~d}, J=2.1 \mathrm{~Hz}, 1 \mathrm{H}, \mathrm{H}_{8}\right), 6.94\left(\mathrm{~d}, J=8.4 \mathrm{~Hz}, 1 \mathrm{H}, \mathrm{H}_{5^{\prime}}\right), 7.64(\mathrm{dd}, J=8.4,2.1$ $\left.\mathrm{Hz}, 1 \mathrm{H}, \mathrm{H}_{6^{\prime}}\right), 7.73$ (d, J = 2.1 Hz, 1H, $\mathrm{H}_{2^{\prime}}$ ), 8.69 (s, 1H, 3-OH), 9.61 (b, 1H, 4'$\mathrm{OH}), 10.70$ (b, 1H, 7-OH).

Quercetin-5-OMe (Q6). (50 mg, 0.16 mmol, 80\%). ${ }^{1} \mathrm{H}-\mathrm{NMR}$ ([D6]DMSO, 300 $\mathrm{MHz}): 3.84\left(\mathrm{~s}, 3 \mathrm{H}, 5-\mathrm{OCH}_{3}\right), 6.36\left(\mathrm{~d}, J=2.1 \mathrm{~Hz}, 1 \mathrm{H}, \mathrm{H}_{6}\right), 6.46(\mathrm{~d}, J=2.1 \mathrm{~Hz}$, $\left.1 \mathrm{H}, \mathrm{H}_{8}\right), 6.88\left(\mathrm{~d}, J=8.4 \mathrm{~Hz}, 1 \mathrm{H}, \mathrm{H}_{5^{\prime}}\right), 7.49\left(\mathrm{dd}, J=8.4,2.1 \mathrm{~Hz}, 1 \mathrm{H}, \mathrm{H}_{6^{\prime}}\right), 7.63(\mathrm{~d}$, $\left.J=2.1 \mathrm{~Hz}, 1 \mathrm{H}, \mathrm{H}_{2^{\prime}}\right), 8.62(\mathrm{~b}, 1 \mathrm{H}, 3-\mathrm{OH}), 9.30$ (b, 1H, 3'-OH), 10.72 (b, 1H, 7$\mathrm{OH})$.

Quercetin-7-OMe (Q7). (55 mg, 0.17 mmol,85\%). ${ }^{1} \mathrm{H}-\mathrm{NMR}$ ([D6]DMSO, 300 $\mathrm{MHz}): 3.88\left(\mathrm{~s}, 3 \mathrm{H}, 7-\mathrm{OCH}_{3}\right), 6.36\left(\mathrm{~d}, J=2.1 \mathrm{~Hz}, 1 \mathrm{H}, \mathrm{H}_{6}\right), 6.71(\mathrm{~d}, J=2.1 \mathrm{~Hz}$, $\left.1 \mathrm{H}, \mathrm{H}_{8}\right), 6.91\left(\mathrm{~d}, J=8.7 \mathrm{~Hz}, 1 \mathrm{H}, \mathrm{H}_{5}\right), 7.59\left(\mathrm{dd}, J=8.4,2.1 \mathrm{~Hz}, 1 \mathrm{H}, \mathrm{H}_{6^{\prime}}\right), 7.74(\mathrm{~d}$, $\left.J=2.1 \mathrm{~Hz}, 1 \mathrm{H}, \mathrm{H}_{2^{\prime}}\right), 9.49$ (b, 1H, 3-OH), 12.50 (s, 1H, 5-OH).

Quercetin-4'-OMe (Q8). (60 mg, 0.19 mmol, 95\%). ${ }^{1} \mathrm{H}-\mathrm{NMR}$ ([D6]DMSO, 300 MHz): 3.86 (s, 3H, 4'- $\left.\mathrm{OCH}_{3}\right), 6.20$ (d, $\left.J=1.8 \mathrm{~Hz}, 1 \mathrm{H}, \mathrm{H}_{6}\right), 6.43(\mathrm{~d}, J=2.1 \mathrm{~Hz}$, 
1H, $\left.\mathrm{H}_{8}\right), 7.09$ (d, $\left.J=8.7 \mathrm{~Hz}, 1 \mathrm{H}, \mathrm{H}_{5^{\prime}}\right), 7.66\left(\mathrm{bm}, 2 \mathrm{H}, \mathrm{H}_{2^{\prime}} \& \mathrm{H}_{6^{\prime}}\right.$ ), 9.34 (s, 1H, 3'$\mathrm{OH}), 9.47$ (b, 1H, 3-OH), 10.82 (b, 1H, 7-OH), 12.46 (s, 1H, 5-OH).

Quercetin-5, 7, 3', 4'-OMe (I3)

Quercetin-5, 7, 3', $4^{\prime}$-OMe (I3) was available from an earlier study, and was obtained by the demethylation of $\mathbf{Q 5}$ with an excess of $\mathrm{AlCl}_{3}$ [21]. 


\section{Chapter 2}

\section{References}

1. Hertog, M. G.; Hollman, P. C.; Katan, M. B. Content of potentially anticarcinogenic flavonoids of 28 vegetables and 9 fruits commonly consumed in The Netherlands. J. Agric. Food Chem. 1992, 40, 23792383.

2. Boots, A. W.; Haenen, G. R.; Bast, A. Health effects of quercetin: from antioxidant to nutraceutical. Eur J Pharmacol 2008, 585, 325-337.

3. Crozier, A.; Lean, M. E.; McDonald, M. S.; Black, C. Quantitative analysis of the flavonoid content of commercial tomatoes, onions, lettuce, and celery. J. Agric. Food Chem. 1997, 45, 590-595.

4. Justesen, U.; Knuthsen, P.; Leth, T. Quantitative analysis of flavonols, flavones, and flavanones in fruits, vegetables and beverages by highperformance liquid chromatography with photo-diode array and mass spectrometric detection. J. Chromatogr. A 1998, 799, 101-110.

5. Willems, A. M.; Bruynzeel, A. M.; Kedde, M. A.; van Groeningen, C. J.; Bast, A.; van der Vijgh, W. J. A phase I study of monohydroxyethylrutoside in healthy volunteers. Cancer Chemother Pharmacol 2006, 57, 678-684.

6. Bruynzeel, A. M.; Niessen, H. W.; Bronzwaer, J. G.; van der Hoeven, J. J.; Berkhof, J.; Bast, A.; van der Vijgh, W. J.; van Groeningen, C. J. The effect of monohydroxyethylrutoside on doxorubicin-induced cardiotoxicity in patients treated for metastatic cancer in a phase II study. Br J Cancer 2007, 97, 1084-1089.

7. Kay, C. D. Aspects of anthocyanin absorption, metabolism and pharmacokinetics in humans. Nutr. Res. Rev. 2006, 19, 137-146.

8. Spencer, J. P.; Kuhnle, G. G.; Williams, R. J.; Rice-Evans, C. Intracellular metabolism and bioactivity of quercetin and its in vivo metabolites. Biochem. J. 2003, 372, 173-181.

9. Spencer, J. P.; Abd-el-Mohsen, M. M.; Rice-Evans, C. Cellular uptake and metabolism of flavonoids and their metabolites: implications for their bioactivity. Arch Biochem Biophys 2004, 423, 148-161. 
10. Mladenka, P.; Macakova, K.; Filipsky, T.; Zatloukalova, L.; Jahodar, L.; Bovicelli, P.; Silvestri, I. P.; Hrdina, R.; Saso, L. In vitro analysis of iron chelating activity of flavonoids. J Inorg Biochem, 105, 693-701.

11. Hermans, N.; Cos, P.; Maes, L.; De Bruyne, T.; Vanden Berghe, D.; Vlietinck, A. J.; Pieters, L. Challenges and pitfalls in antioxidant research. Curr Med Chem 2007, 14, 417-430.

12. Bouktaib, M.; Lebrun, S.; Atmani, A.; Ronaldo, C. Hemisynthesis of all the O-monomethylated analogues of quercetin including the major metabolites, through selective protection of phenolic functions. Tetrahedron 2002, 58, 10001-10009.

13. van Acker, F. A.; Hageman, J. A.; Haenen, G. R.; van Der Vijgh, W. J.; Bast, A.; Menge, W. M. Synthesis of novel 3,7-substituted-2-(3',4'dihydroxyphenyl)flavones with improved antioxidant activity. J. Med. Chem. 2000, 43, 3752-3760.

14. Rice-Evans, C. A.; Miller, N. J.; Paganga, G. Structure-antioxidant activity relationships of flavonoids and phenolic acids. Free Radic. Biol. Med. 1996, 20, 933-956.

15. van den Berg, R.; Haenen, G. R.; van den Berg, H.; Bast, A. Applicability of an improved Trolox equivalent antioxidant capacity (TEAC) assay for evaluation of antioxidant capacity measurements of mixtures. Food Chemistry 1999, 66, 511-517.

16. Castillo, J.; Benavente-Garcia, O.; Lorente, J.; Alcaraz, M.; Redondo, A.; Ortuno, A.; Del Rio, J. A. Antioxidant activity and radioprotective effects against chromosomal damage induced in vivo by X-rays of flavan-3-ols (Procyanidins) from grape seeds (Vitis vinifera): comparative study versus other phenolic and organic compounds. $J$. Agric. Food Chem. 2000, 48, 1738-1745.

17. Miller, N. J.; Rice-Evans, C. A. Factors influencing the antioxidant activity determined by the ABTS.+ radical cation assay. Free Radic. Res. 1997, 26, 195-199. 


\section{Chapter 2}

18. Re, R.; Pellegrini, N.; Proteggente, A.; Pannala, A.; Yang, M.; RiceEvans, C. Antioxidant activity applying an improved ABTS radical cation decolorization assay. Free Radic. Biol. Med. 1999, 26, 12311237.

19. Williamson, G.; Plumb, G. W.; Garcia-Conesa, M. T. Glycosylation, esterification and polymerization of flavonoids and hydroxycinnamates: effects on antioxidant properties. Basic Life Sci. 1999, 66, 483-494.

20. Cao, G.; Sofic, E.; Prior, R. L. Antioxidant and prooxidant behavior of flavonoids: structure-activity relationships. Free Radic. Biol. Med. 1997, 22, 749-760.

21. Heijnen, C. G.; Haenen, G. R.; Vekemans, J. A.; Bast, A. Peroxynitrite scavenging of flavonoids: structure activity relationship. Environmental Toxicology and Pharmacology 2001, 10, 199-206.

22. Haenen, G. R.; Paquay, J. B.; Korthouwer, R. E.; Bast, A. Peroxynitrite scavenging by flavonoids. Biochem. Biophys. Res. Commun. 1997, 236, 591-593.

23. Heijnen, C. G.; Haenen, G. R.; van Acker, F. A.; van der Vijgh, W. J.; Bast, A. Flavonoids as peroxynitrite scavengers: the role of the hydroxyl groups. Toxicol. in Vitro 2001, 15, 3-6.

24. Leopoldini, M.; Russo, N.; Toscano, M. The molecular basis of working mechanism of natural polyphenolic antioxidants. Food Chemistry 2011, 125, 288-306.

25. Leopoldini, M.; Russo, N.; Toscano, M. A comparative study of the antioxidant power of flavonoid catechin and its planar analogue. J Agric Food Chem 2007, 55, 7944-7949.

26. Walle, T. Methylation of dietary flavones increases their metabolic stability and chemopreventive effects. Int J Mol Sci 2009, 10, 50025019.

27. Duenas, M.; Gonzalez-Manzano, S.; Gonzalez-Paramas, A.; SantosBuelga, C. Antioxidant evaluation of O-methylated metabolites of 
Planar conformation and the hydroxyl groups

catechin, epicatechin and quercetin. J Pharm Biomed Anal 2010, 51, 443-449. 



\section{Chapter 3}

\section{Protection of the catechol moiety of quercetin through micro-reactor technology}

Mohamed Moalin, Gino P.F. van Strijdonck, Aalt Bast and Guido R.M.M. Haenen 


\title{
Chapter 3
}

\begin{abstract}
Quercetin $(\mathbf{Q})$ is a ubiquitous dietary anti-oxidant. There is a growing awareness that various health effects of $\mathbf{Q}$ are for the greater part mediated by its metabolites, especially the mono- $O$-methylated derivatives. To selectively synthesize mono- $O$-methylated derivatives of $\mathbf{Q}$, it is imperative to protect its catechol moiety first. Therefore, we have developed a refined method for the protection of the catechol moiety of $\mathbf{Q}$ using micro-reactor technology. The micro-reactor consists of a flow system in which the reactants are mixed in a highly controlled and well-defined micro-reactor. The advantage of this system is the reproducibility and the relatively high purity that can be achieved. Additionally, larger quantities can be produced with relative ease by scaling out.
\end{abstract}




\section{Introduction}

Quercetin $(\mathbf{Q})$ is one of the most studied flavonoids in vitro because of its relatively high anti-oxidant capacity, which is implicated in its health effects [1]. However, $\mathbf{Q}$ is readily metabolized in vivo [2] and it is therefore imperative to test the biological effect of its metabolites as well. In order to make these metabolites available for biological testing, efficient synthetic strategies have to be developed. In addition, chemical modification may generate new derivatives with a biological activity superior to that of $\mathbf{Q}$. This is exemplified by the semisynthetic flavonoid, monohydroxyethyl rutinoside (monoHER), that efficiently protects against the cardiotoxic side-effect of doxorubicin in mice [3].

The chemical modification explored in the present study is $O$-methylation, since the O-methylated metabolites have been implicated in the health effect of $\mathbf{Q}$. Moreover, methylation is a subtle structural modification that can improve the cellular uptake and metabolic stability of $\mathbf{Q}$ [4]. The aim of this study is to develop a refined method for the $O$-methylation of $\mathbf{Q}$ using micro-reactor technology (MRT). The MRT consists of a flow system in which reactants are mixed in a highly controlled and well-defined micro-reactor. The advantage of this system is the reproducibility and the relative ease of optimizing and upscaling to a "Kilo-Flow" [5].

\section{Results and discussion}

In general, phenolics can be readily $O$-methylated by using a non-nucleophilic base and a methylhalide, such as MeI. A problem is that $\mathbf{Q}$ contains several hydroxyl groups, i.e. 3-, 7- and 4'-OH, with similar reactivity (Figure 1). This is because 7-, 4'- and 3-OH groups of $\mathbf{Q}$ are conjugated through the $\pi$-system with the carbonyl group in the 4 position that can lead to keto-enol tautomerisation. This precludes the selective mono- $O$-methylation of $\mathbf{Q}$ and causes that direct methylation always leads to mixtures of mono-, di- and tri- $O$-methylated derivatives of $\mathbf{Q}$, which cannot be efficiently separated. Bouktaib et al. [6] developed a strategy that is based on selective protection of the catechol moiety with dichlorodiphenylmethane (1). 


\section{Chapter 3}
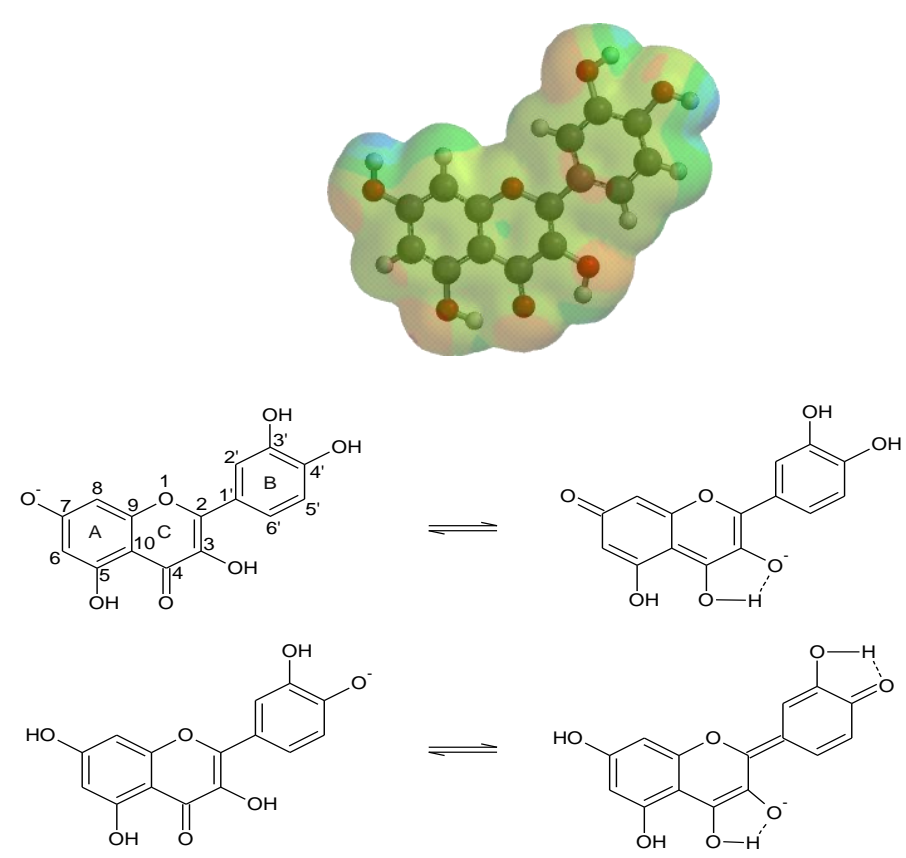

Figure 1. Left illustrates the electrostatic potential map of quercetin, with blue indicating the acidic sites and red indicating the nucleophilic groups. Right is a depiction of keto-enol tautomerization of quercetin, explaining the similar acidity of its 3-, 7- and 4'-OH groups.

Protection of the catechol moiety of $\mathbf{Q}$ does not proceed under basic conditions at room temperature [6], because compound $\mathbf{1}$ is too bulky to undergo an $\mathrm{S}_{\mathrm{N}} 2$ reaction. Relatively high temperatures are needed for $\mathbf{1}$ to form a carbocation that is reactive enough towards the hydroxylgroups of $\mathbf{Q}$ (Scheme 1). The protection of $\mathbf{Q}$ is highly selective because of the relatively high nucleophilicity of the 3 'OH (Figure 1) and the close proximity of the 4'OH. 
Scheme 1. Proposed $S_{N} 1$ mechanism for the protection of $\mathbf{Q}$ with dichlorodiphenylmethane.

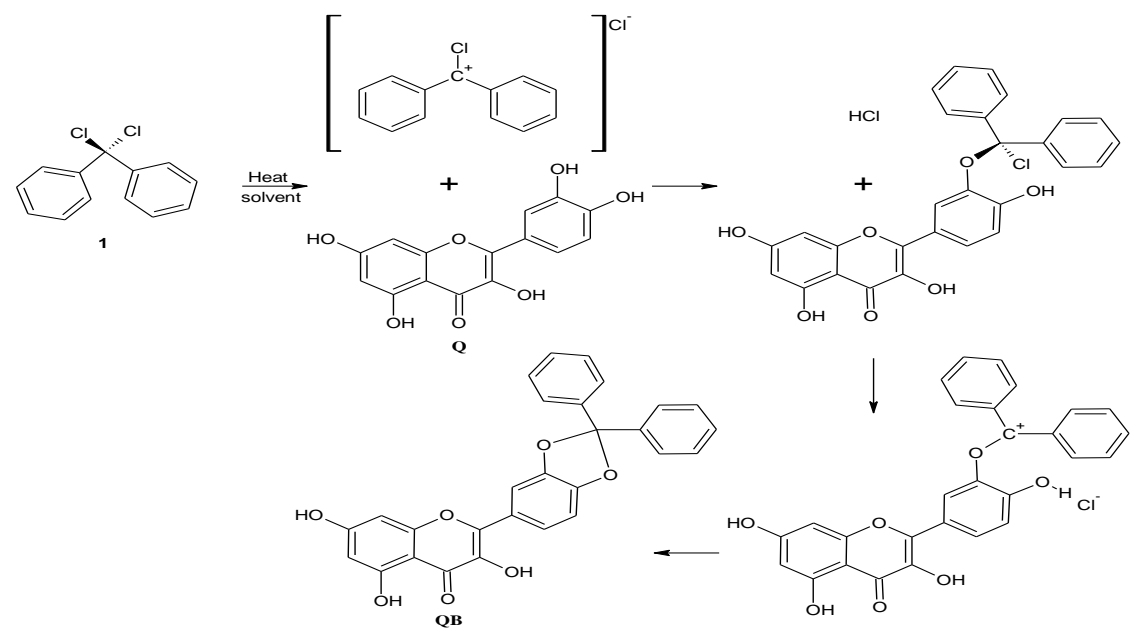

For batch chemistry, the reaction needs around 1 hour to complete at 160-180 ${ }^{\circ} \mathrm{C}$. This also means that only high boiling point solvents, such as NMP, can be used. Many side products (even under inert environment) are formed under these conditions, compromising the yield (Table 1) and leading to tedious purification steps.

With MRT, relatively high temperatures for low boiling point solvents are possible, because the reaction mixture $(\mathrm{RM})$ is pressurized in the micro-reactor. This broadens the spectrum of the solvents that can be used. Hence, solvents such as DMF (bp. $153{ }^{\circ} \mathrm{C}$ ) and toluene (bp. $111^{\circ} \mathrm{C}$ ) can be used in MRT reactions proceeding at $180{ }^{\circ} \mathrm{C}$. In addition, the $\mathrm{RM}$ needs around 5 minutes at $180{ }^{\circ} \mathrm{C}$ to complete, preventing slower forming products.

Reactions of $\mathbf{Q}$ in DMF produce less oxidation products than in NMP. Toluene is used to dissolve compound $\mathbf{1}$, because of the relatively low hygroscopy of toluene. Working with dry solvents and dry reagents is important to prevent hydrolysis of compound $\mathbf{1}$.

Several micro-reactor vessels have been tested and we found that the 3224 model (Figure 2) yields the highest conversion by far (>95\%). This is because the 3224 


\section{Chapter 3}

model has an integrated staggered oriented ridge mixer that efficiently mixes reactants. The reactions were performed in NMP and DMF at different residence times ( 1 to 15 minutes) and different temperatures $\left(160\right.$ to $180{ }^{\circ} \mathrm{C}$ ), and the conversion was monitored with LC-MS. For the setup used, the optimum is 5 minutes residence time at a temperature of $180{ }^{\circ} \mathrm{C}$. The obtained yield is reproducibly around $90 \%$, but more importantly the purification step was a simple filtration on small amount of silica.

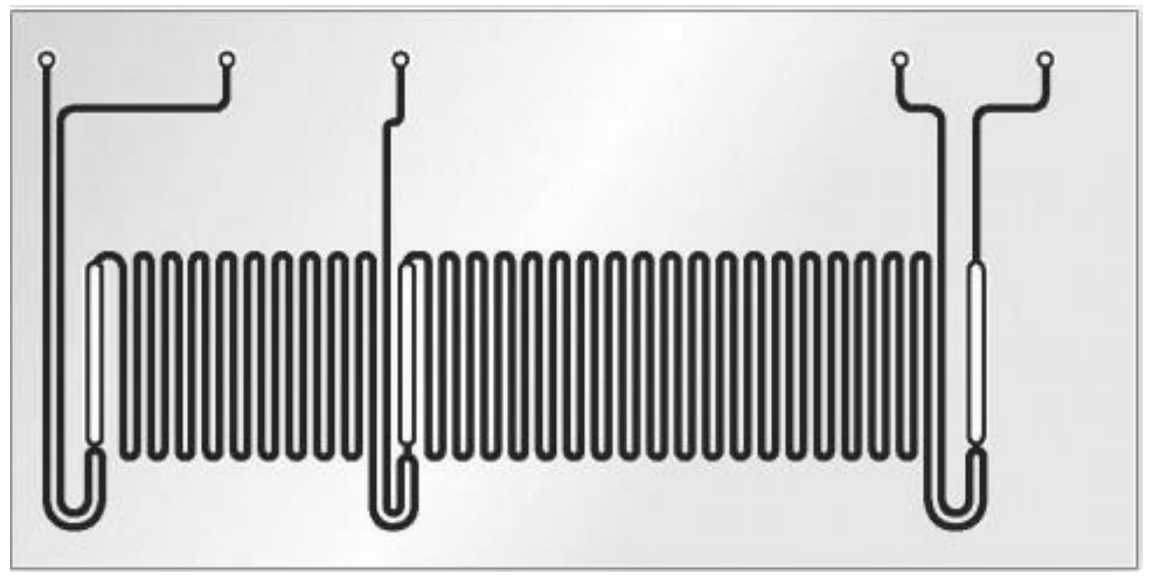

Figure 2. The 3224 micro-reactor has an integrated staggered oriented ridge mixer and a reactor volume of $15 \mu l$.

Compared to the batch chemistry; lots of time, reactants, solvents and silica can be saved. Even though the micro-reactor used can only produce around 200 $\mathrm{mg} /$ day, which is sufficient for biological assays, it can easily be up-scaled to produce more than 1000 times more (Table 1). 
Table 1. Comparison between batch chemistry and flow chemistry for the protection of catechol moeiety of $\mathbf{Q}$.

\begin{tabular}{|l|l|l|}
\hline & $\begin{array}{l}\text { Solvent/MRT }- \text { Kilo } \\
\text { Flow }\end{array}$ & $\begin{array}{l}\text { Solvent/Batch }(250- \\
1000 \mathrm{ml})\end{array}$ \\
\hline $\mathbf{Q}(\mathrm{g})$ & DMF/0.200-200 & NMP/0.100-10 \\
\hline $\begin{array}{l}\text { Dichlorodiphenylmethane } \\
(\mathrm{eq})\end{array}$ & Toluene/3 eq & $\mathrm{NMP} / 5 \mathrm{eq}$ \\
\hline Obtained yield of QB (\%) & $>90$ & $40-70$ \\
\hline
\end{tabular}

Methylation of $\mathbf{Q B}$ or $\mathbf{Q}$ appeared to be difficult with the MRT, due to the poor solubility of the bases used. Sodium carbonate, potassium carbonate and their bicarbonate forms block the micro-reactor channels because of their poor solubility in the solvents used, i.e. MeCN, NMP, DMF, and DMSO. If the carbonate solution is filtered first, the conversion drastically decreases to around $10 \%$. Sodium ethoxide is also poorly soluble in polar solvents, such as DMF, and appears to rapidly oxidize $\mathbf{Q}$ or $\mathbf{Q B}$. When $\mathbf{Q}$ or $\mathbf{Q B}$ is first mixed with MeI and the base is added later, then the ethoxide reacts faster with MeI. Triethylamine is soluble in DMF but it rather reacts with MeI instead of deprotonating $\mathbf{Q}$. In addition, the methylated triethylamine forms a quaternary salt that precipitates and blocks the channels of the micro-reactor.

In conclusion; protection of the catechol moiety of $\mathbf{Q}$ is efficiently realized using MRT. Methylation of QB is achieved with batch chemistry. 


\section{Chapter 3}

\section{Experimentals}

General

Quercetin $\cdot 2 \mathrm{H}_{2} \mathrm{O}$, dichlorodiphenylmethane, $\mathrm{MgSO}_{4}$ and silica-gel 60 A (0.060$0.200 \mathrm{~mm}$ ) were purchased from Acros Organics and used as received. All solvents were obtained from Sigma-Aldrich and were of analytical grade. Toluene and dimethylformamide (DMF) were distilled at reduced pressure and were kept dry with molecular sieves. The micro-reactor reactions were performed with the Labtrix ${ }^{\circledR}-\mathrm{S} 1$, which is a flow system that is fully automated. NMR were recorded on a Bruker BioSpin AG 300 spectrometer and the chemical shifts are given in ppm downfield from tetramethylsilane. $J$ values are given in Hz. Abbreviations used are s (singlet), d (doublet), dd (double doublet), $\mathrm{t}$ (triplet), $\mathrm{b}$ (broad) and bm (broad multiplet). The reactions were monitored with LC-MS using a Shimadzu LCMS-2020 and VisionHT C18 classic (length $=100$ $\mathrm{mm}$, diameter $=2.0 \mathrm{~mm}, 1.5 \mu \mathrm{m})$ UHPLC columns.

\section{Molecular Quantum Calculations}

The density functional theory (DFT) using the B3LYP hybrid functional with the 6-31G* basis set in Spartan '10 (Wavefunction, Irvine, CA, USA) was utilized for calculating the equilibrium geometry, and for generating the electron potential map of quercetin.

\section{General procedure for the batch reactions}

The batch reactions were performed according to earlier work $[1,6]$.

\section{General procedure for MRT reactions}

First, the MRT was purged with $100 \mathrm{ul}$ of the solvents used at $10 \mathrm{ul} / \mathrm{min}$ through the needles A and B (Figure 3). After preparation of the solution of the reaction mixtures (RM), the reaction was started by pumping the solutions into the microreactor. The reaction was held at a constant pressure of 25 bar. Product collection started after at least $50 \mathrm{ul}$ was collected at the required flow and temperature. Only the experiment with the best result is described. 


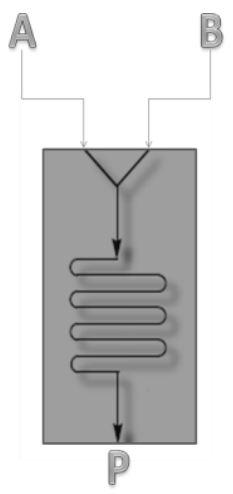

Figure 3. Simplified representation of the micro-reactor system.

Protection of the Catechol Group of Quercetin. Synthesis of 2-(2,2Diphenylbenzo [1,3]dioxol-5-yl)-3,5,7-trihydroxychromen-4-one (QB)

Needle A, containing $1 \mathrm{ml}$ of a solution of $\mathbf{Q}(55 \mathrm{mg}, 0.16 \mathrm{mmol})$ in DMF, and needle $\mathrm{B}$, containing $1 \mathrm{ml}$ of a solution of compound $1(90 \mu 1,0.47 \mathrm{mmol})$ in toluene, were attached to the pump of the MRT system. The solutions were pumped through the micro-reactor model 3224 at a flow of $3 \mu 1 / \mathrm{min}$ till the right pressure $(25$ bar $)$ and temperature $\left(180{ }^{\circ} \mathrm{C}\right)$ were reached. A total of $100 \mu \mathrm{l}(50$ $\mu l$ from each needle) of the RM was pumped through the system before product collection was initiated. After 5 hours, 1900 ul of the RM is collected, diluted with water and extracted with ethylacetate (EA). The organic layer is washed with saturated $\mathrm{NaCl}(\mathrm{aq})$ and dried over $\mathrm{MgSO}_{4}(\mathrm{~s})$. The drying agent is filtered and the organic layer is evaporated. The above procedure is repeated 3 times before purification with silica column. All the products (from 3x55 mg of $\mathbf{Q}$ ) are dissolved in toluene (Tol) and the remainings of compound $\mathbf{1}$ is filtered through silica. A mixture of Tol/EA $(9: 1, \mathrm{v} / \mathrm{v})$ is used to collect the product from the silica. After the evaporation of the solvents, $182 \mathrm{mg}(0.39 \mathrm{mmol}, 93 \%$ of the collected product) of $\mathbf{Q B}$ was isolated. ${ }^{1} \mathrm{H}-\mathrm{NMR}$ ([D3]MeCN, $300 \mathrm{MHz}$ ): 6.21 $\left(\mathrm{d}, J=2.1 \mathrm{~Hz}, 1 \mathrm{H}, \mathrm{H}_{6}\right), 6.48\left(\mathrm{~d}, J=2.1 \mathrm{~Hz}, 1 \mathrm{H}, \mathrm{H}_{8}\right), 7.24(\mathrm{dd}, J=8.7 \mathrm{~Hz}, 2.0 \mathrm{~Hz}$, $\left.1 \mathrm{H}, \mathrm{H}_{5^{\prime}}\right), 7.46-7.61\left(\mathrm{bm}, 10 \mathrm{H}\right.$, diphenyl protons), $7.81\left(\mathrm{~d}, J=2.0 \mathrm{~Hz}, 1 \mathrm{H}, \mathrm{H}_{2^{\prime}}\right), 7.84$ (b, $1 \mathrm{H}, \mathrm{H}_{6^{\prime}}$ ), 12.39 (s, 1H, 5-OH). MS: m/z = 466, TIC (+) 466, TIC (-) 465. 


\section{Chapter 3}

\section{References}

1. Moalin, M.; Strijdonck, G. P.; Beckers, M.; Hageman, G.; Borm, P.; Bast, A.; Haenen, G. R. A planar conformation and the hydroxyl groups in the $\mathrm{B}$ and $\mathrm{C}$ rings play a pivotal role in the antioxidant capacity of quercetin and quercetin derivatives. Molecules 2011, 16, 9636-9650.

2. Justesen, U.; Knuthsen, P.; Leth, T. Quantitative analysis of flavonols, flavones, and flavanones in fruits, vegetables and beverages by highperformance liquid chromatography with photo-diode array and mass spectrometric detection. J. Chromatogr. A 1998, 799, 101-110.

3. Willems, A. M.; Bruynzeel, A. M.; Kedde, M. A.; van Groeningen, C. J.; Bast, A.; van der Vijgh, W. J. A phase I study of monohydroxyethylrutoside in healthy volunteers. Cancer Chemother Pharmacol 2006, 57, 678-684.

4. Spencer, J. P.; Kuhnle, G. G.; Williams, R. J.; Rice-Evans, C. Intracellular metabolism and bioactivity of quercetin and its in vivo metabolites. Biochem. J. 2003, 372, 173-181.

5. Watts, P. Scale out of chemical synthesis in flow reactors. Chemtrix.com 2010, 07-01.

6. Bouktaib, M.; Lebrun, S.; Atmani, A.; Ronaldo, C. Hemisynthesis of all the O-monomethylated analogues of quercetin including the major metabolites, through selective protection of phenolic functions. Tetrahedron 2002, 58, 10001-10009. 


\section{Chapter 4}

Quercetin radical's unpaired electron is delocalized in conjugated $\pi$-system of its B-ring

Mohamed Moalin, Gino P.F. van Strijdonck, Aalt Bast and Guido R.M.M. Haenen 


\title{
Chapter 4
}

\begin{abstract}
The delocalization of the unpaired electron in the quercetin radical $\left(\mathbf{Q}^{*}\right)$ is responsible for its relative low reactivity, which is crucial in the antioxidant activity of quercetin. Electron Spin Resonance (ESR) spectra of $\mathbf{Q}^{\bullet}$ and that of several structural related radicals were recorded to identify the structural elements of $\mathbf{Q}^{\bullet}$ responsible for the delocalization. The ESR spectrum of $\mathbf{Q}^{\bullet}$ has 8 peaks consisting of a doublet $\left(\mathrm{a}=3.18 \mathrm{G}\right.$, caused by $\left.6^{\prime} \mathrm{H}\right)$, split in smaller doublets $\left(\mathrm{a}=1.480 \mathrm{G}\right.$, caused by $\left.5^{\prime} \mathrm{H}\right)$ that are further split into smaller doublets $\left(\mathrm{a}=0.652 \mathrm{G}\right.$, caused by $\left.2^{\prime} \mathrm{H}\right)$. Only protons in the B-ring were found to directly influence the ESR spectrum $\mathbf{Q}^{\bullet}$ and the tested analogues. The two oxygen atoms in the B-ring (i.e. 3' $\mathrm{O}$ and 4'O) as well as the AC-ring (attached to $\mathrm{Cl}^{\prime}$ ') have an electron donating effect that stabilizes the electron deficient $\pi$-system in the Bring of $\mathbf{Q}^{*}$. O-Methylation of the $3 \mathrm{OH}$ group annihilated the electron donating effect of the AC-ring, demonstrating the importance of un-substituted 3-OH group. Based on the findings, it is concluded that the unpaired electron is caged primarily in the conjugated $\pi$-system of the B-ring of $\mathbf{Q}^{*}$, with relatively high spin densities on $\mathrm{Cl}^{\prime}, \mathrm{C} 3$ ' and $\mathrm{C} 4$ '.
\end{abstract}




\section{Introduction}

Quercetin (Q), 2-(3,4-dihydroxyphenyl)-3,5,7-trihydroxy-4H-1-benzopyran-4one, is one of the most prominent dietary flavonoids in the Western diet [1,2]. It is an extremely potent radical scavenger and this activity is implicated in its health benefits. During radical scavenging, a highly reactive and therefore harmful radical is neutralized by $\mathbf{Q}$ through the donation of an electron. In the scavenging reaction; the radical is transformed into a relatively harmless nonradical, while $\mathbf{Q}$ is transformed into a relatively stable radical. The low reactivity of the $\mathbf{Q}$ radical $\left(\mathbf{Q}^{*}\right)$ is caused by delocalization of the unpaired electron (UE) over the $\mathbf{Q}$ molecule. Although this concept is widely acknowledged, the exact mechanism of delocalization of the $\mathbf{U E}$ over the molecule is not well established. Also the roles of various structural elements in $\mathbf{Q}^{*}$, e.g. the $\mathrm{A}, \mathrm{B}$ and $\mathrm{C}$ ring, in the delocalization of $\mathbf{U E}$ are still enigmatic.

The radicals of flavonoids can be investigated using electron spin resonance spectroscopy (ESR). The ESR spectrum caused by the spin of the UE is influenced by the nucleus of para-magnetic atoms in the neighborhood of the UE. The nuclei of these atoms give rise to different peaks in the ESR spectrum, comparable to that in nuclear magnetic resonance spectroscopy (NMR).

In the ESR spectrum of $\mathbf{Q}^{\bullet}$ and the other compounds tested in the present study, the interaction between the protons and the $\mathbf{U E}$ is of relevance. A proton can cause a doublet provided it is close enough to interact with the UE. The higher the interaction between proton and $\mathbf{U E}$, the larger the distance between the peaks of the doublet, i.e. the larger the splitting constant.

In the spectrum, the splitting of different protons is superimposed. Two unequivalent protons will give 4 peaks, each with comparable intensity. Two equivalent protons will give a triplet with a relative intensity of the peaks of 1:2:1 following Pascal's triangle. Consequently, three equivalent protons will give a quartet (relative intensities 1:3:3:1), 4 equivalent protons will give a quintet (relative intensities 1:4:6:4:1) and so forth. In this way, complex spectra can be derived. So, the spectrum of a radical provides information on the protons 


\section{Chapter 4}

that have influenced the spectrum. The splitting constant (a) can be used to calculate the spin density $\left(\rho_{\pi}\right)$ using O'Connels equation: $a=29 * \rho_{\pi}[3]$.

In the present study, the ESR spectra of $\mathbf{Q}^{\bullet}$ and that of several structural related radicals were recorded and examined to resolve the delocalization of the $\mathbf{U E}$ and to identify the structural elements of $\mathbf{Q}^{\bullet}$ responsible for this delocalization.

\section{Materials and Methods}

\section{Chemicals}

All the tested compounds had a purity of at least $95 \%$ on HPLC. Quercetin. $2 \mathrm{H}_{2} \mathrm{O}$ was purchased from Acros Organics, para-hydroxyphenol, kaempferol and myricetin from Fluka, and catechol from Janssen Chimica. The methylated derivatives of quercetin (Table 1) were synthesized earlier [4]. All other chemicals were of the highest grade of purity available. 
Table 1. The structures of quercetin $(\mathbf{Q})$ and its analogues that are investigated in this study.<smiles></smiles>

\begin{tabular}{|c|c|c|c|c|}
\hline Compound & $\mathbf{R}_{3}$ & $\mathbf{R}_{\mathbf{3}^{\prime}}$ & $\mathbf{R}_{\mathbf{4}^{\prime}}$ & $\mathbf{R}_{5^{\prime}}$ \\
\hline $\mathbf{Q}$ & $\mathrm{OH}$ & $\mathrm{OH}$ & $\mathrm{OH}$ & $\mathrm{H}$ \\
\hline Myricetin & $\mathrm{OH}$ & $\mathrm{OH}$ & $\mathrm{OH}$ & $\mathrm{OH}$ \\
\hline Kaempferol & $\mathrm{OH}$ & $\mathrm{H}$ & $\mathrm{OH}$ & $\mathrm{H}$ \\
\hline 3MQ & $\mathrm{OCH}_{3}$ & $\mathrm{OH}$ & $\mathrm{OH}$ & $\mathrm{H}$ \\
\hline 3'MQ & $\mathrm{OH}$ & $\mathrm{OCH}_{3}$ & $\mathrm{OH}$ & $\mathrm{H}$ \\
\hline 4'MQ & $\mathrm{OH}$ & $\mathrm{OH}$ & $\mathrm{OCH}_{3}$ & $\mathrm{H}$ \\
\hline
\end{tabular}

\section{Electron Spin Resonance}

The ESR spectra were recorded on a Bruker ESP300 ESR spectrometer. Modulation frequency was $100 \mathrm{kHz}$, the amplitude $1 \mathrm{G}$. Microwave frequency was set at $9.79 \mathrm{GHz}$, with a power of $20 \mathrm{~mW}$. Magnetic field sweep widths were in the range 0.9-2.0 $\mathrm{mT}$, depending on the spectral widths. For most measurements a modulation amplitude of $0.01 \mathrm{mT}$ was used, and the spectrum was accumulated in ten scans. After placing the flat cell in the microwave cavity, the spectrometer was tuned manually to minimize the time between start of the 


\section{Chapter 4}

reaction and recording the spectrum. The hyperfine couplings (a) observed in the ESR spectrum were used to calculate the spin densities $\left(\rho_{\pi}\right)$ on the carbons according to O'Connell's equation: $\mathrm{a}=29 * \rho_{\pi}[3]$.

\section{Sample preparation}

The compounds tested were dissolved in DMSO to a concentration of 1-5 mM. $250 \mu \mathrm{L}$ of $0.1-1 \mathrm{M}$ solution of $\mathrm{NaOH}$ (aq) was added to $650 \mu \mathrm{L}$ of the flavonoid solution in a flat cell. This resulted in the oxidation of the flavonoid $[5,6]$.

\section{Molecular quantum calculations}

To generate the spin-distribution graphically, the Hartree-Fock equilibrium geometry optimization was used, followed by equilibrium optimization with Moller Plesset MP2 basis set in Spartan ' 10.

\section{Statistics}

All experiments were performed, at least, in triplicate. Data are expressed as means \pm SD or as a typical example.

\section{Results}

To unravel the complicated ESR spectrum of $\mathbf{Q}^{\mathbf{*}}$, the ESR spectra of parahydroxyphenol radical and catechol radical were recorded first (Figure 1). The ESR spectrum of the radical of para-hydroxyphenol is a typical quintet [7], following Pascal's triangle. The observed quintet can be explained by the interaction of the $\mathbf{U E}$ with 4 equivalent protons located at the positions 2'-, 3'-, 5'- and 6'. The hyperfine coupling constant is 2.337 G. The ESR spectrum of the catechol radical shows a triplet that is split into a smaller triplet (Figure 1). The hyperfine coupling $(3.549 \mathrm{G})$ of the large triplet is attributed to the two equivalent protons located at the 1' and 6' position. The hyperfine coupling $(0.8405 \mathrm{G})$ of the smaller triplet is attributed to the other 2 equivalent protons located at the 2' and 5' position as further elaborated in the discussion. 


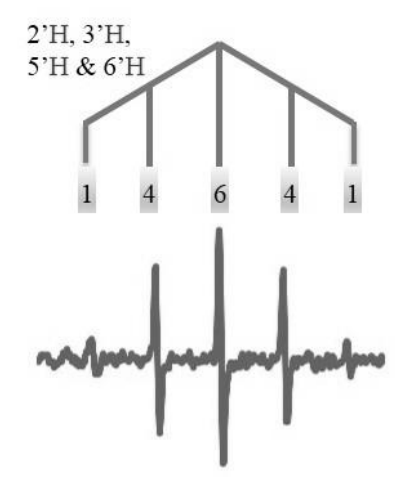

Para-hydroxyphenol radical

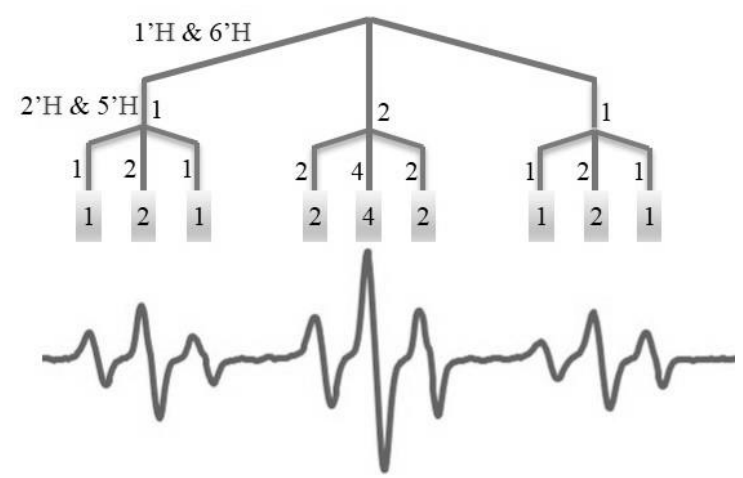

Catechol radical

Figure 1. ESR spectra with the hyperfine couplings explained and the protons causing these couplings indicated. The relative intensities of the peaks are summed up in the grey rectangles. The same carbon numbering as in the B-ring of $\boldsymbol{Q}$ is used in order to facilitate the comparison between para-hydroxyphenol, catechol and the flavonoid radicals. The carbon atoms where the two oxygen atoms are attached have been assigned C1' and C4' for the para-hydroxyphenol radical, and C3' and C4' for the catechol radical.

The ESR spectrum of the myricetin radical is a triplet with a hyperfine coupling of $1.007 \mathrm{G}$ that is caused by the interaction of the $\mathbf{U E}$ with the 2 equivalent protons located at the 2' and 6' position in the B-ring (Figure 2). The ESR spectrum of the kaempferol radical is a quintet [5,6] with a hyperfine coupling of $2.522 \mathrm{G}$ that is caused by the interaction of the $\mathbf{U E}$ with the protons located at the 2'-, 3'-, 5'- and 6' positions in the B-ring, which all appear to cause a similar splitting effect (Figure 2). The ESR spectrum of $\mathbf{Q}^{\bullet}$ is a doublet, doublet, doublet with hyperfine couplings of $3.184,1.480$ and $0.652 \mathrm{G}$ (Figure 2). The UE is interacting with 3 different protons, all located on the B-ring; (i) the 6' proton causing the largest, (ii) the $5^{\prime}$ proton causing the intermediate, and (iii) the 2 ' proton causing the smallest doublet. 


\section{Chapter 4}
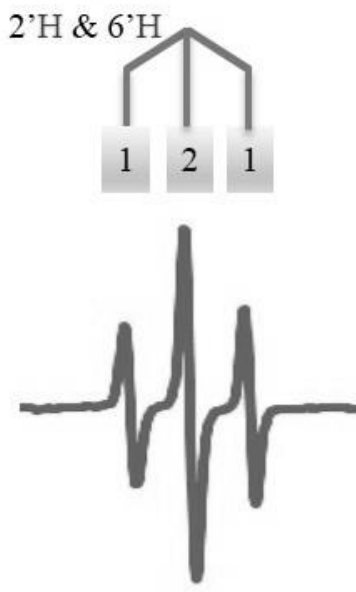

Myricetin radical
2'H, 3'H,

5 ' $\mathrm{H} \&$ 6' $\mathrm{H}$

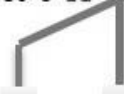

14

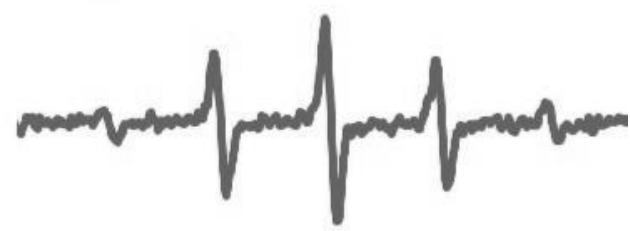

Kaempferol radical

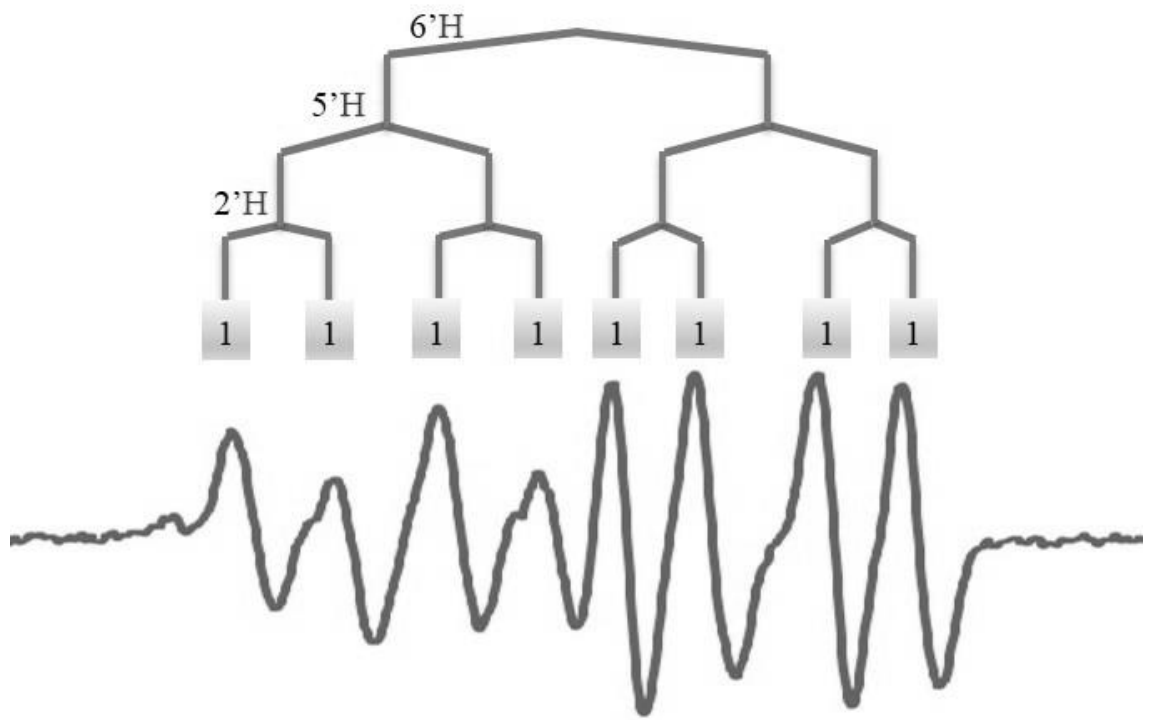

Quercetin radical

Figure 2. ESR spectra of the flavonols tested with the hyperfine couplings explained and the protons causing these couplings indicated. The relative intensities of the peaks are summed up in the grey rectangles. 
The ESR spectrum of the $\mathbf{3 M Q}$ radical is a large doublet that is split into a smaller triplet, with hyperfine couplings of $2.884 \mathrm{G}$ for the doublet and $0.9385 \mathrm{G}$ for the triplet (Figure 3). The UE in the 3MQ radical is interacting with 2 different groups of protons both located on the B-ring; (i) one group consisting of one proton at the 6' position (causing the doublet), (ii) and another group consisting of the two equivalent protons at the 2' and 5' position (causing the triplet).

The ESR spectrum of the 3'MQ radical is a triplet, doublet, quartet with hyperfine couplings of $2.835,0.760$ and $0.684 \mathrm{G}$, respectively (Figure 3 ). The UE in the 3'MQ radical is interacting with 3 different groups of protons, all located on the B-ring; (i) one group consists of the two equivalent protons located at the 5' and 6' position (causing the triplet), (ii) one group consists of the one equivalent proton located at the 2 ' position (causing the doublet), (iii) and one group consists of the 3 equivalent protons of the 3'O-methyl group (causing the quartet).

The ESR spectrum of the 4'MQ radical, similar to the spectrum of the 3'MQ radical, is a triplet, doublet, quartet with hyperfine couplings of $2.811,0.7355$ and $0.7355 \mathrm{G}$, respectively (Figure 3). The UE in the 4'MQ radical is interacting with 3 different groups of protons, all located on the B-ring; (i) one group consists of the two equivalent protons located at the 5' and 6' position (causing the triplet), (ii) one group consists of the one equivalent proton located at the 2 ' (causing the doublet), (iii) and one group consists of the 3 equivalent protons of the 4'O-methyl group (causing the quartet). The hyperfine couplings of the tested compounds are summarized in Table 2. 


\section{Chapter 4}
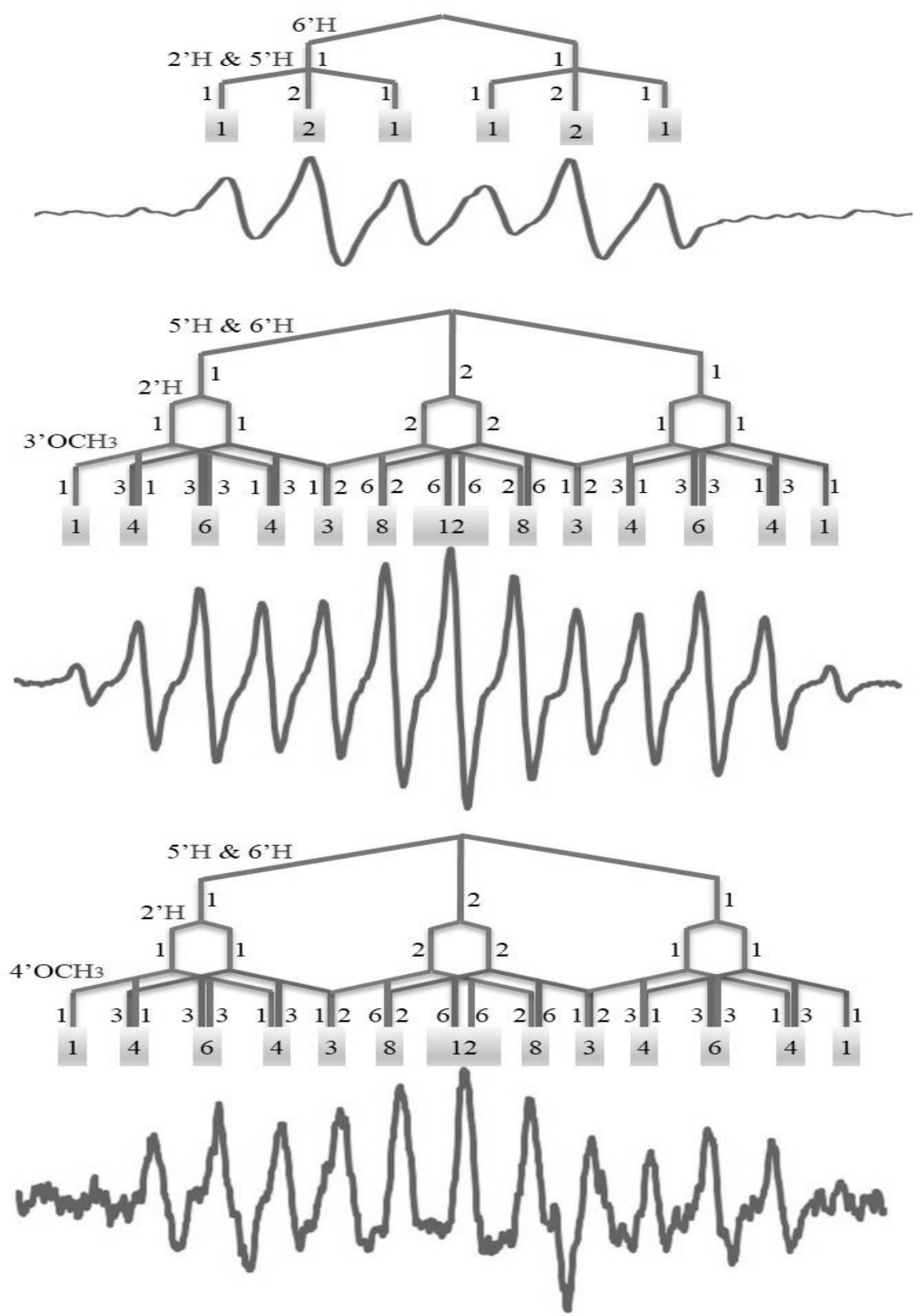

Figure 3. ESR spectra of the O-methylated derivatives of quercetin with the hyperfine couplings explained and the protons causing these couplings indicated. The relative intensities of the peaks are summed up in the grey rectangles. Top belongs to $\mathbf{3 M Q}$ radical, middle to $\mathbf{3}^{\prime} \mathrm{MQ}$ radical and bottom to 4'MQ radical. 
Table 2. Summary of the hyperfine couplings of the compounds investigated in this study.

\begin{tabular}{|c|c|c|c|c|c|c|c|c|}
\hline Proton & Myricetin & $\mathbf{Q}$ & 3MQ & 3'MQ & 4'MQ & Kaempferol & Catechol $^{\mathrm{a}}$ & $\begin{array}{l}\text { Para- } \\
\text { hydroxyphenol }^{\mathrm{a}}\end{array}$ \\
\hline $1^{\prime} \mathrm{H}$ & - & - & - & - & - & - & 3.549 & - \\
\hline $2^{\prime} \mathrm{H}$ & 1.007 & 0.652 & 0.9385 & 0.760 & 0.7355 & 2.522 & 0.8405 & 2.337 \\
\hline 3'H & - & - & - & - & - & 2.522 & - & 2.337 \\
\hline $4{ }^{\prime} \mathrm{H}$ & - & - & - & - & - & - & - & - \\
\hline $5{ }^{\prime} \mathrm{H}$ & - & 1.480 & 0.9385 & 2.835 & 2.811 & 2.522 & 0.8405 & 2.337 \\
\hline 6’H & 1.007 & 3.184 & 2.884 & 2.835 & 2.811 & 2.522 & 3.549 & 2.337 \\
\hline $\mathrm{OCH}_{3}$ & $\mathrm{~b}$ & $\mathrm{~b}$ & $\mathrm{c}$ & 0.684 & 0.7355 & $\mathrm{~b}$ & $\mathrm{~b}$ & $\mathrm{~b}$ \\
\hline
\end{tabular}

${ }^{\mathrm{a}}$ The same numbering as the B-ring of quercetin is used to facilitate comparison

${ }^{\mathrm{b}} \mathrm{OCH}_{3}$ is not present in this compound

${ }^{\mathrm{c}} \mathrm{OCH}_{3}$ has no detectable hyperfine coupling

-no proton present at this position for this compound

\section{Discussion}

The principle of the protective effect of a free radical scavenger is that it converts reactive free radical species into a relatively un-reactive species, e.g. a hydroxyl radical is eventually converted into water. However, during this reaction the antioxidant is converted into a radical and takes over part of the reactivity of the scavenged free radical. To give effective protection, the reactivity of the antioxidant radical has to be substantially lower than that of the scavenged radical. One of the most studied free radical scavenger is $\mathbf{Q}$ that appears to be extraordinary potent. Its antioxidant activity does not only involve its high reactivity towards radical species, but also the relatively low reactivity of the quercetin radical $\left(\mathbf{Q}^{*}\right)$. The essence of the relatively low reactivity of $\mathbf{Q}^{\bullet}$ lies in the delocalization of the UE. The aim of this study is to examine the delocalization of the $\mathbf{U E}$ in $\mathbf{Q}^{*}$, and to elucidate the importance of the A, B and C-ring for the stabilization of the radical. To examine the delocalization of the UE in $\mathbf{Q}^{\bullet}, \mathbf{Q}^{\bullet}$ and several structural related radicals were studied with ESR. 


\section{Chapter 4}

Delocalization of the unpaired electron $(\mathrm{UE})$ and delocalization of the electron pair (EP) donated by the electron donors

The ESR spectrum of the para-hydroxyphenol radical is a typical quintet [7] caused by the interaction of the UE with 4 equivalent protons. This means that the protons at the positions 2'-, 3'-, 5'- and 6' in the para-hydroxyphenol radical have to be equivalent. The equivalency of these protons is generally accepted and might even be considered to be trivial. Close examination, however, shows that this equivalency is not so trivial since it cannot be explained by the delocalization of only the UE (Figure 4A). For example; when the $\mathbf{U E}$ is on the C1' (structure S1 in Figure 4), valence bond theory dictates that it can only be delocalized to $\mathrm{C}^{\prime}$ ' (S2) and $\mathrm{C}^{\prime}$ ' (S2 $\left.{ }^{\mathrm{V}}\right)$, and not to $\mathrm{C} 2$ ' and $\mathrm{C} 6$ '. This would imply that the protons at $\mathrm{C}^{\prime}$ ' and $\mathrm{C}^{\prime}$ ' are not equivalent to the protons at the $\mathrm{C} 3$ ' and C5'. Because the ESR spectrum of para-hydroxyphenol radical demonstrates that all protons are equivalent, Figure $4 \mathrm{~A}$ does not give the complete picture. 


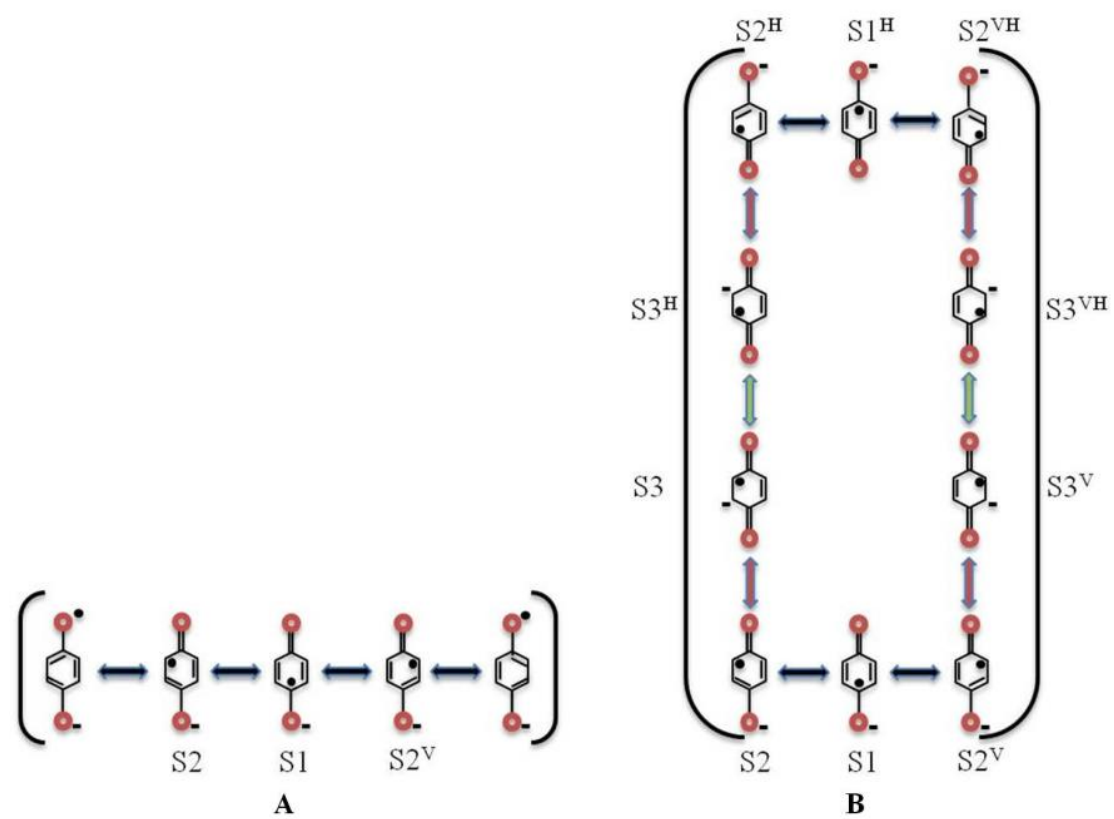

Figure 4. Delocalization in the para-hydroxyphenol radical. A) Delocalization of only the unpaired electron $(\boldsymbol{U E})$. B) Delocalization of the $\boldsymbol{U E}$ and the electron pair $(\boldsymbol{E P})$ donated by the oxygen groups. The delocalization of the $\boldsymbol{U E}$ is indicated with black arrows, the delocalization of the $\boldsymbol{E P}$ is indicated with red arrows and the delocalization of both is indicated with green arrows. The mirror-symmetry of the resonance structures $(S)$ is indicated with superscript ${ }^{H}$ for horizontal mirroring, and superscript ${ }^{V}$ for the vertical mirroring.

To explain the equivalency of the 4 protons in the para-hydroxyphenol radical, the scheme in Figure 4B is constructed. The oxygen atoms can donate an electron pair (EP) to the electron deficient $\pi$-system of the para-hydroxyphenol radical (e.g. S2 $\rightarrow \mathrm{S} 3$ ). The donated EP creates more possible resonance structures for the $\mathbf{U E}$ and increases the diminished electron density of the conjugated $\pi$-system, explaining the relative stability of the para-hydroxyphenol radical.The symmetry between the resonance structures of the parahydroxyphenol radical shows that there are two different groups of carbons with equal spin-densities: one group consists of C2', C3', C5' and C6', and the other 


\section{Chapter 4}

group consists of $\mathrm{C1}^{\text {' }}$ and C4'. This is in accordance with the splitting pattern of the ESR spectrum and was confirmed by ab initio quantum calculations (Figure 5). The spin-density appears to be mostly concentrated (indicated by the color blue in Figure 5) on C1' and C4' that are adjacent to the oxygen groups. This can be explained by the electron rich nature of the oxygen atom that attracts the electron deficient UE. The electron-deficient $\pi$-orbital on the C1', e.g. when the UE is on $\mathrm{Cl}^{\prime}$, , can be stabilized by the electron rich orbitals of the adjacent oxygen atom through hyperconjugation. Hyperconjugation increases the electron density on the electron-deficient $\pi$-orbital without compromising the octet rule, and stabilizes the whole molecule by creating an extended molecular orbital.

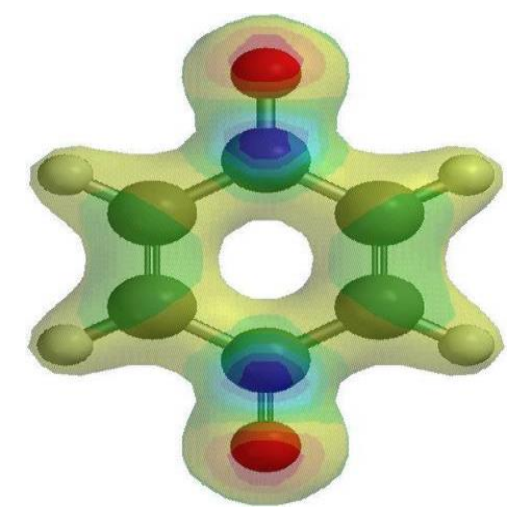

Figure 5. The spin-density distribution of the para-hydroxyphenol radical obtained using ab initio quantum molecular calculations. Blue indicates high, green indicates intermediate, and red indicates low spin-density.

Using O'Connell's equation, we were able to calculate the spin-densities from the hyperfine couplings. In the case of the para-hydroxyphenol radical, the spindensities were calculated to be $8.1 \%$ on C2', C3', C5' and C6' (Table 3). This suggests a relatively high spin-density of $34 \%$ on $\mathrm{C} 1$ ' and $34 \%$ on C4'. This spin-distribution based on the hyperfine couplings is in line with that found with the ab initio quantum calculations. 
Table 3. Summary of the calculated spin-densities of the compounds investigated in this study.

\begin{tabular}{|c|c|c|c|c|c|c|c|c|}
\hline Carbon & Myricetin & $\mathbf{Q}$ & 3MQ & 3'MQ $^{\prime}$ & $\mathbf{4}^{\prime} \mathbf{M Q}$ & Kaempferol & Catechol & $\begin{array}{l}\text { Para- } \\
\text { hydroxyphenol }\end{array}$ \\
\hline $1^{\prime}$ & $23^{\mathrm{c}}$ & $27^{\mathrm{c}}$ & $10^{\mathrm{c}}$ & $<35^{\mathrm{c}}$ & $<35^{\mathrm{c}}$ & $33^{\mathrm{c}}$ & $12^{\mathrm{a}}$ & $34^{\mathrm{c}}$ \\
\hline $2^{\prime}$ & $3.5^{\mathrm{a}}$ & $2.3^{\mathrm{a}}$ & $3.2^{\mathrm{a}}$ & $2.6^{\mathrm{a}}$ & $2.5^{\mathrm{a}}$ & $8.7^{\mathrm{a}}$ & $2.9^{\mathrm{a}}$ & $8.1^{\mathrm{a}}$ \\
\hline $3^{\prime}$ & $23^{\mathrm{c}}$ & $27^{\mathrm{c}}$ & $37^{\mathrm{c}}$ & $>>7.1^{\mathrm{b}}$ & $<35^{\mathrm{c}}$ & $8.7^{\mathrm{a}}$ & $35^{\mathrm{c}}$ & $8.1^{\mathrm{a}}$ \\
\hline $4^{\prime}$ & $23^{\mathrm{c}}$ & $27^{\mathrm{c}}$ & $37^{\mathrm{c}}$ & $<35^{\mathrm{c}}$ & $>>7.6^{\mathrm{b}}$ & $33^{\mathrm{c}}$ & $35^{\mathrm{c}}$ & $34^{\mathrm{a}}$ \\
\hline $5^{\prime}$ & $23^{\mathrm{c}}$ & $5.1^{\mathrm{a}}$ & $3.2^{\mathrm{a}}$ & $10^{\mathrm{a}}$ & $10^{\mathrm{a}}$ & $8.7^{\mathrm{a}}$ & $2.9^{\mathrm{a}}$ & $8.1^{\mathrm{a}}$ \\
\hline $6^{\prime}$ & $3.5^{\mathrm{a}}$ & $11^{\mathrm{a}}$ & $10^{\mathrm{a}}$ & $10^{\mathrm{a}}$ & $10^{\mathrm{a}}$ & $8.7^{\mathrm{a}}$ & $12^{\mathrm{a}}$ & $8.1^{\mathrm{a}}$ \\
\hline
\end{tabular}

${ }^{a}$ Calculated from the empirical hyperfine couplings using O'Connell's equation

${ }^{b}$ Calculated from the hyperfine coupling found for the $\mathrm{OCH}_{3}$ in the methylated derivatives of quercetin. Because the protons are not directly attached to the carbon of the ring, the spin density given will be an underestimate.

${ }^{\mathrm{c}}$ Estimated by equally dividing the not-attributed spin-densities over the remaining carbon atoms (for the flavonoids only the carbons in the B-ring were taken)

\section{The $U E$ is most stable on atoms adjacent to electron donors}

The ESR spectrum of the catechol radical consists of triplet peaks, which are split into smaller triplets. This is caused by the interaction of the UE with 2 different groups of protons, with each group consisting of two equivalent protons. Based on the symmetry of catechol, it is evident that the $2^{\prime} \mathrm{H}$ and $5^{\prime} \mathrm{H}$ are equivalent and belong to one group, and that the $1^{\prime} \mathrm{H}$ and $6^{\prime} \mathrm{H}$ are equivalent and belong to the other group (Figure 6). 


\section{Chapter 4}

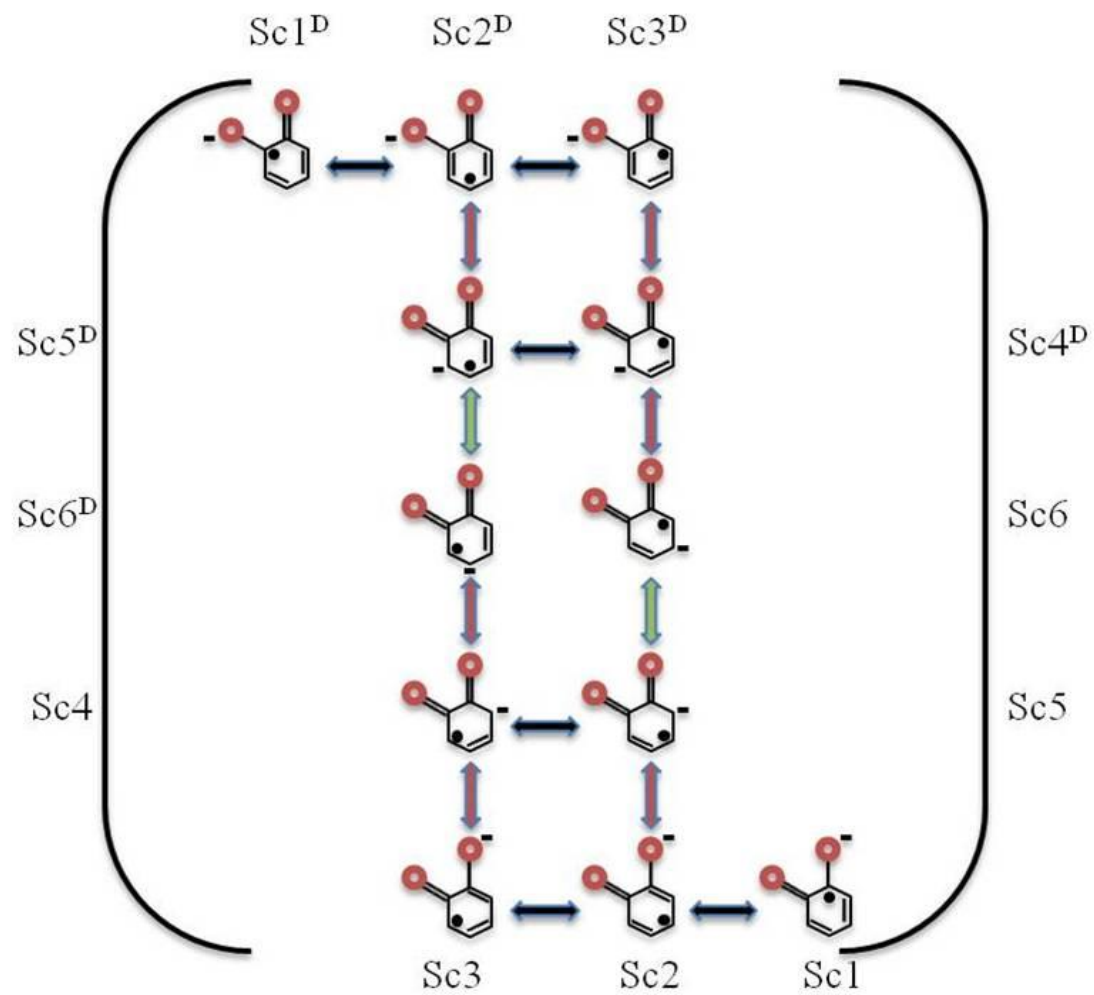

Figure 6. Delocalization of the unpaired electron $(\boldsymbol{U E})$ and the electron pair (EP) donated by the oxygen groups. The delocalization of the $\boldsymbol{U E}$ is indicated with black arrows, the delocalization of the $\boldsymbol{E P}$ is indicated with red arrows and the delocalization of both is indicated with green arrows. The diagonal mirrorsymmetry of the resonance structures $(S c)$ are indicated with superscript ${ }^{D}$.

When the $\mathbf{U E}$ is on $\mathrm{C} 2$ ' (i.e. $\mathrm{Sc} 3, \mathrm{Sc} 4$ and $\mathrm{Sc}^{\mathrm{D}}$ ) or on $\mathrm{C} 5^{\text {' }}$ (i.e. $\mathrm{Sc} 3^{\mathrm{D}}, \mathrm{Sc} 4^{\mathrm{D}}$ and Sc6 ${ }^{\mathrm{D}}$ ), it will be adjacent to an electron deficient carbon atom of a carbonylgroup. This is energetically unfavorable, resulting in a relatively low spin-density on $\mathrm{C} 2$ ' and $\mathrm{C} 5$ ' of the catechol radical.

When the $\mathbf{U E}$ is on $\mathrm{C}^{\prime}$ ' (i.e. $\mathrm{Sc} 2^{\mathrm{D}}$ and $\mathrm{Sc}^{\mathrm{D}}$ ) or on $\mathrm{C} 6$ ' (i.e. $\mathrm{Sc} 2$ and $\mathrm{Sc} 5$ ), it is further away from the electron deficient carbon atom of a carbonylgroup. This explains the higher spin-density on $\mathrm{C1}^{\prime}$ ' and $\mathrm{C} 6$ ' of the catechol radical compared to that on $\mathrm{C} 2$ ' and $\mathrm{C} 5$ '. 
Based on these arguments, the large hyperfine coupling of $3.549 \mathrm{G}$ is attributed to 1 ' $\mathrm{H}$ and 6 ' $\mathrm{H}$; the small hyperfine coupling of $0.841 \mathrm{G}$ is attributed to 2 ' $\mathrm{H}$ and 5'H.

Similar to the para-hydroxyphenol radical; (i) the UE and the EP are delocalized over the conjugated $\pi$-system of the catechol radical, and (ii) the $\mathbf{U E}$ is expected to be primarily located on the carbons (i.e. C3' and C4') bound to the oxygen atoms in the catechol radical. This allocation is confirmed with ab initio quantum calculations (Figure 7). The spin-density appears to be mostly concentrated on C3' and C4', followed by $\mathrm{C1}^{\prime}$ and C6'. Using O'Connell's equation, the spindensities in the catechol radical is found to be $12 \%$ on $\mathrm{C}^{\prime}{ }^{\prime}$ and $\mathrm{C}^{\prime}$ ', and $2.9 \%$ on C2' and C5' (Table 3). This suggests a high spin-density of 35\% on C3' and C4'.

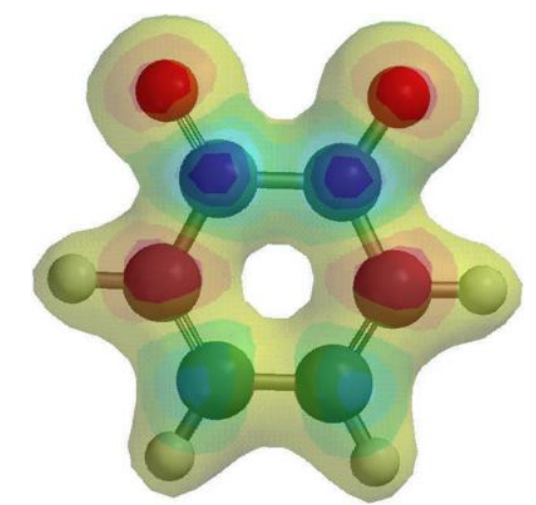

Figure 7. The spin-density distribution of the catechol radical obtained using $a b$ initio quantum molecular calculations. Blue indicates high, green indicates intermediate, and red indicates low spin-density.

\section{The $A C_{Q}$-ring behaves like an electron donor}

The ESR spectrum of the kaempferol radical and that of the para-hydroxyphenol radical are strikingly similar. Both spectra display typical quintets [5-7], stemming from the interaction of the UE with 4 equivalent protons. The only 4 protons that can be equivalent in the kaempferol radical are located in the B-ring, i.e. $2^{\prime} \mathrm{H}, 3^{\prime} \mathrm{H}, 5^{\prime} \mathrm{H}$ and $6^{\prime} \mathrm{H}$. This indicates that (i) the UE and the EP are primarily delocalized over the conjugated $\pi$-system in the B-ring, similar to the para-hydroxyphenol radical (Figure $4 \mathrm{~B}$ ), and that (ii) the $\mathrm{AC}_{\mathrm{Q}}$-ring appears to 


\section{Chapter 4}

have a similar effect as the oxygen atom, i.e. the $4^{\prime} \mathrm{O}$, in the $\mathrm{B}$-ring of the kaempferol radical.

To verify the previous statements, the ESR spectrum of the myricetin radical is recorded. The ESR spectrum of the myricetin radical is a triplet that is caused by the interaction of the UE with 2 equivalent protons. When considering the symmetry of myricetin (Figure 8), the only protons that can be equivalent are located in the B-ring of myricetin. These findings corroborate our earlier conclusions that (i) the $\mathbf{U E}$ is primarily delocalized over the conjugated $\pi$-system in the $\mathrm{B}$-ring, and that (ii) the $\mathrm{AC}_{\mathrm{Q}}$-ring behaves as an electron donor similar to an oxygen.

\section{Resolving the delocalization of the $U E$ in $Q^{\bullet}$}

The ESR spectrum of $\mathbf{Q}^{\bullet}$ displays a doublet, split in smaller doublets that is split into even smaller doublets with hyperfine couplings of 3.184, 1.480 and $0.652 \mathrm{G}$, respectively.

The findings that (i) the UE is primarily delocalized over the conjugated $\pi$ system in the $\mathrm{B}$-ring, that (ii) the $\mathrm{AC}_{\mathrm{Q}}$-ring behaves as an electron donor, and that (iii) the $\mathbf{U E}$ is most stable on atoms adjacent to electron donors, are used to assign the protons of $\mathbf{Q}^{*}$.

It was deduced that the $\mathbf{U E}$ in $\mathbf{Q}^{\bullet}$ interacts with the 3 different protons in the Bring, i.e. 2'H, 5' $\mathrm{H}$ and 6' $\mathrm{H}$. The 2'H will cause the lowest hyperfine coupling because the $\mathrm{C} 2$ ' will be adjacent to two electron deficient atoms.

The B-ring of $\mathbf{Q}^{\bullet}$ can be regarded as a hybrid of para-hydroxyphenol radical and catechol radical. In the para-hydroxyphenol radical, the spin-density on C6' is equal to that on $\mathrm{C}^{\prime}$ '. In the catechol radical, the spin-density on C6' is larger than that on $\mathrm{C}^{\prime}$ '. Therefore, the larger hyperfine coupling was attributed to 6' $\mathrm{H}$ in $\mathbf{Q}^{*}$.

From the hyperfine couplings of the ESR spectrum of $\mathbf{Q}^{*}$, the spin-densities were calculated to be $2.3 \%$ on $\mathrm{C}^{\prime}$ ', $5.1 \%$ on the $\mathrm{C}^{\prime}$ ' and $11 \%$ on the $\mathrm{C}^{\prime}$ ' (Figure 8 ). This suggests a relatively high spin-density of $27 \%$ on the $\mathrm{C} 1$ ', $\mathrm{C} 3$ ' and the $\mathrm{C} 4$ ' (Table 3). 
<smiles>O=c1cc2oc(-c3cc([O-])c([O-])c([O-])c3)c([O-])c(O)c-2c(O)c1</smiles>

Myricetin Radical

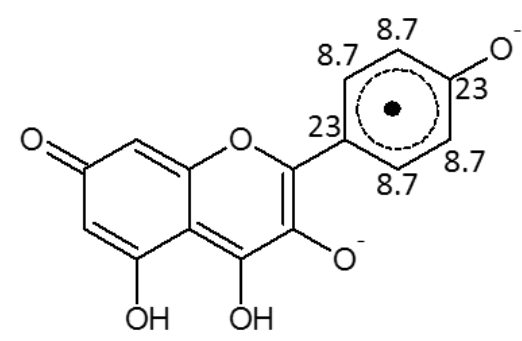

Kaempferol Radical<smiles>[H][R7]1ccc(-c2oc3cc(=O)cc(O)c-3c(O)c2[O-])cc1[O-]</smiles>

Quercetin Radical

Figure 8. Proposed structures of the tested flavonols, with the spin-distribution (\%) calculated by O'Connell's equation from the hyperfine couplings of their ESR data.

\section{The ESR spectra of the radicals of methylated derivatives of $Q$ substantiate}

\section{that the $U E$ is in the B-ring}

To substantiate the proposed delocalization of the $\mathbf{U E}$ in the B-ring of $\mathbf{Q}^{\mathbf{*}}$, the ESR spectrum of the 3MQ, 3'MQ and 4'MQ radicals were recorded (Figure 3). It is important to note that there is no quartet peak in the ESR spectrum of $\mathbf{3 M Q}$ radical, O-methylated in the C-ring, indicating negligible interaction of the $\mathbf{U E}$ with the three equivalent protons of the methylgroup in the C-ring. This corroborates previous findings that indicate the B-ring as the primary frame for delocalization of the $\mathbf{U E}$.

The ESR spectrum of the radical of 3MQ shows a large doublet (2.884 G) split into smaller triplet $(0.939 \mathrm{G})$ peaks. These peaks can only be caused by 


\section{Chapter 4}

interaction of the $\mathbf{U E}$ with two un-equivalent groups of protons; one group containing one proton causing the large doublet, and the other group containing two protons causing the smaller triplet. The resonance structures of the $\mathbf{3 M Q}$ radical resemble that of the catechol radical. This means that $6^{\prime} \mathrm{H}$ in the $\mathbf{3 M Q}$ radical, just like in the catechol radical, causes the largest peak splitting that is a doublet of $2.884 \mathrm{G}$. In addition, 2'H and 5'H of the 3MQ radical, similar to the catechol radical, are equivalent and responsible for the smaller triplets $(0.939 \mathrm{G})$. Intriguingly, the electron donating effect of the AC-ring can be reduced to practically zero by a subtle modification (i.e. methylation) of the $3 \mathrm{OH}$ group in Q. This is in line with previous studies, indicating the importance of the $3 \mathrm{OH}$ for the interaction of the AC-ring with the B-ring in $\mathbf{Q}[8,9]$.

Further evidence that the $\mathbf{U E}$ is primarily delocalized in the B-ring can be found in the spectra of the radicals of 3'MQ and 4'MQ, which are both O-methylated on the B-ring. Both spectra are relatively complicated, 13 peaks per spectrum, clearly revealing the interaction of the methoxy protons with the UE.

The UE of the 3'MQ radical is interacting with 3 different groups of protons, all located on the B-ring; (i) one group consists of the two equivalent protons located at the 5' and 6' position (causing the triplet of $2.835 \mathrm{G}$ ), (ii) one group consists of the one equivalent proton located at the 2' (causing the doublet of $0.760 \mathrm{G}$ ), (iii) and one group consists of the 3 equivalent protons of the 3 ' $\mathrm{O}$ methyl group (causing the quartet of $0.684 \mathrm{G}$ ).

The ESR spectrum of the 4'MQ radical is very similar to that of the 3'MQ radical, and can be explained in a similar way (Table $2 \& 3$ ), except that the 3 equivalent protons that cause the quartet are now found in the 4'methoxy group.

\section{Conclusion}

The ESR spectra of $\mathbf{Q}^{\bullet}$ and related compounds indicate that the $\mathbf{U E}$ is primarily delocalized in the B-ring. The oxygen atoms in the B-ring (i.e. 3' $\mathrm{O}$ and 4'O) and the $\mathrm{AC}_{\mathrm{Q}}$-ring have an electron donating effect that stabilize the electron deficient

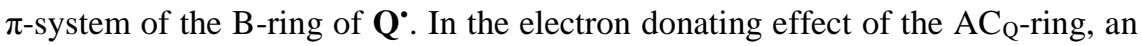
un-substituted $\mathrm{OH}$ group at the 3 position in the $\mathrm{C}$-ring is essential. The relative 
stability of $\mathbf{Q}^{\bullet}$ is one of the main reasons for $\mathbf{Q}^{\prime}$ s exceptional antioxidant activity. So, the $\mathbf{U E}$ is caged and stabilized in the conjugated $\pi$-system of the B-ring of $\mathbf{Q}^{\bullet}$ by the electron donating properties of the $\mathrm{AC}_{\mathrm{Q}}$-ring and the two oxygens in that ring (i.e. 3'O and 4'O). 


\section{Chapter 4}

\section{References}

1. Crozier, A.; Lean, M. E.; McDonald, M. S.; Black, C. Quantitative analysis of the flavonoid content of commercial tomatoes, onions, lettuce, and celery. J. Agric. Food Chem. 1997, 45, 590-595.

2. Justesen, U.; Knuthsen, P.; Leth, T. Quantitative analysis of flavonols, flavones, and flavanones in fruits, vegetables and beverages by highperformance liquid chromatography with photo-diode array and mass spectrometric detection. J. Chromatogr. A 1998, 799, 101-110.

3. Wertz, J. E.; Bolton, J. R. Electron Spin Resonance: elementary theory and practical applications. New York: McGraw-Hill; 1972.

4. Moalin, M.; Strijdonck, G. P.; Beckers, M.; Hageman, G.; Borm, P.; Bast, A.; Haenen, G. R. A planar conformation and the hydroxyl groups in the $\mathrm{B}$ and $\mathrm{C}$ rings play a pivotal role in the antioxidant capacity of quercetin and quercetin derivatives. Molecules 2011, 16, 9636-9650.

5. van Acker, S. A.; de Groot, M. J.; van den Berg, D. J.; Tromp, M. N.; Donne-Op den Kelder, G.; van der Vijgh, W. J.; Bast, A. A quantum chemical explanation of the antioxidant activity of flavonoids. Chem Res Toxicol 1996, 9, 1305-1312.

6. Pirker, K. F.; Stolze, K.; Reichenauer, T. G.; Nohl, H.; Goodman, B. A. Are the biological properties of kaempferol determined by its oxidation products? Free Radic Res 2006, 40, 513-521.

7. Kuhnle, J. A.; Windle, J. J.; Waiss, A. C. Electron paramagnetic resonance spectra of flavonoid anion-radicals. Journal of the Chemical Society B: Physical Organic 1969, 613-616.

8. Moalin, M.; Strijdonck, G. P.; Beckers, M.; Hagemen, G.; Borm, P.; Bast, A.; Haenen, G. R. A planar conformation and the hydroxyl groups in the $\mathrm{B}$ and $\mathrm{C}$ rings play a pivotal role in the antioxidant capacity of quercetin and quercetin derivatives. Molecules, 16, 9636-9650.

9. Moalin, M.; van Strijdonck, G. P.; Bast, A.; Haenen, G. R. Competition between ascorbate and glutathione for the oxidized form of methylated 
quercetin metabolites and analogues: tamarixetin, 4'O-methylquercetin, has the lowest thiol reactivity. J Agric Food Chem, 60, 9292-9297. 



\section{Chapter 5}

Peroxynitrite scavenging of quercetin and structural analogues:

The AC-ring of quercetin donates the first electron, the $B$-ring scavenges the AC-ring and safely cages the unpaired electron in the quercetin radical.

Mohamed Moalin, Gino P.F. van Strijdonck, Aalt Bast and Guido R.M.M. Haenen 


\title{
Chapter 5
}

\begin{abstract}
Quercetin and its mono methylated derivatives are excellent at scavenging peroxynitrite (PON) that has been implicated in a wide range of diseases. In accordance with previous studies, our results show that $\mathbf{Q}$ has two nutricophores, i.e. the AC- and the B-ring. Although both nutricophores are potent PON scavengers on their own, there are indications that they do not act independently. Based on our results and quantum molecular calculations, we postulate that the AC-ring is prone to donating the first electron. This is followed by the intramolecular scavenging of the AC-ring radical by the B-ring in quercetin radical. The unpaired electron is then caged safely in the B-ring and the AC-ring gets its potency back to scavenge another free radical.
\end{abstract}




\section{Introduction}

Peroxynitrite (PON) has been implicated in a wide range of human diseases [1] and it has been shown that flavonols, such as quercetin $(\mathbf{Q})$, are effective PON scavengers [2-4]. However, the molecular mechanism for Q's potent activity is still enigmatic. Previous studies, using flavones with less $\mathrm{OH}$ groups than $\mathbf{Q}$, have clearly shown that the antioxidant mechanism of $\mathbf{Q}$ is complicated because of its many functional groups [2,3]. These functional groups were divided into two separate pharmacophores, i.e. the AC-ring and the B-ring of $\mathbf{Q}$. This means that both the AC-ring and the B-ring of $\mathbf{Q}$ can readily scavenge PON by donating electrons. However, it is still unclear which of the pharmacophores of $\mathbf{Q}$, the $\mathrm{AC}$ - or the B-ring, is more prone to donating electrons to free radicals. To investigate this, we have synthesized the complete series of monomethylated $\mathbf{Q}$ derivatives (Table 1) and examined them in a well-developed competition assay. In this assay, the activity of each flavonoid is determined by examining how well they compete against dihydrorhodamine 123 (DHR) for the scavenging of PON [5]. 


\section{Chapter 5}

Table 1. The structures of quercetin $(\mathbf{Q})$ and its methylated derivatives that are investigated in this study.

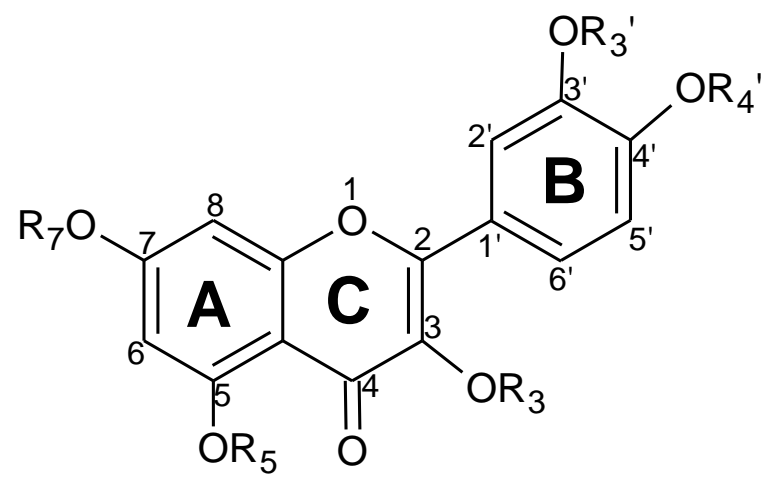

\begin{tabular}{|c|c|c|c|c|c|}
\hline Compound & $\mathrm{R}_{3}$ & $\mathrm{R}_{5}$ & $\mathrm{R}_{7}$ & $\mathrm{R}_{3}$ & $\mathrm{R}_{4}$ \\
\hline Q & $\mathrm{H}$ & $\mathrm{H}$ & $\mathrm{H}$ & $\mathrm{H}$ & $\mathrm{H}$ \\
\hline Q3M & $\mathrm{CH}_{3}$ & $\mathrm{H}$ & $\mathrm{H}$ & $\mathrm{H}$ & $\mathrm{H}$ \\
\hline Q3,7M & $\mathrm{CH}_{3}$ & $\mathrm{H}$ & $\mathrm{CH}_{3}$ & $\mathrm{H}$ & $\mathrm{H}$ \\
\hline QpentaM & $\mathrm{CH}_{3}$ & $\mathrm{CH}_{3}$ & $\mathrm{CH}_{3}$ & $\mathrm{CH}_{3}$ & $\mathrm{CH}_{3}$ \\
\hline Q3'M & $\mathrm{H}$ & $\mathrm{H}$ & $\mathrm{H}$ & $\mathrm{CH}_{3}$ & $\mathrm{H}$ \\
\hline Q4'M & $\mathrm{H}$ & $\mathrm{H}$ & $\mathrm{H}$ & $\mathrm{H}$ & $\mathrm{CH}_{3}$ \\
\hline Q5M & $\mathrm{H}$ & $\mathrm{CH}$ & $\mathrm{H}$ & $\mathrm{H}$ & $\mathrm{H}$ \\
\hline Q7M & $\mathrm{H}$ & $\mathrm{H}$ & $\mathrm{CH} 3$ & $\mathrm{H}$ & $\mathrm{H}$ \\
\hline
\end{tabular}

\section{Materials and methods}

\section{Chemicals}

Quercetin. $2 \mathrm{H}_{2} \mathrm{O}$ was purchased from Acros Organics, peroxynitrite from Calbiochem, apigenin and kaempferol from Fluka, catechol from Janssen Chimica and chrysin, dihydrorhodamine 123, galangin, 3-hydroxy flavone, 5hydroxyflavone, 7-hydroxyflavone, luteolin and morin from Sigma-Aldrich. The methylated quercetin derivatives were synthesized and can be currently purchased (www.maxamed-chem.com). 


\section{Peroxynitrite scavenging assay}

PON scavenging was measured by the oxidation of DHR as described by Kooy et al. [5]. Fluorescence measurements were performed at $37^{\circ} \mathrm{C}$ on a SPF-500C spectrofluorometer (SLM Aminco) with excitation and emission wavelengths of 500 and $536 \mathrm{~nm}$, respectively. The PON scavenging activity is expressed as the percentage DHR that is prevented from reacting with PON by the test compound (Figure 1\&2). The scavenging reaction was done in phosphate buffer ( $\mathrm{pH} 7.4)$.

\section{Molecular quantum calculations}

A HOMO-Map on $\mathbf{Q}$ was generated by using Hartree-Fock 6-31G** equilibrium geometry optimization method in Spartan ' 10 .

\section{Statistics}

All experiments were performed, at least, in triplicate. Data are expressed as means \pm SD or as a typical example.

\section{Results}

PON scavenging

The flavonoids have been divided into groups, because they displayed large differences in PON scavenging. For each group, the concentrations of PON, DHR and flavonoid was optimized to be able to elucidate their differences. The non-methylated flavones were examined at $10 \mathrm{uM}$ (Figure 1a) and at $1 \mathrm{uM}$ (Figure 1b) flavonoid against $5 \mathrm{uM}$ DHR and $0.4 \mathrm{uM}$ PON. Q and its methylated derivatives have been examined at $0.5 \mathrm{uM}$ flavonoid against $5 \mathrm{uM}$ DHR for 0.4 uM PON (Figure 2a). To elucidate the difference between the most potent flavonols, i.e. Q, kaempferol and morin, $1 \mathrm{uM}$ of flavonol was used against 50 uM DHR and 0.25 uM PON (Figure 2b). 


\section{Chapter 5}

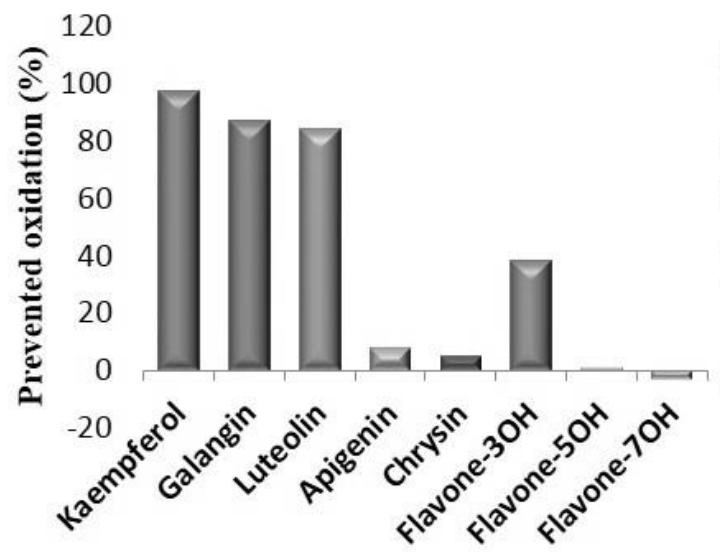

(a)

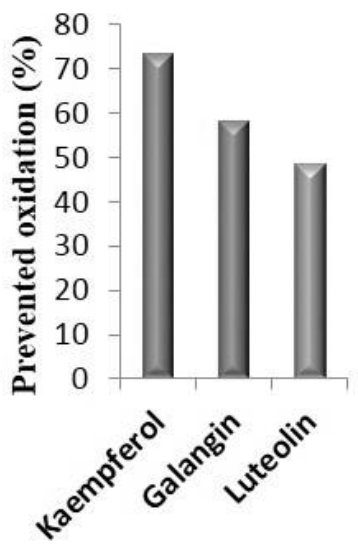

(b)

Figure 1. PON scavenging activity of flavones with less $\mathrm{OH}$ groups than $\mathbf{Q}$ with (a) 10 uM flavone vs 5 uM DHR and (b) 1 uM flavone vs 5 uM DHR.

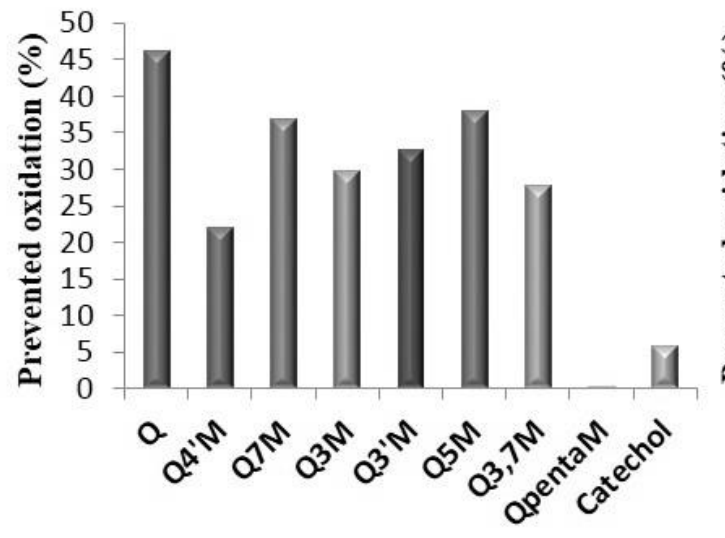

(a)

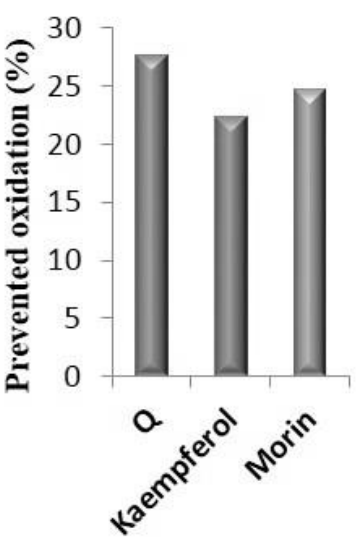

(b)

Figure 2. PON scavenging activity of $\boldsymbol{Q}$ and its structural analogues, (a) $0.5 \mathrm{uM}$ flavonoid against 5 uM DHR for 0.4 uM PON (b) 1 uM of flavonol was used against $50 \mathrm{uM}$ DHR and $0.25 \mathrm{uM} P O N$. 
Quantum molecular calculations

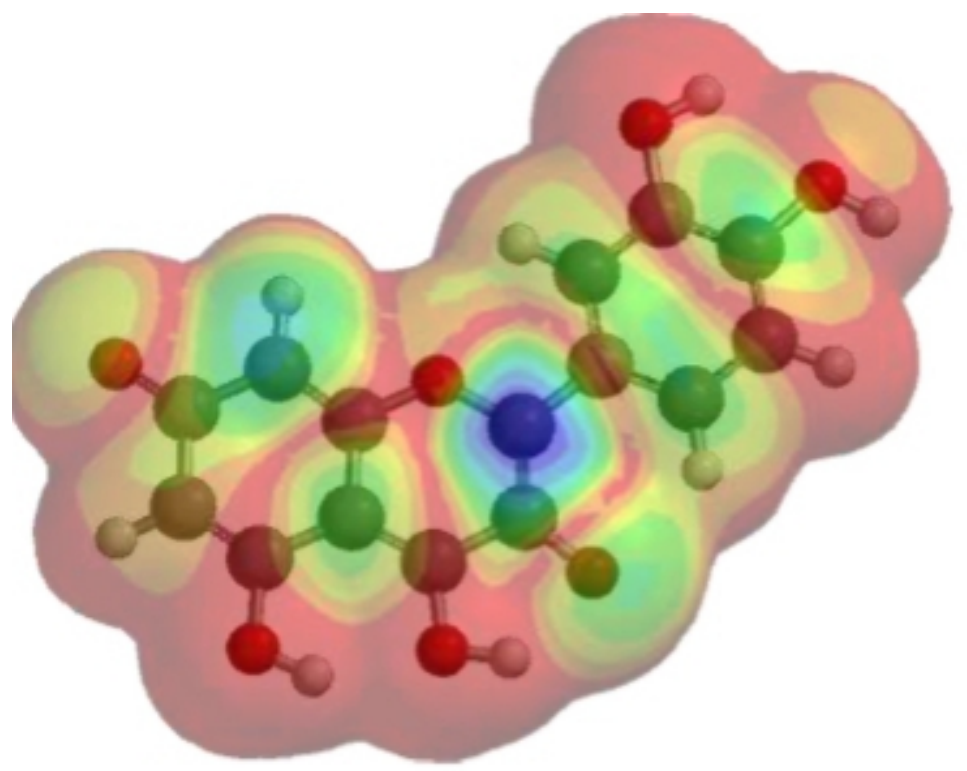

Figure 3. HOMO map, generated with ab initio calculations in Spartan '10, on the activated form of $Q$. Blue indicates a high concentration of the HOMO, and red indicates the lowest concentration.

\section{Discussion}

It is known for several decades that $\mathbf{Q}$ is one of the most potent antioxidant found in nature. To date, the molecular mechanism for its potent activity is still enigmatic. Previous studies, using flavones with less $\mathrm{OH}$ groups than $\mathbf{Q}$, have clearly shown that the antioxidant mechanism of $\mathbf{Q}$ is complicated because of its many functional groups [2,3]. These functional groups were divided into two separate pharmacophores, i.e. the AC-ring and the B-ring of $\mathbf{Q}$. This means that both the AC-ring and the B-ring of $\mathbf{Q}$ can readily scavenge radicals by the donation of electrons. However, it is still unclear which of the pharmacophores of $\mathbf{Q}$, the $\mathrm{AC}$ - or the B-ring, is more prone to donating electrons to free radicals. 


\section{Chapter 5}

The importance of the $3 \mathrm{OH}$ group

In accordance with previous studies [2,3], we also see flavones with the same AC-ring as $\mathbf{Q}$ (e.g. galangin), or the same B-ring as $\mathbf{Q}$ (e.g. luteolin) to be potent scavengers in our assay (Figure 1). It is generally accepted that the electrons in the highest occupied molecular orbital (HOMO) of $\mathbf{Q}$ are the easiest to donate. The HOMO energies of flavones are increased by the electron donating effect of $\mathrm{OH}$ groups. However, the input of the different $\mathrm{OH}$ groups for the antioxidant activity of $\mathbf{Q}$ is clearly not equal. The $\mathrm{OH}$ group at the 3 position seems to have a critical role in the antioxidant activity of $\mathbf{Q}$, e.g. galangin (88\%) vs chrysin (8\%) and kaempferol $(98 \%)$ vs apigenin $(12 \%)$ in Figure 1a. The $3 \mathrm{OH}$ seems to be enhanced by the 5- and the $7 \mathrm{OH}$, e.g. galangin (88\%) vs flavone-3OH (38\%) in Figure 1a. In addition, the 4'OH also enhances the activity of the $3 \mathrm{OH}$ group, e.g. kaempferol $(75 \%)$ vs galangin $(58 \%)$ in Figure 1 b. The methylation of the $3 \mathrm{OH}$ position of $\mathbf{Q}$ (3MQ) also seems to have a drastic effect on the antioxidant activity, e.g. Q (47\%) vs 3MQ (28\%) in Figure 2a.

To explain the critical role of the $3 \mathrm{OH}$ group, it is imperative to also take the other functional groups, besides the $\mathrm{OH}$ groups, into account. For example, the carbonyl group at the 4 position can channel the negative charge donated by the oxygens at the 5 and the 7 position due to keto-enol tautomerization (Scheme 1). Keto-enol tautomerization can readily occur in aquatic environment, because of the ability of water to stabilize electronically charged compounds. During the keto-enol tautomerization of $\mathbf{Q}$, the oxygen at the 4 position readily deprotonates the $3 \mathrm{OH}$ group intra-molecularly. The deprotonation of the $3 \mathrm{OH}$ concentrates the electron density, via the $\mathrm{C} 3=\mathrm{C} 2$ double bond, on the $\mathrm{C} 2$ position through resonance effect. 
<smiles>O=c1c(O)c(-c2ccc(O)c(O)c2)oc2cc([O-])cc(O)c12</smiles><smiles>O=c1cc2oc(-c3ccc(O)c(O)c3)c(O)c([O-])c-2c(O)c1</smiles><smiles>O=C1C=C(O)C2=C(O)C(=O)C(c3ccc(O)c(O)c3)OC2=C1</smiles><smiles>O=c1cc2oc(-c3ccc(O)c(O)c3)c([O-])c([O-])c-2c(O)c1</smiles>

Scheme 1. Stepwise illustration of the activation of the $3 \mathrm{OH}$ group through the keto-enol tautomerization. The activation by the $70 H$ group is taken as an example.

Even though the oxygen at the 3 position is the only group that increase the electron density on the $\mathrm{C} 2$ position directly; the oxygens at 1, 5 and 7 position in $\mathbf{Q}$ can also increase the electron density on the $\mathrm{C} 2$ indirectly by activating the $3 \mathrm{OH}$ group via the carbonylgroup (Scheme 1\&2). In contrast, the electron density in the $\mathrm{C} 1^{\prime}$ is only increased by the 4'OH group. Therefore, we postulate the AC-ring of $\mathbf{Q}$ as the donor of the first electron because of the relatively higher electron density on the $\mathrm{C} 2$ position. 


\section{Chapter 5}<smiles>O=C1C=C(O)C2=C(O)C(=O)C(c3ccc(O)c(O)c3)OC2=C1</smiles>

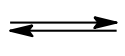<smiles>O=C1C=C(O)C=C2OC(c3ccc(O)c(O)c3)C(=O)C(O)=C12</smiles>

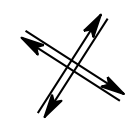<smiles>O=C1C(O)=c2c(O)cc(O)cc2=[O+]C1c1ccc(O)c(O)c1</smiles><smiles>O=C1C(=O)C(c2ccc(O)c(O)c2)Oc2cc(O)cc(O)c21</smiles>

Scheme 2. Four different resonance structures where the C2 position is ionized, illustrating its high electron density.

It is important to note that the electron densities will always be the highest on the oxygen groups because of their relatively high electronegativity, and that high electron density does not directly correlate with higher tendency to donate electrons. The tendency to donate electrons correlates better with the highest occupied molecular orbital (HOMO). The electrons in the HOMO are farthest from the nuclei and are the easiest to donate. To visualize the electron donating site, a HOMO map is generated on the activated form of $\mathbf{Q}$ by employing quantum molecular calculations (Figure 3). As expected, the HOMO is highly concentrated (blue color) on the $\mathrm{C} 2$ position. We postulate that the free radical, with the electron deficient single occupied molecular orbital (SOMO), will be attracted to the electron rich HOMO of $\mathbf{Q}$ that has a relatively high concentration on the $\mathrm{C} 2$ position. The HOMO of $\mathbf{Q}$ can then donate an electron to the SOMO of the free radical leading to the scavenging of the free radical, and the formation of the relatively more stable $\mathbf{Q}$ radical (Scheme 3). 


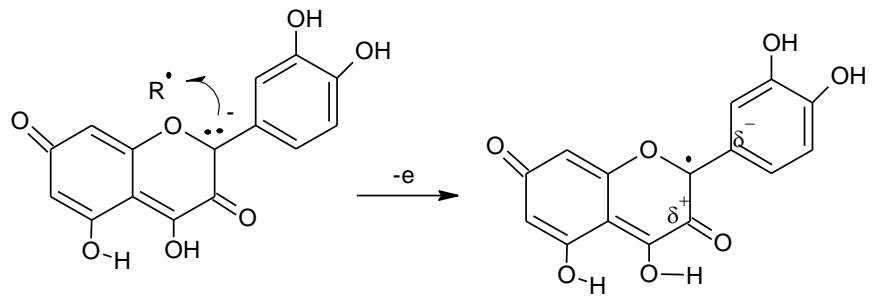

Scheme 3. The proposed mechanism of the first electron donation of $\boldsymbol{Q}$, from the electron rich $C 2$ position of $\boldsymbol{Q}$, to an electron deficient radical.

The importance of the 4'OH group

Schemes $1 \& 2$ explain why the $3 \mathrm{OH}$ group is essential for the donation of the first electron, but not why methylation of the $4^{\prime} \mathrm{OH}$ of $\mathbf{Q}$ has an even larger effect than methylation of the $3 \mathrm{OH}$ (Figure 2a). The clue can be found in an earlier study on the ESR spectra of the radicals of $\mathbf{Q}$ and its methylated derivatives [6]. In that study, it was clearly revealed that the unpaired electron was located in the B-ring of $\mathbf{Q}$ radical. With this information, we were able to postulate the subsequent reaction that occurs after the AC-ring of $\mathbf{Q}$ has scavenged a radical (Scheme 4). Once the AC-ring donates the first electron, it becomes a radical with its unpaired electron located between the electron deficient $\mathrm{C} 3$ and the electron rich $\mathrm{C}^{1}$ ' (Scheme 3). Because of the close proximity, the radical on the $\mathrm{C} 2$ position can immediately be scavenged by the $\mathrm{C} 1$ ' intra-molecularly. This leads to the regeneration of the scavenging potential of the AC-ring and a resonance stabilized unpaired electron in the B-ring [6]. 


\section{Chapter 5}

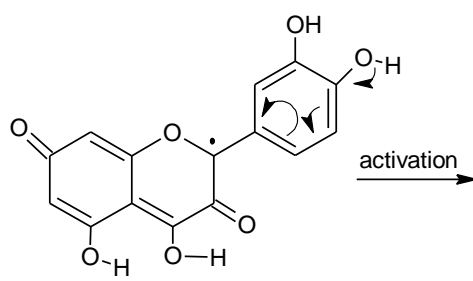<smiles>O=C1C=C(O)C2=C(O)C(=O)C(I)(c3ccc(O)c(O)c3)OC2=C1</smiles>

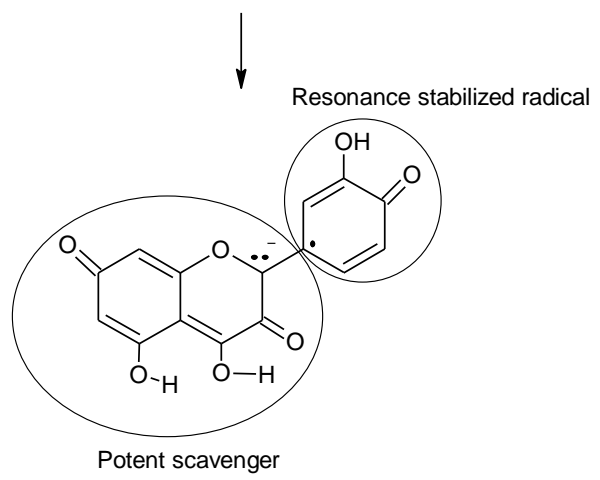

Scheme 4. The proposed scavenging mechanism of the AC-ring radical by the $B$ ring in $Q$ radical.

The regenerated AC-ring has then enough electrons to scavenge another radical inter-molecularly (Scheme 5). This leads to an unpaired electron on the C2 position and an unpaired electron in the B-ring, which can readily pair to form the resonance stabilized quinone methide [7-9]. Methylation of the $4^{\prime} \mathrm{OH}$ of $\mathbf{Q}$ diminishes the intra-molecular scavenging of the AC-ring of $\mathbf{Q}$ radical by the Bring, which slows down the second electron donation by the AC-ring. This would suggest that the rate limiting step is the intra-molecular scavenging, explaining the relatively high importance of the 4'OH group of $\mathbf{Q}$. Additionally, methylation of the 4'OH group would also diminish the stabilization of the unpaired electron in the

B-ring [6]. 


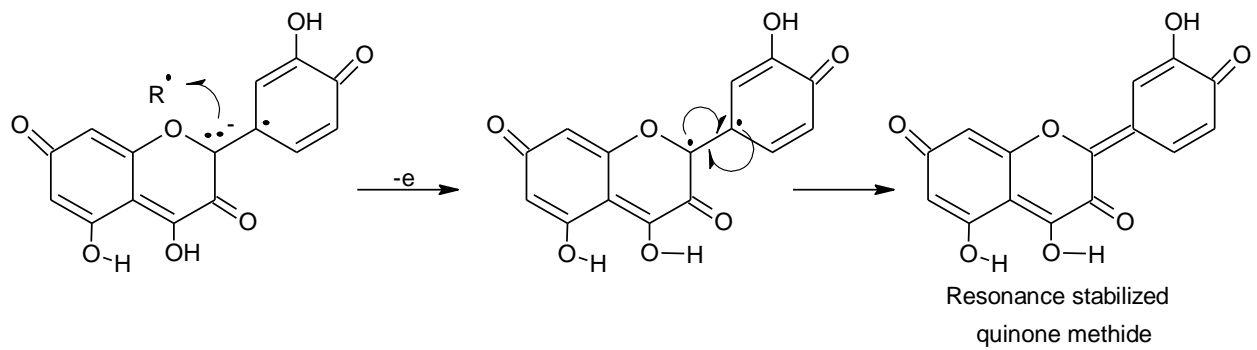

Scheme 5. The proposed scavenging of the second radical by $\boldsymbol{Q}$ radical.

\section{Conclusion}

In corroboration with earlier studies [2,3], our results show that $\mathbf{Q}$ has two pharmacophores, i.e. the $\mathrm{AC}$ - and the $\mathrm{B}$-ring, that are both potent $\mathrm{PON}$ scavengers on their own. In addition, we have investigated which of the pharmacophores of $\mathbf{Q}$, i.e. the $\mathrm{AC}$ - or the B-ring, is more prone to donating electrons to free radicals.

The distribution of the HOMO, the molecular orbital that is most likely to donate electrons, on $\mathbf{Q}$ was generated utilizing quantum molecular calculations. The HOMO seems to be mostly concentrated on the $\mathrm{C} 2$ position. We postulate that the oxygen at the 3 position of $\mathbf{Q}$ potentiates the $\mathrm{C} 2$ position in the AC-ring, resulting in the highest concentration of the HOMO. The oxygens at the 5 and the 7 position of $\mathbf{Q}$ activate the $3 \mathrm{OH}$ via the carbonylgroup at the 4 position that further increases the $\mathrm{HOMO}$ at the $\mathrm{C} 2$ position. So, the $\mathrm{AC}$-ring of $\mathbf{Q}$ is more prone to donating the first electron.

Subsequently, the B-ring of $\mathbf{Q}$ radical can intra-molecularly scavenge the ACring by the donation of an electron. The oxygen at 4' position potentiates $\mathrm{Cl}^{\prime}$, enhancing the intra-molecular scavenging of the AC-ring in $\mathbf{Q}$ radical. In addition, the oxygens at 4' and 3' positions increase the stability of the unpaired electron in the B-ring [6]. So, the unpaired electron is stabilized in the B-ring of $\mathbf{Q}$ radical [6], and its AC-ring gets its potency back to scavenge another free radical by the donation of an electron. After the donation of the second electron, a quinone methide is formed that can be processed in the antioxidant network of the body $[7,8]$. 


\section{Chapter 5}

To summarize, we postulate that the reactivity of free radicals is channeled stepwise in a controlled fashion into the antioxidant network, by the cooperation of the two pharmacophores of $\mathbf{Q}$. The $3 \mathrm{OH}$ is a prerequisite for the scavenging potential of the AC-ring of $\mathbf{Q}$, and the $4^{\prime} \mathrm{OH}$ is a prerequisite for the intramolecular scavenging of the AC-ring of $\mathbf{Q}$ radical and the stabilization of the unpaired electron in the B-ring. 


\section{References}

1. Szabo, C.; Ischiropoulos, H.; Radi, R. Peroxynitrite: biochemistry, pathophysiology and development of therapeutics. Nat Rev Drug Discov 2007, 6, 662-680.

2. Haenen, G. R.; Paquay, J. B.; Korthouwer, R. E.; Bast, A. Peroxynitrite scavenging by flavonoids. Biochem. Biophys. Res. Commun. 1997, 236, 591-593.

3. Heijnen, C. G.; Haenen, G. R.; van Acker, F. A.; van der Vijgh, W. J.; Bast, A. Flavonoids as peroxynitrite scavengers: the role of the hydroxyl groups. Toxicol. in Vitro 2001, 15, 3-6.

4. Heijnen, C. G.; Haenen, G. R.; Vekemans, J. A.; Bast, A. Peroxynitrite scavenging of flavonoids: structure activity relationship. Environmental Toxicology and Pharmacology 2001, 10, 199-206.

5. Kooy, N. W.; Royall, J. A.; Ischiropoulos, H.; Beckman, J. S. Peroxynitrite-mediated oxidation of dihydrorhodamine 123. Free Radic Biol Med 1994, 16, 149-156.

6. Moalin, M.; Strijdonck, G. P.; Bast, A.; Haenen, G. The unpaired electron in the quercetin radical is delocalized in the conjugated $\pi$ system of its B-ring. In press. 2013.

7. Jacobs, H.; Moalin, M.; Bast, A.; van der Vijgh, W. J.; Haenen, G. R. An essential difference between the flavonoids monoHER and quercetin in their interplay with the endogenous antioxidant network. PLoS One 2010, 5, e13880.

8. Moalin, M.; van Strijdonck, G. P.; Bast, A.; Haenen, G. R. Competition between ascorbate and glutathione for the oxidized form of methylated quercetin metabolites and analogues: tamarixetin, 4'O-methylquercetin, has the lowest thiol reactivity. J Agric Food Chem, 60, 9292-9297.

9. Boots, A. W.; Kubben, N.; Haenen, G. R.; Bast, A. Oxidized quercetin reacts with thiols rather than with ascorbate: implication for quercetin supplementation. Biochem. Biophys. Res. Commun. 2003, 308, 560-565. 



\section{Chapter 6}

\section{Competition between ascorbate and glutathione for the oxidized form of methylated quercetin metabolites and analogues:}

Tamarixetin, 4'O-Methylquercetin, has the lowest thiol reactivity

Mohamed Moalin, Gino P.F. van Strijdonck, Aalt Bast and Guido R.M.M. Haenen

J. Agric. Food Chem. 2012, 60, 9292-97 


\title{
Chapter 6
}

\begin{abstract}
Quercetin (Q) is a bioactive compound with excellent antioxidant activity. However, the thiol reactivity of its oxidation product (oxQ) forms a disadvantage. The aim of the present study was to decrease this thiol toxicity. We found that methylated $\mathbf{Q}$ metabolites displayed lower thiol reactivity than $\mathbf{Q}$. The most effective was tamarixetin, 4'O-methylquercetin (4'MQ), that has a corresponding oxidation product (ox4'MQ) with thiol reactivity 350 times lower than oxQ. The endogenous metabolism of $\mathbf{Q}$ to 4'MQ might be a physiological way to safely benefit from the antioxidant potential of $\mathbf{Q}$ in vivo. Our results were explained with Pearson's HSAB concept and corroborated by quantum molecular calculations that revealed a strong correlation between the relative thiol reactivity and the Lowest Unoccupied Molecular Orbital (LUMO). The polarity of the molecule and the $\pi-\pi$ interaction between the $\mathrm{AC}$ - and the B-ring appeared to determine the LUMO and the thiol reactivity of the oxidation product.
\end{abstract}




\section{Introduction}

Flavonoids are important nutrients, ubiquitously found in our diet and they are also used as nutraceuticals [1]. Some of them, with quercetin $(\mathbf{Q})$ as the best studied example, display an excellent antioxidant activity. However, the reactive oxidation products that are formed out of flavonoids, i.e. electrophilic quinones, form a disadvantage. These quinones are harmful because they readily react with vital thiol groups [2]. To protect against quinone toxicity, cells are endorsed with an intricate antioxidant network. The most prominent constituents of this network that can protect against quinone toxicity are ascorbate and glutathione (GSH) [3]. It should be noted that both antioxidants neutralize quinones differently. Ascorbate converts quinones back to the parent flavonoid, whereas GSH reacts with quinones to form a GSH-flavonoid adduct. The reaction of oxidized $\mathbf{Q}(\mathbf{o x Q})$ with GSH is much faster than with ascorbate [4]. When GSH is depleted, thiol-containing proteins become the new targets for the electrophilic $\mathbf{o x Q}$. The reaction with thiol-containing proteins will cause toxicity. In addition, GSH might only offer partial protection since GSH-Q adducts rapidly react with protein-thiols at physiological conditions, hence, spreading the toxicity over the cells [5].

To circumvent thiol toxicity, we aim to identify quercetin derivatives that would preferentially react with ascorbate rather than with thiols. Besides preventing toxicity, an additional advantage is that in the reaction with ascorbate, the parent flavonoid is recycled which enhances the antioxidant activity of the flavonoid. We tested a series of methylated $\mathbf{Q}$ derivatives that included two of the major metabolites of $\mathbf{Q}$ formed in vivo, i.e. tamarixetin (4'MQ) and isorhamnetin (3'MQ). These metabolites are held responsible for at least part of the health benefits of $\mathbf{Q}$ [6-8]. We determined the Competition between Ascorbate and Thiols for the oxidized flavonoids (CAT). GSH was used as thiol and the CAT was calculated as the reaction rate of oxidized flavonoid with ascorbate $\left(\mathrm{V}_{\text {Asc }}\right)$ divided by the reaction rate of the oxidized flavonoid with the thiol GSH ( $\left.\mathrm{V}_{\mathrm{GSH}}\right)$. Our final goal is to identify the structural elements that will direct the reactivity of the oxidized product towards ascorbate instead of thiols, in other words, to 


\section{Chapter 6}

increase the CAT. With this knowledge, strategies might be developed that selectively direct the reactivity of free radicals more safely into the endogenous cellular antioxidant network.

\section{Materials and Methods}

\section{Chemicals}

Quercetin. $2 \mathrm{H}_{2} \mathrm{O}$ was purchased from Acros Organics and rutin. $3 \mathrm{H}_{2} \mathrm{O}$ from Sigma-Aldrich (Steinheim, Germany). The methylated derivatives of quercetin (Table 1) were synthesized and can be currently purchased (www.maxamedchem.com). Glutathione (GSH), hydrogen peroxide $\left(\mathrm{H}_{2} \mathrm{O}_{2}\right)$, horseradish peroxidase (HRP), L-ascorbic acid (vitamin C) were purchased from Sigma (St. Louis, MO, USA). Trifluoroacetic acid (TFA) was acquired from Sigma-Aldrich (Steinheim, Germany). Acetonitrile, HPLC grade, was obtained from Biosolve (Valkenswaard, The Netherlands).

\section{Oxidation of the flavonoids}

All solutions were freshly prepared and used within three hours. The flavonoids were dissolved in DMSO. GSH, Vitamin $\mathrm{C}$ and $\mathrm{H}_{2} \mathrm{O}_{2}$ were dissolved in $145 \mathrm{mM}$ phosphate buffer ( $\mathrm{pH}$ 7.4). In the incubations, the reactants, i.e. flavonoid, GSH, vitamin $\mathrm{C}$ and $\mathrm{H}_{2} \mathrm{O}_{2}$ were used at equimolar concentrations $(50 \mu \mathrm{M})$, unless otherwise noted. The oxidation reaction was performed at $37{ }^{\circ} \mathrm{C}$ in $145 \mathrm{mM}$ phosphate buffer ( $\mathrm{pH}$ 7.4) and started with the addition of HRP. HRP was used in a concentration that oxidized the flavonoid under investigation at a rate of approximately $50 \%$ flavonoid in 5 minutes at $37{ }^{\circ} \mathrm{C}$. The reactions were monitored spectrophotometrically and by HPLC. 
Table 1. The Competition between Ascorbate and Thiols, CAT, for the oxidized flavonoid.

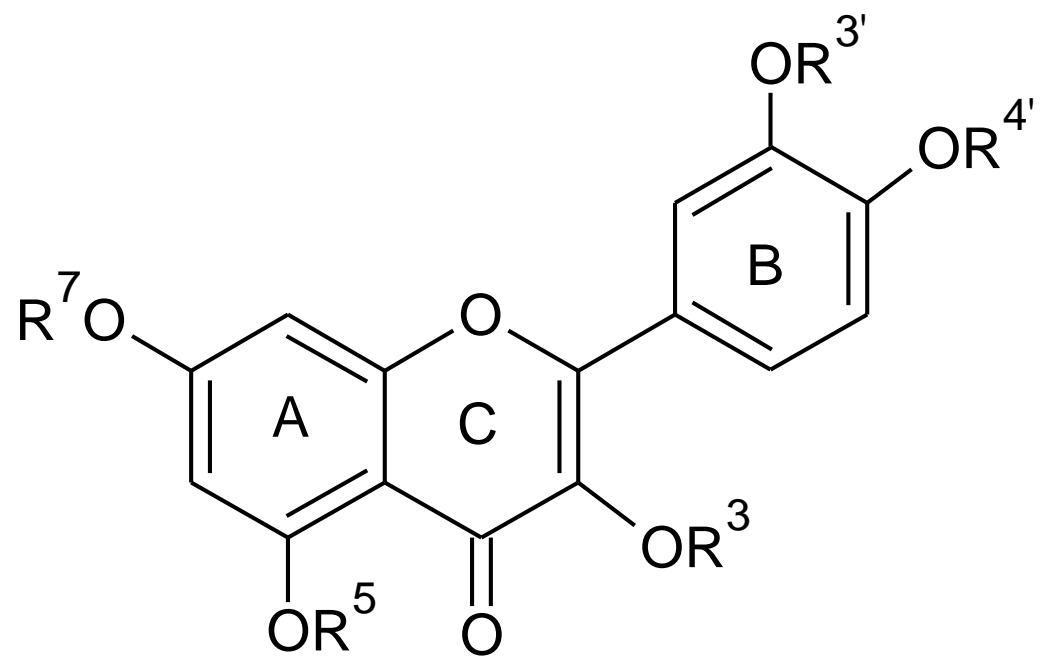

\begin{tabular}{l|l|l|l|l|l|l} 
Compound & $\mathbf{R}^{\mathbf{3}}$ & $\mathbf{R}^{\mathbf{5}}$ & $\mathbf{R}^{\mathbf{7}}$ & $\mathbf{R}^{\mathbf{3}}$ & $\mathbf{R}^{\mathbf{4}}$ & $\mathbf{C A T}$ \\
\hline $\mathbf{Q}$ & $\mathrm{H}$ & $\mathrm{H}$ & $\mathrm{H}$ & $\mathrm{H}$ & $\mathrm{H}$ & $0.04 \pm 0.03$ \\
\hline $\mathbf{5 M Q}$ & $\mathrm{H}$ & $\mathrm{CH}_{3}$ & $\mathrm{H}$ & $\mathrm{H}$ & $\mathrm{H}$ & $0.11 \pm 0.05$ \\
\hline $\mathbf{7 M Q}$ & $\mathrm{H}$ & $\mathrm{H}$ & $\mathrm{CH}_{3}$ & $\mathrm{H}$ & $\mathrm{H}$ & $0.24 \pm 0.03$ \\
\hline 3'MQ & $\mathrm{H}$ & $\mathrm{H}$ & $\mathrm{H}$ & $\mathrm{CH}_{3}$ & $\mathrm{H}$ & $0.75 \pm 0.13$ \\
\hline 3MQ & $\mathrm{CH}_{3}$ & $\mathrm{H}$ & $\mathrm{H}$ & $\mathrm{H}$ & $\mathrm{H}$ & $1.77 \pm 0.20$ \\
\hline 3,7MQ & $\mathrm{CH}_{3}$ & $\mathrm{H}$ & $\mathrm{CH}_{3}$ & $\mathrm{H}$ & $\mathrm{H}$ & $1.93 \pm 0.19$ \\
\hline 3RuQ & $\mathrm{Ru}^{\mathrm{a}}$ & $\mathrm{H}$ & $\mathrm{H}$ & $\mathrm{H}$ & $\mathrm{H}$ & $2.90 \pm 0.51$ \\
\hline 4'MQ & $\mathrm{H}$ & $\mathrm{H}$ & $\mathrm{H}$ & $\mathrm{H}$ & $\mathrm{CH}_{3}$ & $14.5 \pm 3.8$
\end{tabular}

${ }^{\mathrm{a}} \mathrm{Ru}$ is a rutinosylgroup that is a disaccharide consisting of glucose and rhamnose

\section{Spectrophotometric analysis}

Spectrophotometric analysis was performed with a Varian Carry 50 spectrophotometer (Varian, Mulgrave, VIC, Australia). All absorption spectra were recorded from 200 to $500 \mathrm{~nm}$ with a scan speed of $600 \mathrm{~nm} / \mathrm{min}$, using quartz cuvettes. The UV/Vis scans were started 15 seconds after the addition of HRP and the reaction was monitored for 10 minutes at $37^{\circ} \mathrm{C}$. 


\section{Chapter 6}

\section{HPLC analysis}

High-performance liquid chromatography (HPLC) was performed using a HP 1100 series HPLC system (Agilent Technologies, Palo Alto, CA, USA). Analytical separations were achieved using Alltima HP C18 column ( $3 \mu \mathrm{m}, 15$ $\mathrm{cm} \times 3.0 \mathrm{~mm}$ ). The mobile phase consisted of water containing $0.1 \%$ (v/v) TFA with a linear gradient from $5 \%$ acetonitrile to $20 \%$ acetonitrile in 5 minutes, followed by an increase to $60 \%$ acetonitrile at 10 minutes. A flow rate of 1 $\mathrm{ml} / \mathrm{min}$ was used. Detection was carried out with a diode array detector (DAD). The HPLC measurements were performed 5 minutes after the reaction was started.

The Competition between Ascorbate and Thiols for the oxidized flavonoid (CAT)

The Competition between Ascorbate and Thiols for the oxidized flavonoid, the CAT, is determined as the rate of reaction of oxidized flavonoid with ascorbate $\left(\mathrm{V}_{\mathrm{Asc}}\right)$ divided by the rate of the reaction of the oxidized flavonoid with the thiol GSH $\left(\mathrm{V}_{\mathrm{GSH}}\right)$, when both ascorbate and $\mathrm{GSH}$ are present at an equimolar concentration: $\mathrm{CAT}=\mathrm{V}_{\mathrm{Asc}} / \mathrm{V}_{\mathrm{GSH}}$.

The concentrations of GSH and ascorbate vary within the body. Typically, GSH concentrations in the cells are in the millimolar range whereas in blood plasma GSH is practically absent. Ascorbate concentrations range from 40-60 uM in blood plasma up to the millimolar range in cells. The concentrations used for the competition experiment were $50 \mu \mathrm{M}$ GSH and $50 \mu \mathrm{M}$ ascorbate. GSH is known to react with oxidized flavonoids to give GSH-flavonoid adducts and in this reaction, GSH-flavonoid adduct formation equals flavonoid consumption. Ascorbate reduces oxidized flavonoids to the parent flavonoid, but it can also partially inhibit HRP activity as reported previously [4]. Both activities of ascorbate will prevent net consumption of the flavonoid. So, in the competition between GSH $(50 \mu \mathrm{M})$ and ascorbate $(50 \mu \mathrm{M})$ for the oxidized flavonoids, ascorbate has two non-negligible activities: (i) reduction of the oxidized flavonoid to the parent flavonoid, (ii) inhibition of the rate of flavonoid oxidation 
by inhibiting HRP activity. When GSH is in excess (10 $\mathrm{mM})$ compared to ascorbate $(50 \mu \mathrm{M})$, the rate of the oxidized flavonoid with ascorbate is negligible to that with GSH. Hence, all the oxidized flavonoids will be trapped by the excess of GSH, and the $50 \mu \mathrm{M}$ ascorbate can only protect against flavonoid consumption by inhibiting the HRP enzyme. The rate of oxidation of the

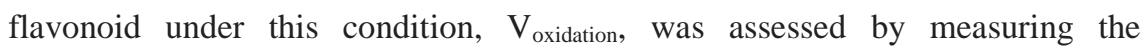
consumption of the flavonoid using HPLC. Similarly, flavonoid consumption by HRP in the presence of $50 \mu \mathrm{M}$ GSH and $50 \mu \mathrm{M}$ ascorbate was used to determine $\mathrm{V}_{\mathrm{GSH}} \cdot \mathrm{V}_{\mathrm{Asc}}$, the rate of the reaction of the oxidized flavonoid with ascorbate in the competition experiment with $50 \mu \mathrm{M}$ GSH and $50 \mu \mathrm{M}$ ascorbate, was calculated by subtracting $\mathrm{V}_{\mathrm{GSH}}$ from $\mathrm{V}_{\text {oxidation }}$ : $\mathrm{V}_{\mathrm{Asc}}=\mathrm{V}_{\text {oxidation }}-\mathrm{V}_{\mathrm{GSH}}$.

Using the procedure described in this section, we were able to correct for the inhibition of HRP by $50 \mu \mathrm{M}$ ascorbate. Although $\mathrm{V}_{\text {asc }}$ and $\mathrm{V}_{\mathrm{GSH}}$ are presented as absolute rates, they represent relative values where both rates are relative to each other. The rate limiting step is the oxidation of the flavonoid by $\mathrm{HRP} / \mathrm{H}_{2} \mathrm{O}_{2}$ that generates the quinone. Subsequently, the quinone reacts very quickly with either GSH or ascorbate. Because $\mathrm{V}_{\text {asc }}$ and $\mathrm{V}_{\mathrm{GSH}}$ are related to each other, we used their ratio, i.e. CAT.

\section{Quantum molecular calculations}

Quantum molecular calculations were performed using Spartan'10 (Wavefunction, Irvine, CA, USA) to determine the relative abundance of the tautomers of the oxidized flavonoids. Subsequently, the Lowest Unoccupied Molecular Orbital, LUMO, energies $(\mathrm{kJ} / \mathrm{mol})$ of the most abundant tautomers was calculated as well as their equilibrium geometry. The latter was used to determine the dihedrals $(\varphi)$, the angles between the plane of the AC-ring and that of the B-ring in the oxidized flavonoids. Previous studies have shown that $\mathrm{ab}$ initio calculations using the Hartree-Fock (HF) 3-21G basis set provides sufficiently good results for estimating chemical "hardness" [9] and therefore this was used. 


\section{Chapter 6}

\section{Statistics}

All experiments were performed, at least, in triplicate. Data are expressed as means \pm SD or as a typical example.

\section{Results}

GSH reacts with oxidized quercetin to form GSHQ adducts

UV analysis shows that the reaction of $\mathbf{Q}$ with $\mathrm{HRP} / \mathrm{H}_{2} \mathrm{O}_{2}$ leads to a decrease of the absorbance at $380 \mathrm{~nm}\left(\lambda_{\max }\right.$ of $\left.\mathbf{Q}\right)$ that indicates the oxidation of $\mathbf{Q}$ (Figure 1A). When $\mathbf{Q}$ is oxidized in the presence of GSH, isosbestic points in the UV spectrum at 308 and $354 \mathrm{~nm}$ are seen (Figure 1B) that clearly differ from those without GSH, i.e. 284 and $364 \mathrm{~nm}$ (Figure 1A). HPLC analysis confirms that in the presence of GSH, two GSH-Q adducts are formed previously identified as the 6- and the 8-GSQ adducts (Figure 2) [4].

\section{Ascorbate regenerates oxidized $Q$ to $Q$}

Addition of ascorbate to the incubation mixture containing $\mathbf{Q}$ and $\mathrm{HRP} / \mathrm{H}_{2} \mathrm{O}_{2}$ prevents the consumption of the flavonoid, since the absorbance between 300 and $400 \mathrm{~nm}$ due to $\mathbf{Q}$ remains unchanged (Figure 1C). At the same time, ascorbate is consumed, evidenced by the decrease in absorbance at $270 \mathrm{~nm}$ ( $\lambda_{\max }$ of ascorbate). A control experiment showed that when $\mathbf{Q}$ is omitted from the incubation mixture, there is no detectable ascorbate consumption. This indicates that ascorbate does not react with $\mathrm{HRP} / \mathrm{H} 2 \mathrm{O} 2$. Therefore it is concluded that $\mathbf{Q}$ is oxidized by $\mathrm{HRP} / \mathrm{H}_{2} \mathrm{O}_{2}$ and is then immediately regenerated by ascorbate. HPLC analysis confirms that there is no net $\mathbf{Q}$ consumption when ascorbate is present, within the 5 minutes of incubation.

The Competition between Ascorbate and Thiols for the oxidized flavonoid $(\boldsymbol{C A T})$

The CATs of the flavonoids were quantitatively determined using HPLC analysis. As a typical example, $\mathrm{V}_{\mathrm{GSH}}$ with oxQ was $4.6 \mu \mathrm{M} / \mathrm{min}$ while $\mathrm{V}_{\text {Asc }}$ was only $0.2 \mu \mathrm{M} / \mathrm{min}$. This means that the reaction rate of oxQ with ascorbate is 
much lower than the reaction rate of $\mathbf{o x Q}$ with GSH, which is reflected by a low CAT of 0.04 (Table 1).

Similarly to $\mathbf{Q}$, the derivatives of $\mathbf{Q}$ are oxidized by $\mathrm{HRP} / \mathrm{H}_{2} \mathrm{O}_{2}$. The oxidation products are regenerated in the presence of ascorbate, and form GSH-adducts in the presence of GSH. The CATs are depicted in Table 1. It was found that methylation increased the CAT. Methylation of the 4'OH group had the most profound effect; it increased the CAT of $\mathbf{Q}$ from 0.04 to 14.5.

(A) Q+HRP/ $\mathrm{H}_{2} \mathrm{O}_{2}$

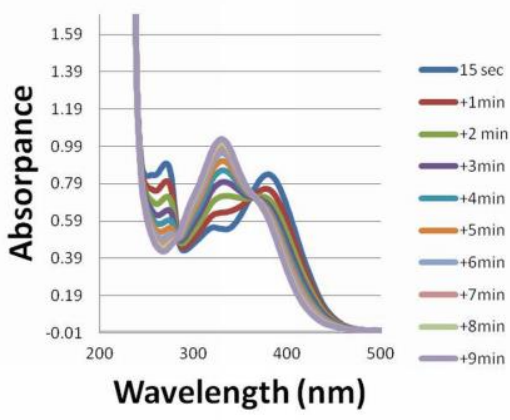

(C) Q+vitC+HRP/ $\mathrm{H}_{2} \mathrm{O}_{2}$

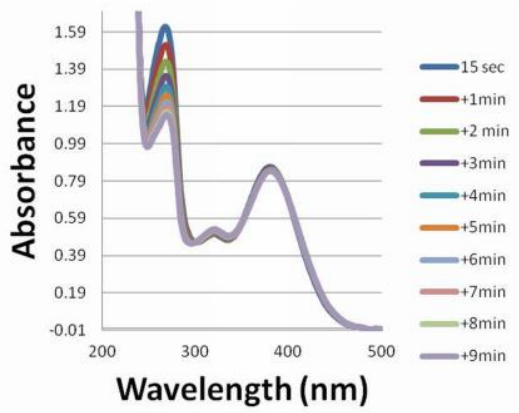

(B) Q+GSH+HRP/ $\mathrm{H}_{2} \mathrm{O}_{2}$

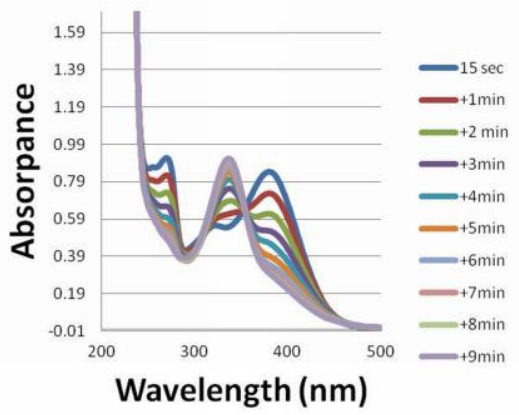

(D) Q+GSH+vitC+HRP/ $\mathrm{H}_{2} \mathrm{O}_{2}$

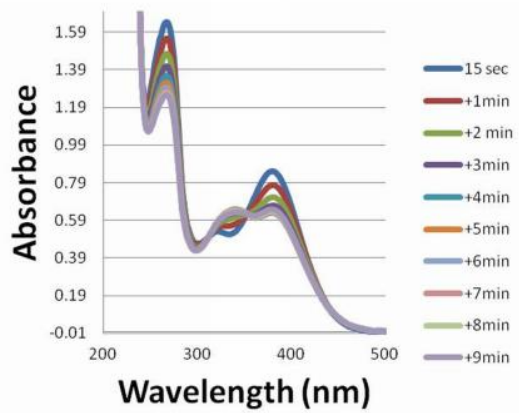

Figure 1. UV scans of the incubation mixture containing $1.6 \mathrm{nM} \mathrm{HRP,50 \mu M}$ quercetin and $50 \mu \mathrm{M} \mathrm{H}_{2} \mathrm{O}_{2}$ (A). The same experiment was carried out in the presence of $50 \mu M G S H(B)$ or $50 \mu M$ ascorbate $(C)$, and in the presence of both $50 \mu M$ ascorbate and $50 \mu M$ GSH (D). The UV scans were started 15 seconds after the addition of HRP and had a speed scan of $600 \mathrm{~mm} / \mathrm{min}$. After each minute one scan was taken with a total of 10 scans per reaction. 


\section{Chapter 6}<smiles>O=c1c(O)c(-c2ccc(O)c(O)c2)oc2cc(O)c(S(F)(F)F)c(O)c12</smiles><smiles>O=c1c(O)c(-c2ccc(O)c(O)c2)oc2c([Se])c(O)cc(O)c12</smiles>

Figure 2. The GSH adducts of $\mathbf{Q}$. On the left is 6-GSQ depicted and on the right 8-GSQ.

\section{Quantum molecular calculations}

The oxidized flavonoids have four different tautomers $\left(\mathrm{T}_{1}-\mathrm{T}_{4}\right)$ as illustrated in Figure 3 and 4 for some of these compounds. Quantum molecular calculations, performed as described in the Materials and Methods section, revealed that for oxQ the $\mathrm{T}_{3}$ tautomer is by far the most favorable one with an abundance of more than $99 \%$. For ox5MQ, ox3'MQ and for ox4'MQ this also is $\mathrm{T}_{3}$. For ox7MQ this is $\mathrm{T}_{4}$, for $\mathbf{0 x 3 M Q}$, ox3RuQ and $\mathbf{0 x 3}, 7 \mathrm{MQ}$ this is $\mathrm{T}_{1}$.

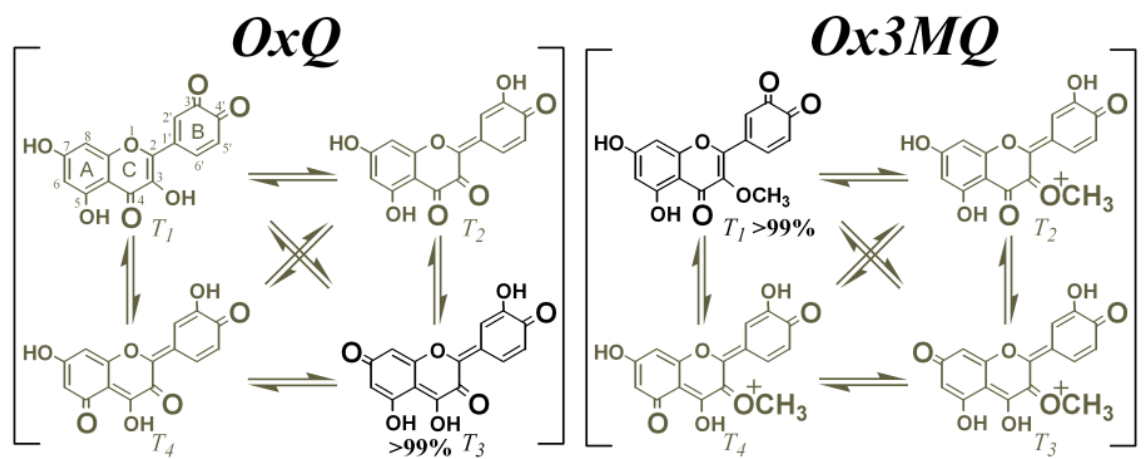

Figure 3. Tautomers of oxidized $Q(\operatorname{oxQ})$ and oxidized $3 M Q(\operatorname{ox} 3 M Q)$. For oxQ,

$T_{3}$ is the most favorable tautomer because the carbonyl groups are at maximum distance from each other. For ox $3 \mathrm{MQ}, T_{1}$ is the only tautomer that is not charged making it the most energetically favorable configuration. The other tautomers of ox $3 \mathrm{MQ}, T_{2}-T_{4}$, are positively charged making them energetically less favorable. Quantum molecular calculations indicate that the preferred tautomer of both compounds has a relative abundance of more than $99 \%$. 


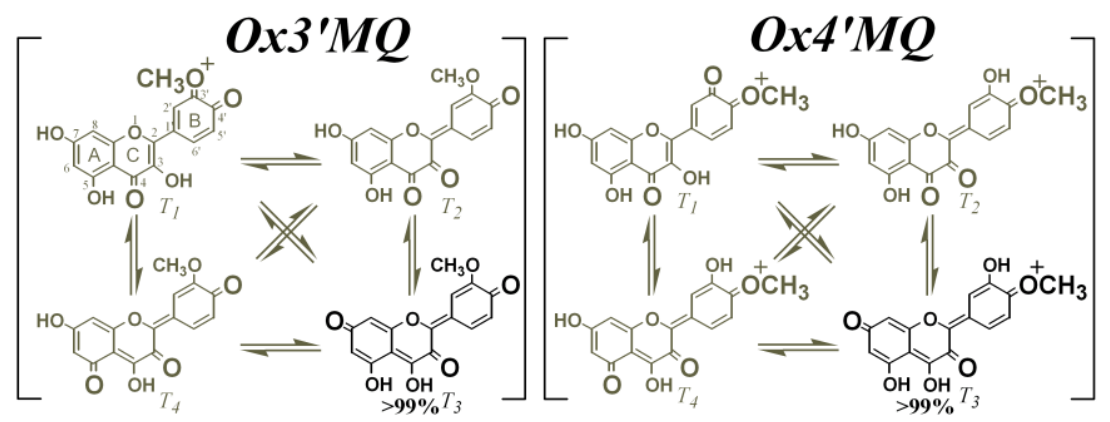

Figure 4. Tautomers of oxidized 3'MQ (ox3'MQ) and oxidized 4'MQ (ox4'MQ). For ox3'MQ, $T_{3}$ is the most favorable tautomer because the carbonyl groups are at maximum distance from each other. In ox4'MQ, all the possible tautomers are positively charged. Also for ox4'MQ, $T_{3}$ is the most favorable. Because of its positive charge the chemical nature of ox4'MQ is much "harder" than that of ox3'MQ. Quantum molecular calculations indicate that the preferred tautomer of both compounds has a relative abundance of more than $99 \%$.

OxQ is planar with a dihedral between the plane of the AC-ring and that of the B-ring of $0.0^{\circ}$. Methylation at the 30-position increases this dihedral (Table 2). A methyl group at the 3O-position as in ox3MQ and ox3,7MQ induces an angle of $13^{\circ}$. The more bulky rutinosyl group in ox3RuQ increases the dihedral to $29^{\circ}$. 


\section{Chapter 6}

Table 2. The most abundant tautomer of the oxidized flavonoids, their LUMOs and dihedrals $(\varphi)$, the angles between the plane of the AC-ring and that of the Bring. The tautomeric forms are denoted as $T_{1}, T_{2}, T_{3}$ and $T_{4}$. In $T_{1}$ the carbonyls are located at the 4, 3' and 4' positions; in $\mathrm{T}_{2}$ they are at the 3,4 and 4' positions; in $\mathrm{T}_{3}$ they are at the 3,7 and 4' positions; in $\mathrm{T}_{4}$ they are at the 3,5 and 4' positions.

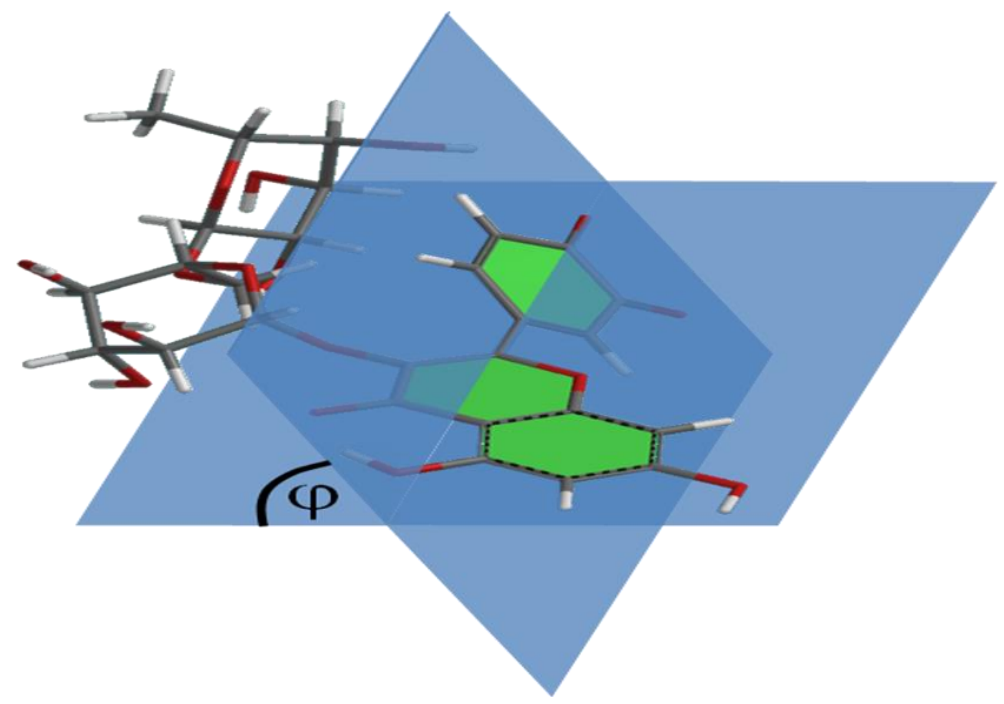

\begin{tabular}{l|c|l|l} 
Compound & $\begin{array}{l}\text { Most abundant } \\
\text { tautomer }\end{array}$ & $\begin{array}{l}\text { LUMO } \\
(\mathbf{k J} / \mathbf{m o l})\end{array}$ & $\boldsymbol{\varphi}$ \\
\hline OxQ & $\mathrm{T}_{3}$ & -112.14 & $0.0^{\circ}$ \\
\hline Ox5MQ & $\mathrm{T}_{3}$ & -98.35 & $0.0^{\circ}$ \\
\hline Ox7MQ & $\mathrm{T}_{4}$ & -74.00 & $0.0^{\circ}$ \\
\hline Ox3'MQ & $\mathrm{T}_{3}$ & -49.45 & $0.0^{\circ}$ \\
\hline Ox3MQ & $\mathrm{T}_{1}$ & -15.74 & $13^{\circ}$ \\
\hline Ox3,7MQ & $\mathrm{T}_{1}$ & -11.24 & $13^{\circ}$ \\
\hline Ox3RuQ & $\mathrm{T}_{1}$ & -24.30 & $29^{\circ}$ \\
\hline Ox4'MQ & $\mathrm{T}_{3}{ }^{*}$ & 21.33 & $0.0^{\circ}$ \\
${ }^{*}$ Contains a positive charge & &
\end{tabular}


The energies of the LUMOs of the most abundant tautomer of oxQ, its methylated derivatives and $\mathbf{0 x 3 R \mathbf { R Q }}$ are depicted in Table 1. OxQ has the lowest LUMO energy and O-methylation lead to an increase of the LUMO energy. Ox4'MQ has the highest LUMO energy of the methylated derivatives. It was found that the LUMO energies highly correlated $\left(\mathrm{R}^{2}=0.9713\right)$ with the CATs, as illustrated in Figure 5. The relationship, which covered a wide range of CAT, was: $\ln (\mathrm{CAT})=0.0407 \mathrm{LUMO}+1.5736$.

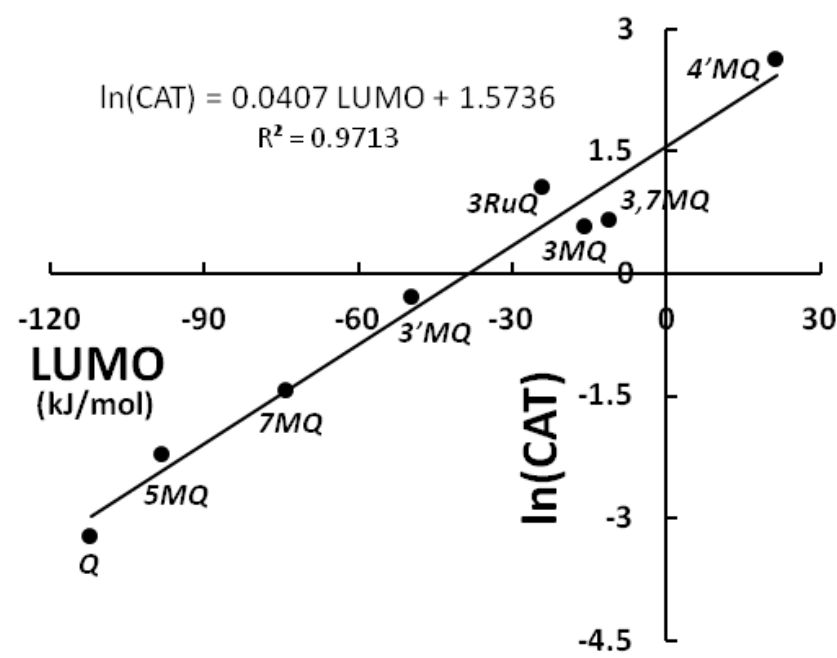

Figure 5. Correlation of the energy of the Lowest Unoccupied Molecular Orbital (LUMO) of the most abundant tautomer of ox $Q$ and its derivatives with the Competition between Ascorbate and Thiols for these oxidized flavonoids (CAT).

\section{Discussion}

In the present study, the effect of $\mathrm{O}$-methylation of $\mathbf{Q}$ on the Competition between Ascorbate and Thiols (the CAT), with GSH as thiol, for the oxidized flavonoid is determined. The oxidized flavonols have four tautomeric forms, denoted as $T_{1}, T_{2}, T_{3}$ and $T_{4}$ in the present study. In $T_{1}$ the carbonyls are located at the 4, 3' and 4' positions; in $\mathrm{T}_{2}$ they are at the 3, 4 and 4' positions; in $\mathrm{T}_{3}$ they are at the 3, 7 and 4' positions; in $\mathrm{T}_{4}$ they are at the 3,5 and 4' positions. 


\section{Chapter 6}

$Q$ vs $3 M Q$

It appears that the CAT of $\mathbf{3 M Q}$ (1.77) is substantially higher than that of $\mathbf{Q}$ (0.04). For oxQ, $T_{3}$ appeared to be the most abundant, which has also been reported previously [10]. In the case of $\mathbf{0 x 3 M Q}$, the electronically uncharged $\mathrm{T}_{1}$ form is energetically the most favorable one because the other tautomers have an unfavorable positive charge. Therefore ox3MQ will almost exclusively (>99\%) be in the $\mathrm{T}_{1}$ form. The difference in structure between oxQ $\left(\mathrm{T}_{3}\right)$ and ox3MQ $\left(\mathrm{T}_{1}\right)$ forms the basis of their difference in CAT, which can be explained by applying Pearson's HSAB concept [11]. The gist of this theory is that "soft" electrophiles react faster with "soft" nucleophiles, whereas "hard" electrophiles react faster with "hard" nucleophiles. "Hard" electrophiles are chemical species that are small, highly polarized, and have a high oxidation state [11,12]. The difference in "hardness" between the most abundant tautomer of OxQ and ox3MQ lies mainly in their polarity. The carbonyl groups represent the most polarized moiety and a close proximity of these groups will make the oxidized compound "hard".

In $\mathrm{T}_{3}$, which is the most abundant tautomer of $\mathbf{o x Q}$, the distance between the carbonyl groups is at its maximum, making it the "softest" electrophile of the series. Thiols such as GSH are known to be "softer" than ascorbate [10]. The HSAB concept dictates that the "soft" electrophile, oxQ, should react faster with the "softer" GSH than with ascorbate, explaining the relatively low CAT of $\mathbf{Q}$.

In $T_{1}$, which is the most abundant tautomer of ox3MQ, the two carbonyl groups in the B-ring are adjacent, making the molecule relatively "harder" than oxQ. In contrast to oxQ, the relatively "harder" ox3MQ prefers the "hard" ascorbate over the "soft" GSH, explaining the higher CAT of ox3MQ. This exemplifies the correlation of the CAT with the "hardness" of the oxidized flavonoid; the "harder" the oxidized product the higher the CAT.

\section{$3 M Q$ vs $3 R u Q$ (Rutin)}

Ox3MQ and ox3RuQ are substituted at the same position, and $\mathrm{T}_{1}$ is the most preferred tautomer for both compounds. However, the CAT of $\mathbf{3 R u Q}$ (2.90) is 
higher than that of $\mathbf{3 M Q}$ (1.77). Quantum molecular calculations showed that the bulky rutinosyl group at the 3-O position in the case of ox3RuQ induces a torsion angle (dihedral) of $29^{\circ}$ between the plane of the AC-ring and that of the B-ring in its most preferred tautomer (Table 2). The methylgroup in ox3MQ induces a dihedral of only $13^{\circ}$, whereas in $\mathbf{0 x Q}$ the dihedral is $0.0^{\circ}$. A higher dihedral reduces the interaction between the $\pi$-system of the $\mathrm{AC}$ and that of the B-ring due to less $\pi-\pi$ overlap, and thus further concentrates the polarity on the B-ring. This means that ox3RuQ will be more polarized than ox3MQ, making ox3RuQ a "harder" electrophile that is reflected in the higher CAT of $\mathbf{3 R u Q}$. Actually, oxQ's complete planar structure indicates a maximal interaction between the $\mathrm{AC}$ - and the $\mathrm{B}$-ring. This strong $\pi-\pi$ interaction, over the entire molecule, in oxQ forms the backbone of its "soft" character.

\section{3'MQ vs 4'MQ}

The difference in CAT between 3'MQ (0.75) and 4'MQ (14.5) is remarkably high. Similarly to $\mathbf{o x Q}, \mathrm{T}_{3}$ is also the preferred form for $\mathbf{0 x 3}$ 'MQ that has a dihedral of practically zero. This indicates that the "softness" of $\mathbf{0 x 3}$ ' $\mathbf{M Q}$ is close to that of $\mathbf{o x Q}$, explaining their relatively similar CATs.

In the derivatives discussed so far, their most abundant tautomer had no positive charge and the most polarized groups were the carbonyl moieties. In the case of Ox4'MQ, all the possible tautomers have a positive charge located on the 4' position as depicted in Figure 4. This positively charged moiety is much more polarized than the carbonyl groups. The presence of a moiety with a positive charge renders ox4'MQ to be the "hardest" electrophile in our series. This explains why 4'MQ has the highest CAT in our series. The most preferred tautomer of ox4'MQ is also $\mathrm{T}_{3}$ with a dihedral of practically zero. This indicates that the "hard" character of ox4'MQ is not due to a distortion of the planar backbone of the molecule. 


\section{Chapter 6}

\section{$5 M Q$ and $7 M Q$}

The most abundant tautomer of ox5MQ $\left(\mathrm{T}_{3}\right)$ and that that of ox7MQ $\left(\mathrm{T}_{4}\right)$ have no positive charge and the distance between the carbonyl groups is relatively large. This indicates that the difference in "softness" of ox5MQ and ox7MQ with oxQ is relatively small, explaining their comparable CATs (Table 1).

\section{$3,7 M Q$}

We have also tested a dimethylated $\mathbf{Q}$ derivative, namely 3,7MQ. The CAT and the dihedral of this compound are similar to that of $\mathbf{3 M Q}$, which confirms that the dihedral plays a pivotal role and emphasizes the importance of the $\pi-\pi$ interaction of the $\mathrm{AC}$ - with the B-ring.

\section{Correlation between the LUMO and the CAT}

Chemical reactions are generally governed by the interaction between the frontier orbitals, more specifically, the interaction between the HOMO (highest occupied molecular orbital) of the nucleophile and the LUMO (lowest unoccupied molecular orbital) of the electrophile. "Hard" electrophiles are known to have relatively higher LUMO energies than "soft" electrophiles [12]. Because all reactants in the oxidation assay were the same, except for the oxidized flavonoids, we focused on the LUMO energies of the most abundant tautomer of the oxidized flavonoids. The LUMOs of the oxidized flavonoids show a high correlation with their CATs as depicted in Figure 5. This correlation is in line with the theory that a "harder" molecule has a higher LUMO energy, which is reflected in lower thiol reactivity and a higher CAT.

\section{$Q$ derivatives that would preferentially interact with ascorbate over thiols}

To decrease thiol toxicity, the $\mathbf{Q}$ derivative has to have a higher preference for ascorbate than for thiols, i.e. it has to have a high CAT. Methylation at the 5 and 7 position hardly affects the CAT. Methylation at the $3^{\prime} \mathrm{O}$ or the $3 \mathrm{O}$ position leads to a relatively small increase in the CAT. This effect is enhanced when a relatively large substituent is placed at the 3 position, since this greatly distorts 
the planar structure of $\mathbf{Q}$. By far, the greatest effect was found when the 4' position was substituted. In fact, methylation at the 4' position decreases the thiol reactivity of $\mathbf{Q}$ more than 350 times.

It appears that for a high CAT, methylation at $4^{\prime} \mathrm{O}$ position of $\mathbf{Q}$ is the most effective. In general, O-methylation will reduce the antioxidant effect of quercetin. Nevertheless, 4'MQ still possesses significant antioxidant activity $[6,13]$. Moreover, ox4'MQ will be regenerated by ascorbate in the antioxidant network to 4'MQ that will boost its potency. Additionally, it has been demonstrated that the cellular uptake of 4'MQ is superior to that of $\mathbf{Q}$ [7,8]. Our data indicate that 4'MQ would be less toxic than Q. Spencer et al. [7] have shown that this is indeed the case.

It is becoming increasingly more evident that metabolites of flavonoids are partly, or even primarily, responsible for the health benefits. In particular, the methylated flavonoids are of interest [8,14]. Interestingly, 4'MQ is formed in vivo by catechol O-methyl transferase (COMT) as one of the metabolites of $\mathbf{Q}$ [15]. The present study indicates that the disadvantageous thiol toxicity of $\mathbf{Q}$ is diminished in 4'MQ. The endogenously formed 4'MQ might be a physiological way to safely benefit from the antioxidant potential of quercetin in vivo. 


\section{Chapter 6}

\section{References}

1. Boots, A. W.; Haenen, G. R.; Bast, A. Health effects of quercetin: from antioxidant to nutraceutical. Eur J Pharmacol 2008, 585, 325-337.

2. Boots, A. W.; Li, H.; Schins, R. P.; Duffin, R.; Heemskerk, J. W.; Bast, A.; Haenen, G. R. The quercetin paradox. Toxicol Appl Pharmacol 2007, 222, 89-96.

3. Meister, A. Glutathione, ascorbate, and cellular protection. Cancer Res 1994, 54, 1969s-1975s.

4. Boots, A. W.; Kubben, N.; Haenen, G. R.; Bast, A. Oxidized quercetin reacts with thiols rather than with ascorbate: implication for quercetin supplementation. Biochem. Biophys. Res. Commun. 2003, 308, 560-565.

5. Jacobs, H.; Moalin, M.; van Gisbergen, M. W.; Bast, A.; van der Vijgh, W. J.; Haenen, G. R. An essential difference in the reactivity of the glutathione adducts of the structurally closely related flavonoids monoHER and quercetin. Free Radic Biol Med 2011, 51, 2118-2123.

6. Duenas, M.; Gonzalez-Manzano, S.; Gonzalez-Paramas, A.; SantosBuelga, C. Antioxidant evaluation of O-methylated metabolites of catechin, epicatechin and quercetin. J Pharm Biomed Anal 2010, 51, 443-449.

7. Spencer, J. P.; Kuhnle, G. G.; Williams, R. J.; Rice-Evans, C. Intracellular metabolism and bioactivity of quercetin and its in vivo metabolites. Biochem. J. 2003, 372, 173-181.

8. Spencer, J. P.; Abd-el-Mohsen, M. M.; Rice-Evans, C. Cellular uptake and metabolism of flavonoids and their metabolites: implications for their bioactivity. Arch Biochem Biophys 2004, 423, 148-161.

9. Shankar, R.; Senthilkumar, K.; Kolandaivel, P. Calculation of Ionization Potential and Chemical Hardness: A Comparative Study of Different Methods. International Journal of Quantum Chemistry 2009, 109, 764-771.

10. Jacobs, H.; Moalin, M.; Bast, A.; van der Vijgh, W. J.; Haenen, G. R. An essential difference between the flavonoids monoHER and quercetin 
in their interplay with the endogenous antioxidant network. PLoS One 2010, 5, e13880.

11. Pearson, R. G. Hard and Soft Acids and Bases. Journal of the American Chemical Society 1963, 85, 3533-3539.

12. Chattaraj, P. K.; Schleyer, P. v. R. An ab Initio Study Resulting in a Greater Understanding of the HSAB Principle. Journal of the American Chemical Society 1994, 116.

13. Moalin, M.; Strijdonck, G. P.; Beckers, M.; Hageman, G.; Borm, P.; Bast, A.; Haenen, G. R. A planar conformation and the hydroxyl groups in the $\mathrm{B}$ and $\mathrm{C}$ rings play a pivotal role in the antioxidant capacity of quercetin and quercetin derivatives. Molecules 2011, 16, 9636-9650.

14. Jacobs, H.; Peters, R.; den Hartog, G. J.; van der Vijgh, W. J.; Bast, A.; Haenen, G. R. Identification of the metabolites of the antioxidant flavonoid 7-mono-O-(beta-hydroxyethyl)-rutoside in mice. Drug Metab Dispos 2011, 39, 750-756.

15. Wright, B.; Gibson, T.; Spencer, J.; Lovegrove, J. A.; Gibbins, J. M. Platelet-mediated metabolism of the common dietary flavonoid, quercetin. PLoS One 2010, 5, e9673. 



\section{Chapter 6}

Supplemental information 


\section{Chapter 6}
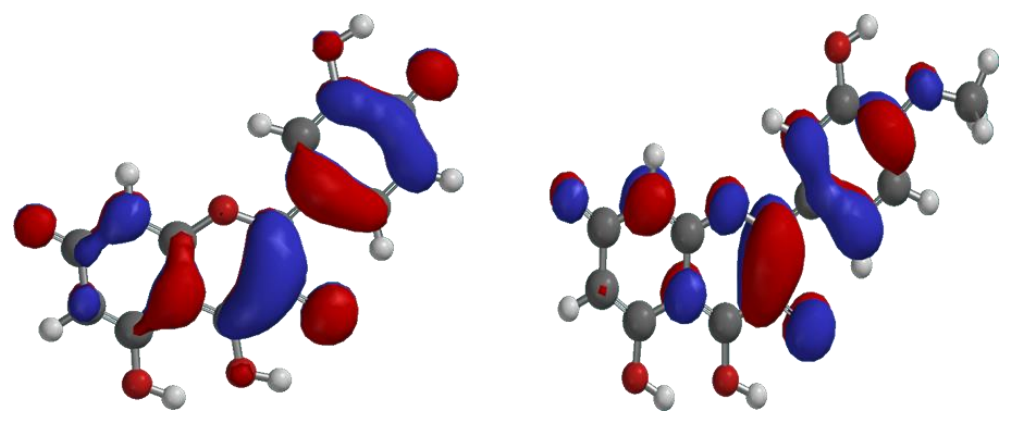

Supplemental figure. Delocalization of the LUMO of oxQ $\left(T_{3}\right)$ and ox4'MQ $\left(T_{3}\right)$. Left is the LUMO of oxQ and right is the LUMO of ox4'MQ. The LUMO of ox4'MQ is less delocalized than that of oxQ, which corresponds to the harder character of ox4'MQ compared to ox $Q$.<smiles></smiles><smiles>COc1cc(O)cc2c1C(=O)[C@@](O)(C(=O)c1ccc(O)c(O)c1)O2</smiles><smiles>O=C1C=CC(=C2Oc3cc(O)cc(O)c3C(=O)C2(O)O)C=C1O</smiles>

A<smiles>O=C1c2c(O)cc(O)cc2O[C@@]2(c3ccc(O)c(O)c3)O[C@]12O</smiles>

Supplemental scheme. Proposed reaction mechanism of ox $Q$ with water. The formation of product $\boldsymbol{A}$ is driven by the hard-hard interaction suggested by the $H S A B$ concept that is immediately followed by the restoration of the aromaticity of the A-ring. The formation of product $\boldsymbol{B} *$ is driven by the restoration of the aromaticity of the B-ring. The formation of product $\boldsymbol{C}$ is a Favorskii rearrangement, driven by the release of tension caused by the epoxy-group. Note that of product $\boldsymbol{B}$ and $\boldsymbol{C}$, only one isomer of the two possible isomers is shown. It is expected that both isomers are equally formed.

* Previously, an epoxy compound similar to that of $\mathbf{B}$ has been isolated and fully characterized when $\mathbf{Q}$ was oxidized under aprotic conditions [1]. 
In the incubations with GSH the amount of mono-GSH adducts formed equaled the amount of quercetin consumed. In the incubations with ascorbate, no net consumption of quercetin was observed. Apparently the reaction of ox $\boldsymbol{Q}$ with either GSH or ascorbate is much quicker than the reaction of oxQ with water. The reaction of the ox $Q$ with water can be neglected when either GSH or ascorbate is present.

Supplemental table. ${ }^{1} \mathrm{H}$-NMR signal assignment of the oxidation product $\boldsymbol{C}$ in DMSO-d6. Our data is compared to earlier reported ${ }^{1} \mathrm{H}-\mathrm{NMR}$ data for $\mathrm{C}$ in $\mathrm{DMSO}_{-} \mathrm{d}_{6}[2]$.

\begin{tabular}{|c|c|c|c|c|c|}
\hline Proton & 6-H & $8-\mathrm{H}$ & 2'-H & 5'-H & 6'-H \\
\hline OxQ (C) & $\begin{array}{l}5.96(\mathrm{~d}, \\
1.8 \mathrm{~Hz})\end{array}$ & $\begin{array}{l}5.90(\mathrm{~d}, \\
1.8 \mathrm{~Hz})\end{array}$ & $7.56(b)$ & $\begin{array}{l}6.80(\mathrm{~d}, \\
8.1 \mathrm{~Hz})\end{array}$ & $\begin{array}{l}7.54 \\
\text { (bm) }\end{array}$ \\
\hline $\begin{array}{l}\text { OxQ (C, } \\
\text { lit.) [2] }\end{array}$ & $\begin{array}{l}5.96(\mathrm{~d}, \\
1.7 \mathrm{~Hz})\end{array}$ & $\begin{array}{l}5.90(\mathrm{~d}, \\
1.7 \mathrm{~Hz})\end{array}$ & $\begin{array}{l}7.56(\mathrm{~d}, \\
2.0 \mathrm{~Hz})\end{array}$ & $\begin{array}{l}6.80(\mathrm{~d}, \\
8.2 \mathrm{~Hz})\end{array}$ & $\begin{array}{l}7.53 \\
\text { (dd) }\end{array}$ \\
\hline
\end{tabular}

\section{Supplemental references}

1. Schreier, P.; Miller, E. Studies on Flavonol Degradation by Peroxidase (Donor: $\mathrm{H}_{2} \mathrm{O}_{2}$-oxidoreductase, EC 1.11.1.7): Part 2-Quercetin. Food Chem. 1985, 18, 301-317.

2. Jorgensen, L. V.; Cornett, C.; Justesen, U.; Skibsted, L. H.; Dragsted, L. O. Two-electron electrochemical oxidation of quercetin and kaempferol changes only the flavonoid C-ring. Free Radic. Res. 1998, 29, 339-350. 

Summary 


\section{Summary}

\section{Summary}

An important principle in toxicology is that the risk of a compound depends on its hazard and its exposure. For humans, the highest exposure comes from air with molecular oxygen as the culprit. The hazard of molecular oxygen partly arises from its diradical $\left(\mathrm{O}_{2}^{2}{ }^{\bullet}\right)$ nature. It can be fairly deduced that the hazard in combination with the high exposure makes oxygen by far the greatest risk to humans. Unfortunately, reducing exposure is not an option because $\mathrm{O}_{2}{ }^{2} \bullet$ is, paradoxically, the most important substance for sustaining human life. In the body, its vital function is to release energy from food resulting in the conversion of oxygen into water. Another paradox is that in its vital function, oxygen toxicity is also promoted. This is due to the formation of several types of reactive oxygen species (ROS) as byproducts. These ROS are even more hazardous than oxygen and are thought to actually initiate oxygen toxicity. It is well known that ROS can cause oxidative stress in vivo and severely damage tissues. Fortunately, the body is endowed with an intricate network of anti-oxidants that provide protection against ROS. The anti-oxidants derived from food form a pivotal part of this protection.

In this thesis, the focus is put on free radical scavenging anti-oxidants. As elaborated in this thesis, a free radical scavenger functions as a catalyst that channels the dangerous reactivity of ROS safely into the anti-oxidant network of the body. From this definition, three important criteria have been deduced that make up a good scavenging anti-oxidant: (i) the anti-oxidant should be able to react relatively fast with radicals, (ii) it should form a relatively stable product when it has neutralized a ROS and finally (iii) the oxidized anti-oxidant should be safely regenerated in the anti-oxidant network of the body.

Quercetin $(\mathbf{Q})$, which is the most prominent anti-oxidant found in the Western diet (Figure 1), and its methylated derivatives have been chosen as anti-oxidant models for our research. Our aim is to identify the structural elements that are important for an anti-oxidant to fulfill the three criteria mentioned above. This will help to elucidate the biological effect of $\mathbf{Q}$ and will provide a rational for the 
use of this anti-oxidant and/or its methylated derivatives. The final goal is to rationally design more potent anti-oxidants that can combat oxygen toxicity.<smiles></smiles>

Figure 1. The chemical structure of quercetin with the numbering of the carbon atoms and the rings $A, C$ and $B$ indicated.

Chapter 1 reviews the metabolism of $\mathbf{Q}$ and gives an inventory of its known metabolites. $\mathbf{Q}$ is extensively metabolized in vivo and is mainly found as metabolites. This is shifting the focus on the anti-oxidant research to the metabolites of $\mathbf{Q}$, because these metabolites might actually be responsible for the health benefits associated with $\mathbf{Q}$ intake. The initial routes of metabolism appear to be $O$-glucuronidation, $O$-methylation and $O$-sulfation. Especially the methylated metabolites are of interest because of their relatively low toxicity, relatively high metabolic stability and improved absorption in vivo when compared to $\mathbf{Q}$.

In Chapter 2, we have developed a refined method for the $O$-methylation of $\mathbf{Q}$ using micro-reactor technology. The micro-reactor consists of a flow system in which the reactants are mixed in a highly controlled and well-defined microreactor. The advantage of this system is the reproducibility and the relatively high purity that can be achieved. Additionally, larger quantities can be produced with relative ease by up-scaling to a "Kilo-Flow".

In Chapter 3, the anti-oxidant capacity of $\mathbf{Q}$ and its methylated derivatives were established. The electron donating effect of the hydroxyl groups and the relatively planar structure of $\mathbf{Q}$ has been shown to be the main structural element 


\section{Summary}

responsible for its high anti-oxidant capacity. The planar conformation enables the distribution of the electron donating effect through the large conjugated $\pi$ system over the entire molecule. This is essential for the cooperation of the electron donors located in the AC-ring with those located in the B-ring of $\mathbf{Q}$. The mono-methylated derivatives of $\mathbf{Q}$ also demonstrate relatively high anti-oxidant capacity, which is influenced by the position of methylation. The monomethylated derivative with the lowest anti-oxidant capacity, tamarixetin, still has twice the anti-oxidant capacity of ascorbate. This indicates that the methylated metabolites of $\mathbf{Q}$ possess sufficient anti-oxidant capacity to exert health effects in vivo.

In Chapter 4, we have used electron spin resonance (ESR) spectroscopy to investigate the structures of the radicals of $\mathbf{Q}\left(\mathbf{Q}^{*}\right)$ and its methylated metabolites. The delocalization of the unpaired electron (UE) in $\mathbf{Q}^{\bullet}$ is responsible for its relatively low reactivity that is crucial in the anti-oxidant activity. Our findings demonstrate that the $\mathbf{U E}$ is primarily delocalized in the Bring of $\mathbf{Q}^{\bullet}$ (Figure 2). This is because the oxygen atoms in the B-ring (i.e. 3'O and 4'O) and the $\mathrm{AC}_{\mathrm{Q}}$-ring have an electron donating effect that stabilizes the electron deficient $\pi$-system in the B-ring of $\mathbf{Q}^{*}$. Our findings also demonstrate that an un-substituted $\mathrm{OH}$ group at the $\mathrm{C} 3$ position in the $\mathrm{C}$-ring is essential for the electron donating effect of the $\mathrm{AC}_{\mathrm{Q}}$-ring. The conclusion is that one of the main reasons for Q's exceptional anti-oxidant activity is the ability of its radical (i.e. $\left.\mathbf{Q}^{\bullet}\right)$ to safely cage and stabilize the $\mathbf{U E}$ in the conjugated $\pi$-system of its Bring. 


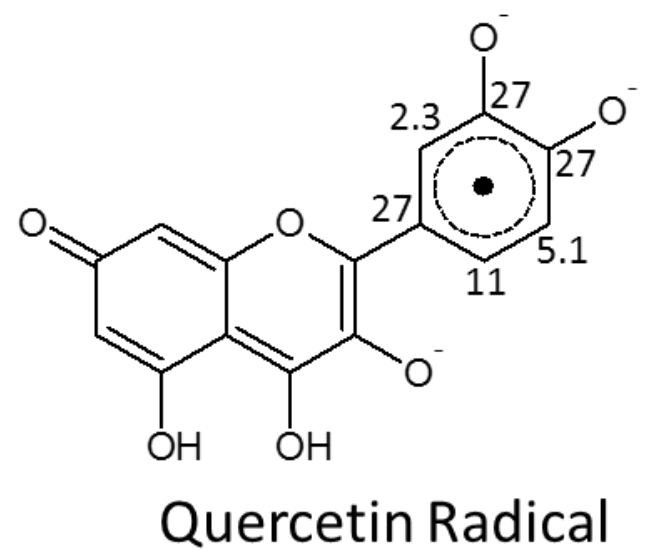

Figure 2. Simplified structure of the quercetin radical, with the spin-distribution (\%) calculated by O'Connell's equation from the hyperfine couplings of its ESR spectrum.

In Chapter 5, we have investigated which of the two pharmacophores, i.e. the AC-ring or the B-ring, of $\mathbf{Q}$ is prone to donate an electron to reactive species, by studying peroxynitrite (PON) scavenging. Our findings corroborate previous studies that both the AC-and the B-ring are potent PON scavengers on their own. In addition, quantum molecular calculations illustrate that the highest occupied molecular orbital (HOMO) is mostly concentrated on the AC-ring of Q, specifically on the C2 position (Figure 3). The HOMO is the molecular orbital that is most likely to donate electrons to a free radical. The electron donation, through resonance effect, of the $3 \mathrm{OH}$ of $\mathbf{Q}$ is the main reason for the high concentration of the HOMO at the $\mathrm{C} 2$ position. In addition, the oxygens at the 5 and the 7 position of $\mathbf{Q}$ activate the $3 \mathrm{OH}$ via the carbonylgroup at the 4 position through resonance effect. This further increases the HOMO concentration at the $\mathrm{C} 2$ of $\mathbf{Q}$. So, the AC-ring of $\mathbf{Q}$ is most likely to donate the first electron. 


\section{Summary}

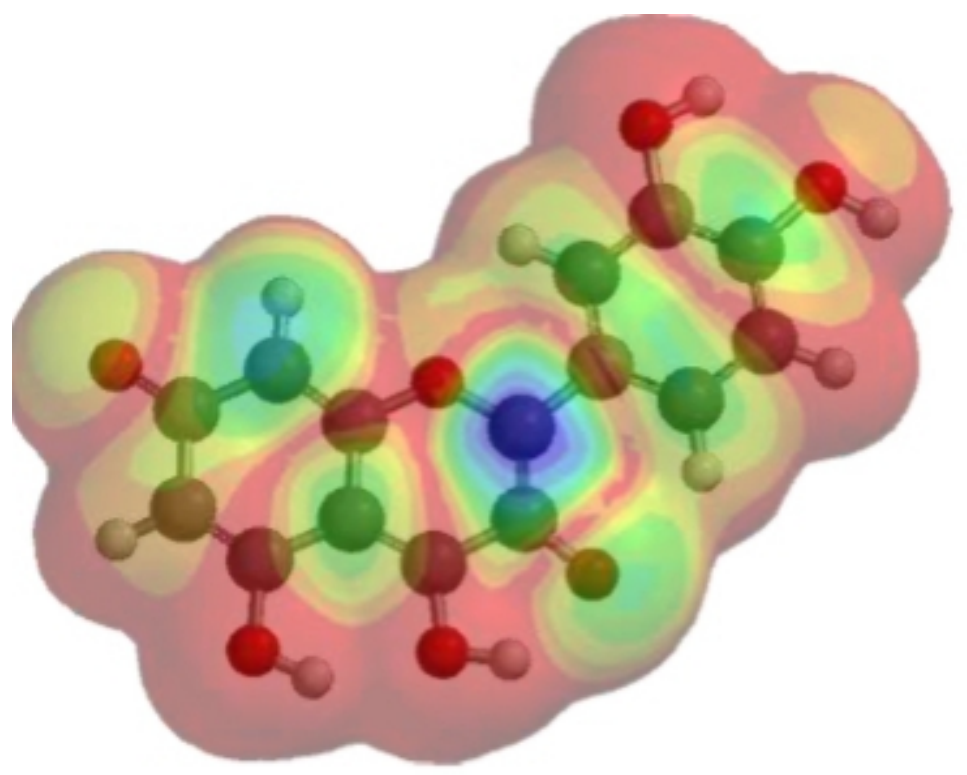

Figure 3. HOMO map, generated with ab initio calculations in Spartan '10, on the activated form of $\boldsymbol{Q}$. Blue indicates a high concentration of the HOMO, and red indicates the lowest concentration.

After the first electron donation to a free radical from the $\mathrm{C} 2$ of $\mathbf{Q}$, the $\mathbf{U E}$ should be located on the AC-ring of $\mathbf{Q}^{\bullet}$ at its C2 position (Figure 4). However, the ESR spectrum of $\mathbf{Q}^{\bullet}$ (Chapter 4) clearly indicates that the $\mathbf{U E}$ is primarily in the B-ring. To resolve this contradiction, i.e. that the $\mathbf{U E}$ is formed in the ACring and subsequently stabilized in the B-ring, we postulate that the B-ring intramolecularly scavenges the AC-ring of $\mathbf{Q}^{\bullet}$ to safely cage the $\mathbf{U E}$ in the conjugated $\pi$-system of its B-ring. This means that the electron richness of the AC-ring is restored, enabling it to donate another electron to a second free radical. After the donation of the second electron, a quinone methide is formed that can be processed in the anti-oxidant network of the body. 


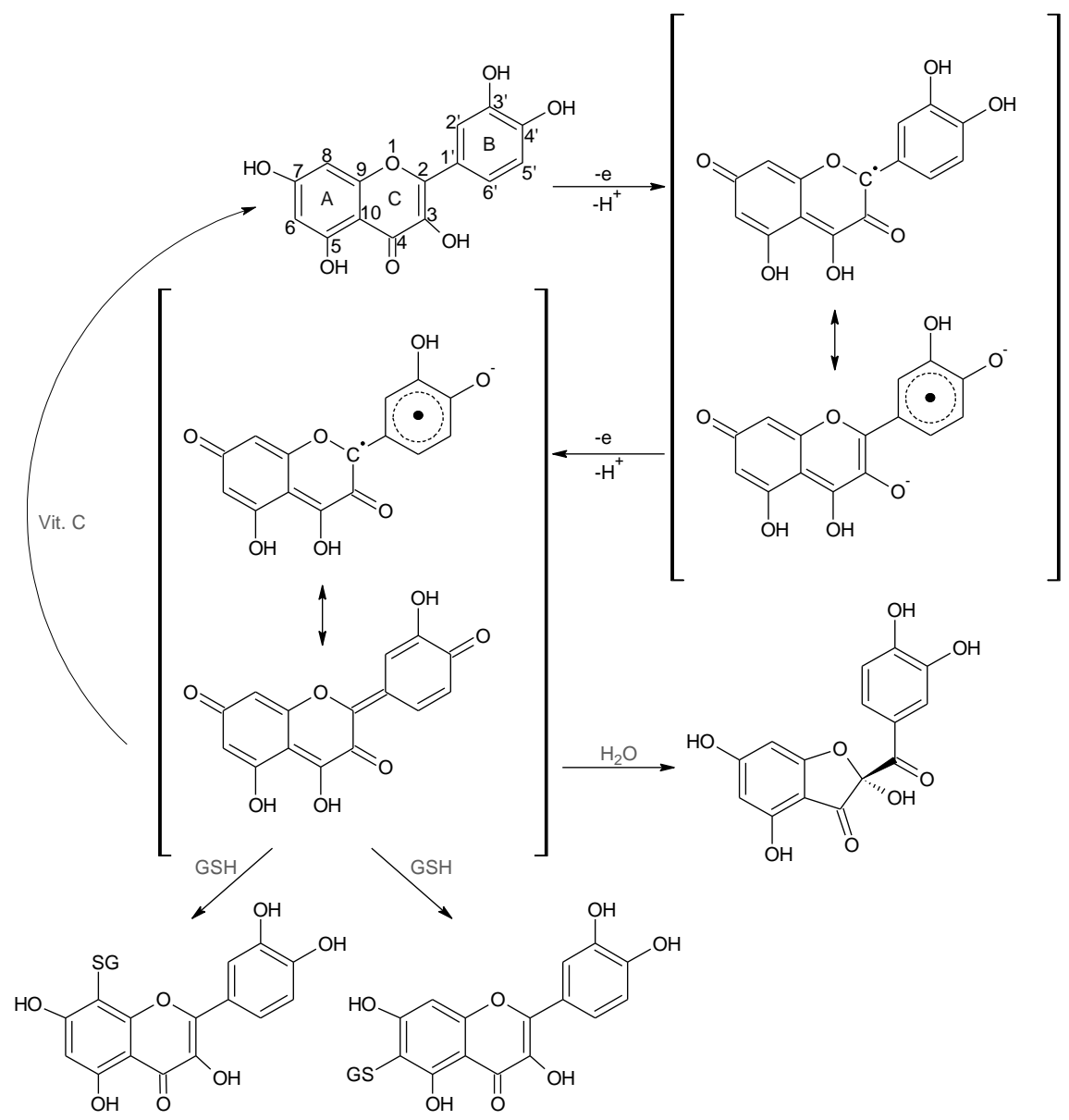

Figure 4. Schematic representation of the different steps involved in the antioxidant mechanism of $\boldsymbol{Q}$.

In Chapter 6, the interaction between the anti-oxidant network and the quinones of $\mathbf{Q}$ and its methylated metabolites are described. We have illustrated three main pathways that the quinone methide of $\mathbf{Q}(\mathbf{o x} \mathbf{Q})$ can undergo in Figure 4 ; i) $\mathbf{o x Q}$ can react with water, ii) oxQ can react with GSH to form GSH-adducts and iii) $\mathbf{o x} \mathbf{Q}$ can be regenerated to $\mathbf{Q}$ by ascorbate. In corroboration with previous studies, our findings also demonstrate that oxQ reacts much faster with thiols such as GSH than with ascorbate. This relatively high thiol reactivity of oxQ can 


\section{Summary}

be disadvantageous in vivo because it can impair the function of vital thiolcontaining proteins. To circumvent thiol toxicity, our strategy was to identify $\mathbf{Q}$ derivatives that would rather react with ascorbate than with thiols. An additional advantage of the reaction with ascorbate is that the parent flavonoid is recycled, which enhances the overall anti-oxidant activity of the flavonoid. Oxidized ascorbate can easily be regenerated in vivo by dehydroascorbate reductase, with nicotinamide adenine dinucleotide (NADH) as a cofactor, completing the antioxidant cycle.

We have found that the most effective derivative was tamarixetin, 4'Omethylquercetin (4'MQ), that has a corresponding oxidation product (ox4'MQ) with thiol reactivity 350 times lower than oxQ. This indicates that the endogenous metabolism of $\mathbf{Q}$ to 4'MQ might actually be a physiological way to safely benefit from the potential of $\mathbf{Q}$. 
Conclusions and implications 


\section{Conclusions and implications}

\section{Conclusions}

In this thesis, the focus is put on free radical scavenging anti-oxidants and three important criteria have been deduced that make up a good scavenging antioxidant: (i) the anti-oxidant should be able to react relatively fast with radicals, (ii) it should form a relatively stable product when it has neutralized a ROS and finally (iii) the oxidized anti-oxidant should be safely regenerated in the antioxidant network of the body. We have determined the effect of monomethylation of $\mathbf{Q}$ on each of the three important criteria. More specifically, we have elucidated which structural elements are pivotal in each of the three criteria involved in the mode of action of $\mathbf{Q}$.

\section{First criteria}

Our findings indicate that the AC-ring of $\mathbf{Q}$ is prone to donate the first electron to free radicals. This is because the conjugated $\pi$-system of the AC-ring can focus the electron density, donated by the hydroxyl groups, through resonance effect on one carbon (i.e. C2). This leads to a relatively high concentration of the HOMO, the molecular orbital that is most likely to donate electrons to a free radical, on the $\mathrm{C} 2$ position. So, for the first criteria it is important to have electron donors, as many as possible, that have a $\pi-\pi$ interaction with a conjugated $\pi$-system that can concentrate the donated electron density on a single carbon. In other words, a relatively high and concentrated HOMO energy is needed for an anti-oxidant to rapidly react with free radicals.

\section{Second criteria}

Once the AC-ring of $\mathbf{Q}$ donates the first electron from the $\mathrm{C} 2$ position, it becomes a radical that has an $\mathbf{U E}$ on the $\mathrm{C} 2$ position. The $\mathbf{U E}$ is transferred to the B-ring by an internal scavenging reaction. The scavenging potential of the Bring is mostly due to the oxygen at the 4' position, and its conjugated $\pi$-system that can concentrate the donated electron density on $\mathrm{C} 1$ '. It is important to note that $\mathrm{C}^{\prime}$ ' is adjacent to the $\mathbf{U E}$ on $\mathrm{C} 2$, leading to a relatively fast scavenging reaction. In addition, the $\mathbf{U E}$ can be stabilized in the conjugated $\pi$-system of the 


\section{Conclusions and implications}

B-ring by the electron donors, i.e. AC-ring and the oxygens at 3' and 4' position, in $\mathbf{Q}^{*}$. So, for the second criteria it is important to have a conjugated $\pi$-system that can delocalize the UE plus an ortho and/or para positioned electron donors that can compensate for the electron deficiency of the $\pi$-system.

\section{Third criteria}

Once the $\mathbf{U E}$ is safely caged in the B-ring of $\mathbf{Q}^{*}$, the electron richness of the ACring is restored, thus enabling it to donate another electron to a second free radical. After the donation of the second electron, the $\mathbf{U E}$ on the $\mathrm{C} 2$ position and the $\mathbf{U E}$ in the B-ring can pair, leading to a quinone methide (oxQ) that can impair the function of vital thiol-containing proteins. There are two important anti-oxidants, i.e. GSH and ascorbate, in the anti-oxidant network that can protect against quinone toxicity. These two anti-oxidants prevent quinone toxicity in different ways; ascorbate converts quinones back to the parent flavonoid, whereas GSH reacts with quinones to form a GSH-flavonoid adduct. However, GSH might only offer partial protection since GSH-Q adducts rapidly react with protein-thiols at physiological conditions, hence, spreading the toxicity over the cells. So, for the third criteria it is important that the oxidized form of the tested anti-oxidant should prefer ascorbate over thiols. We have seen that the lowest unoccupied molecular orbital (LUMO) of the oxidized form of the flavonoid could be used as an indicator for their ascorbate preference. Our findings demonstrate that the oxidized form of tamarixetin, i.e. ox4'MQ, has the highest LUMO energy of the mono-methylated derivatives, leading to the highest preference for ascorbate. The thiol reactivity of ox4'MQ is actually 350 times lower than oxQ. So, for the third criteria $\mathbf{Q}$ should be $O$-methylated at the 4' position, leading to an increase in LUMO of the corresponding quinone methide.

In conclusion, our study shows that $O$-methylation at the 4' position of $\mathbf{Q}$ seems to be the most effective way of decreasing the negative effects of $\mathbf{Q}$ while still retaining enough of the anti-oxidant potency. The anti-oxidant potency of 4'MQ is around two times lower than that of $\mathbf{Q}$ (Chapter $3 \& 5$ ) but still much higher 


\section{Conclusions and implications}

than common anti-oxidants such as ascorbate and vitamin E. Additional advantage of 4'MQ over $\mathbf{Q}$ is that the cellular uptake is higher, which can compensate for the relative low potency of 4'MQ.

\section{Implications}

The anti-oxidant mechanism described in this thesis forms the fundament for explaining and predicting the health promoting effect of $\mathbf{Q}$ and structurally related compounds. This knowledge may also lead to the development of a new class of anti-oxidants that may strengthen our arsenal against oxygen toxicity. Future research should be directed to test the knowledge gained in this thesis on more complex systems, and eventually in humans. 
Samenvatting 


\section{Samenvatting}

\section{Samenvatting}

Toxicologie is gebaseerd op het principe dat het risico van een stof is gecorreleerd aan zijn intrinsieke giftigheid en blootstelling. Mensen ervaren een levenslange blootstelling aan zuurstof, die een intrinsieke giftigheid heeft omdat het in de natuur voorkomt als een reactieve diradicaal. Helaas kan de blootstelling aan zuurstof niet verminderd worden, omdat het essentieel is voor het menselijke leven. In het lichaam wordt de reactiviteit van zuurstof gebruikt om energie vrij te maken vanuit de voeding. In dit proces, worden reactieve zuurstof soorten (reactive oxygen species [ROS]) gevormd als bijproducten. Deze bijproducten kunnen zelfs gevaarlijker zijn dan zuurstof. Het is algemeen bekend dat deze ROS kunnen leiden tot oxidatieve stress. De bescherming tegen ROS is in dat geval niet meer toereikend. Het gevolg is dat weefsels beschadigen. De bescherming van het lichaam tegen ROS bestaat uit een netwerk van anti-oxidanten die op een elegante manier kunnen samenwerken. Daarmee wordt het evenwicht in het lichaam bewaard. Het anti-oxidant netwerk van het lichaam kan versterkt worden door anti-oxidanten die opgenomen worden uit de voeding.

In dit proefschrift wordt de nadruk gelegd op anti-oxidanten die vrije radicalen onschadelijk maken door er direct mee te reageren. In dit proefschrift wordt een anti-oxidant gepositioneerd als een stof die de gevaarlijke reactiviteit van ROS veilig in het anti-oxidant netwerk van het lichaam kan leiden. Vanuit deze definitie zijn er drie belangrijke eisen voor een goede anti-oxidant afgeleid: (i) de anti-oxidant moet relatief snel kunnen reageren met radicalen, (ii) vervolgens moet de geoxideerde anti-oxidant een relatief stabiel product vormen, (iii) en uiteindelijk moet de geoxideerde anti-oxidant veilig geregenereerd kunnen worden in het anti-oxidant netwerk van het lichaam.

Quercetine $(\mathbf{Q})$ is één van de meest prominente anti-oxidant in het westerse dieet (Figure 1). Q en zijn gemethyleerde derivaten zijn gekozen als model voor ons onderzoek. Het doel van ons onderzoek was om de structuurelementen te identificeren die belangrijk zijn, om aan de drie eisen die boven gesteld zijn te voldoen. Dit, zo stelden wij, zal leiden tot meer inzicht in de biologische werking 
van $\mathbf{Q}$ en een rationaal geven voor het gebruiken van deze anti-oxidant en/of zijn methyl derivaten. Het ultieme doel is om rationeel anti-oxidanten te ontwikkelen die grotere potentie hebben, om het lichaam te beschermen tegen zuurstoftoxiciteit.<smiles>O=c1c(O)c(-c2c#cccc2)oc2cc(O)cc(O)c12</smiles>

Figuur 1. Chemische structuur van quercetine met de drie (A, $C$ en $B)$ ringen, en de nummering van de atomen in de drie ringen aangegeven.

Hoofdstuk $\mathbf{1}$ is een review over de metabolisme van $\mathbf{Q}$ en inventariseert reeds geïdentificeerde metabolieten. Uit de literatuur blijkt dat $\mathbf{Q}$ extensief gemetaboliseerd wordt en in vivo bijna volledig als metabolieten terug wordt gevonden. Het anti-oxidant onderzoek rondom $\mathbf{Q}$ is de laatste jaren verschoven naar zijn metabolieten vanwege het inzicht dat de metabolieten waarschijnlijk verantwoordelijk zijn voor de gezondheidseffecten die worden geassocieerd met inname van $\mathbf{Q}$. Metabolisme van $\mathbf{Q}$ lijkt te beginnen met $O$-glucuronidering, $O$ methylering en $O$-sulfatering. Vooral de gemethyleerde metabolieten zijn interessant omdat ze een relatief lage toxiciteit, een hoge metabole inertie en een verbeterde absorptie vertonen in vitro in vergelijking met $\mathbf{Q}$.

In Hoofdstuk 2 hebben we een elegante methode ontwikkeld voor de Omethylering van $\mathbf{Q}$ m.b.v. micro-reactor technologie. De technologie bestaat uit een "flow" systeem, en de reactanten worden gemengd in de zeer gecontroleerde en goed gedefinieerde micro-reactor omgeving. De voordelen van zo'n systeem blijken de reproduceerbaarheid en de relatief hoge zuiverheden die bereikt 


\section{Samenvatting}

kunnen worden. Verder kunnen relatief grote hoeveelheden geproduceerd worden, omdat de procedure met gemak te vertalen is naar een "Kilo-Flow".

In Hoofdstuk 3 zijn de anti-oxidant capaciteiten van $\mathbf{Q}$ en zijn methylderivaten vast gelegd. Het elektrondonerende effect van de hydroxylgroepen en de relatief vlakke structuur van $\mathbf{Q}$ blijken de belangrijkste structuurelementen te zijn voor zijn hoge anti-oxidant capaciteit. Door de vlakke structuur kunnen de gedoneerde elektronen, via het relatief grote geconjugeerde $\pi$-systeem, over het hele molecuul verspreid worden. Dit is essentieel voor de samenwerking tussen de elektrondonoren in de AC-ring en de elektrondonoren in de B-ring. De mono gemethyleerde derivaten van $\mathbf{Q}$ blijken nog steeds een groot gedeelte van de antioxidant capaciteit te bezitten. De positie van methylgroep in het molecuul is in dit verband van belang. Het mono gemethyleerde derivaat met de laagste capaciteit is tamarixetine. Deze stof blijkt nog altijd twee keer meer anti-oxidant capaciteit te hebben dan vitamine C. Dit geeft aan dat de gemethyleerde metabolieten van $\mathbf{Q}$ nog steeds genoeg anti-oxidant capaciteit hebben om in vivo werkzaam te zijn.

In Hoofdstuk 4 hebben we de elektronspinresonantie (ESR) techniek gebruikt om de structuur van de radicalen van $\mathbf{Q}\left(\mathbf{Q}^{*}\right)$ en zijn gemethyleerde metabolieten te bestuderen. Delokalisatie van het ongepaarde elektron in $\mathbf{Q}^{*}$ is verantwoordelijk voor zijn relatief lage reactiviteit, die cruciaal is voor de antioxidant activiteit. Onze bevinding tonen aan dat het ongepaarde elektron hoofdzakelijk gedelokaliseerd is in de B-ring van $\mathbf{Q}^{\bullet}$ (Figure 2). Dit komt door het elektrondonerend effect van de zuurstof atomen in de B-ring (i.e. 3'O en 4'O) en de AC-ring, die stabiliserend werken op het elektrondeficiënte $\pi$-systeem in de B-ring van $\mathbf{Q}^{*}$. Voor het elektrondonerende effect van de AC-ring is vooral een niet-gesubstitueerde $\mathrm{OH}$ groep op de $\mathrm{C} 3$ positie in de C-ring essentieel. Dus een van de belangrijkste redenen voor de hoge anti-oxidant activiteit van $\mathbf{Q}$ is; het vermogen van zijn radicaal $\left(\mathbf{Q}^{*}\right)$ om het ongepaarde elektron veilig op te vangen en te stabiliseren in het geconjugeerde $\pi$-systeem van de B-ring. 


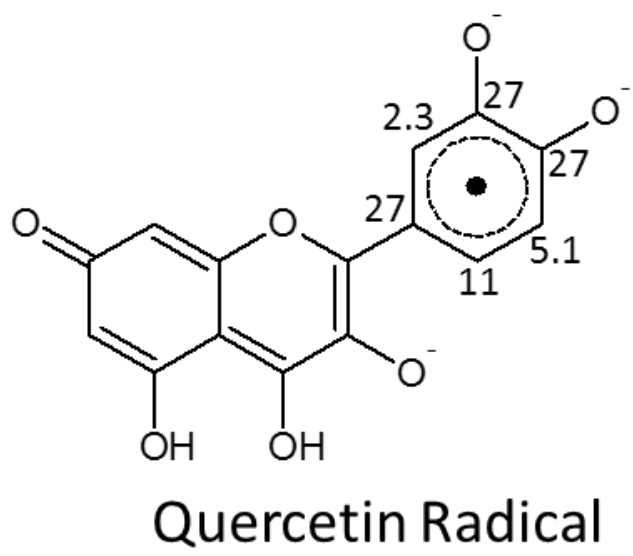

Figure 2. De structuur van het quercetine radicaal met de relatieve spinverdeling (\%) die afgeleid zijn van de hyperfijne koppelingen van zijn ESR spectrum.

In Hoofdstuk 5 hebben we onderzocht welke van de twee farmacoforen, de ACof de B-ring, van $\mathbf{Q}$ meer neigen naar de elektrondonering. Dit hebben we onderzocht door gebruik te maken van de peroxynitriet assay. In deze assay wordt de snelheid gemeten waarmee anti-oxidanten met peroxynitriet reageren. Onze resultaten geven aan dat beide ringen, $\mathrm{AC}$ - en B-ring, van $\mathbf{Q}$ direct bescherming kunnen geven tegen peroxynitriet. Uit quantum moleculaire berekeningen blijkt dat de hoogste bezette moleculaire orbitaal, de HOMO, vooral is geconcentreerd op de C2 positie in de AC-ring van $\mathbf{Q}$ (Fig. 3). De HOMO is de orbitaal die als eerste een elektron doneert. De elektrondonering van de $3 \mathrm{OH}$ van $\mathbf{Q}$ is hoofdzakelijk verantwoordelijk voor de hoge concentratie van de HOMO op de C2 positie. Dit komt door het resonantie effect. Daarnaast kunnen de $5 \mathrm{OH}$ en de $7 \mathrm{OH}$ van $\mathbf{Q}$, door resonantie, activerend werken op de $3 \mathrm{OH}$ via de carbonylgroep op de 4 positie. Dit leidt ook tot een verhoging van de HOMO concentratie op de C2. Het lijkt er dus op dat de AC-ring van $\mathbf{Q}$ meer geneigd is om het eerste elektron te doneren. 


\section{Samenvatting}

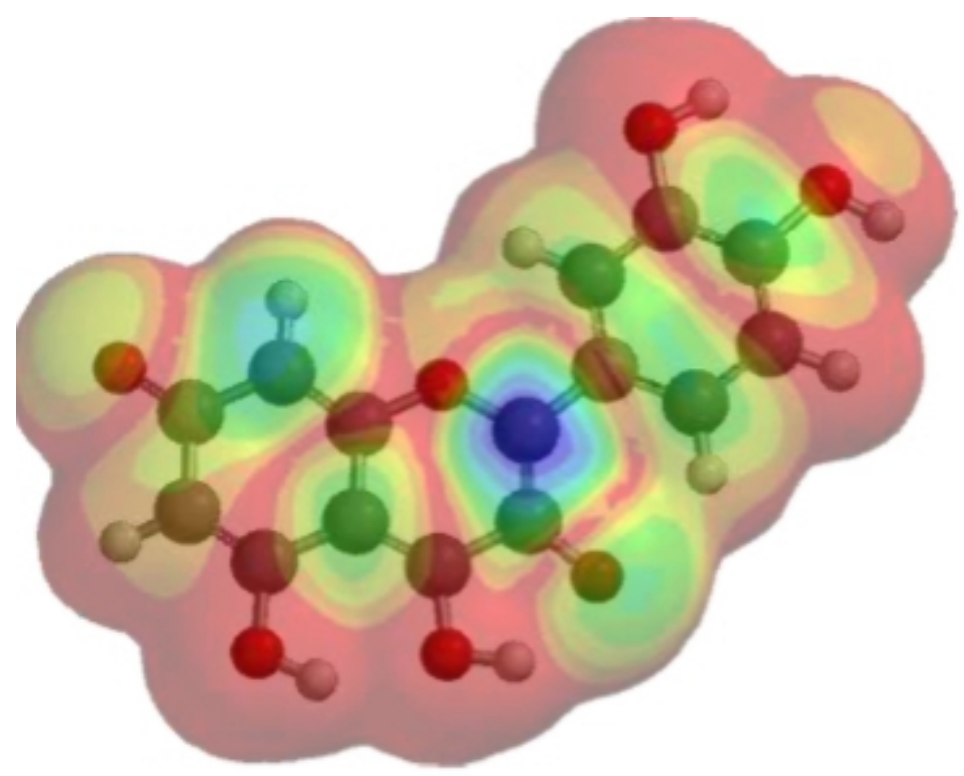

Figuur 3. De HOMO verdeling op de geactiveerde vorm van $\boldsymbol{Q}$ die gemaakt is met quantum moleculaire berekeningen in Spartan '10. Hoogste concentratie van de HOMO wordt aangegeven met blauw kleur, en laagste concentratie wordt aangegeven met rood.

$\mathrm{Na}$ het doneren van het eerste elektron vanuit de $\mathrm{C} 2$ van $\mathbf{Q}$ zou het ongepaarde elektron op de C2 van $\mathbf{Q}^{\bullet}$ moeten zitten (Figure 4). Het ESR spectrum van $\mathbf{Q}^{\bullet}$ (Hoofdstuk 4) laat echter duidelijk zien dat het ongepaarde elektron hoofdzakelijk te vinden is in de B-ring en niet in de AC-ring. Om deze paradox op te lossen postuleren we dat de B-ring van $\mathbf{Q}^{*}$, intra-moleculair, een elektron doneert aan de AC-ring om zo het ongepaarde elektron veilig op te vangen in zijn geconjugeerde $\pi$-systeem. Als gevolg wordt de potentie van de AC-ring van $\mathbf{Q}^{\bullet}$ hersteld, en kan de AC-ring nog een elektron doneren. Na het doneren van het tweede elektron, wordt er een quinone methide gevormd die vervolgens verwerkt kan worden in het anti-oxidant netwerk van het lichaam. 


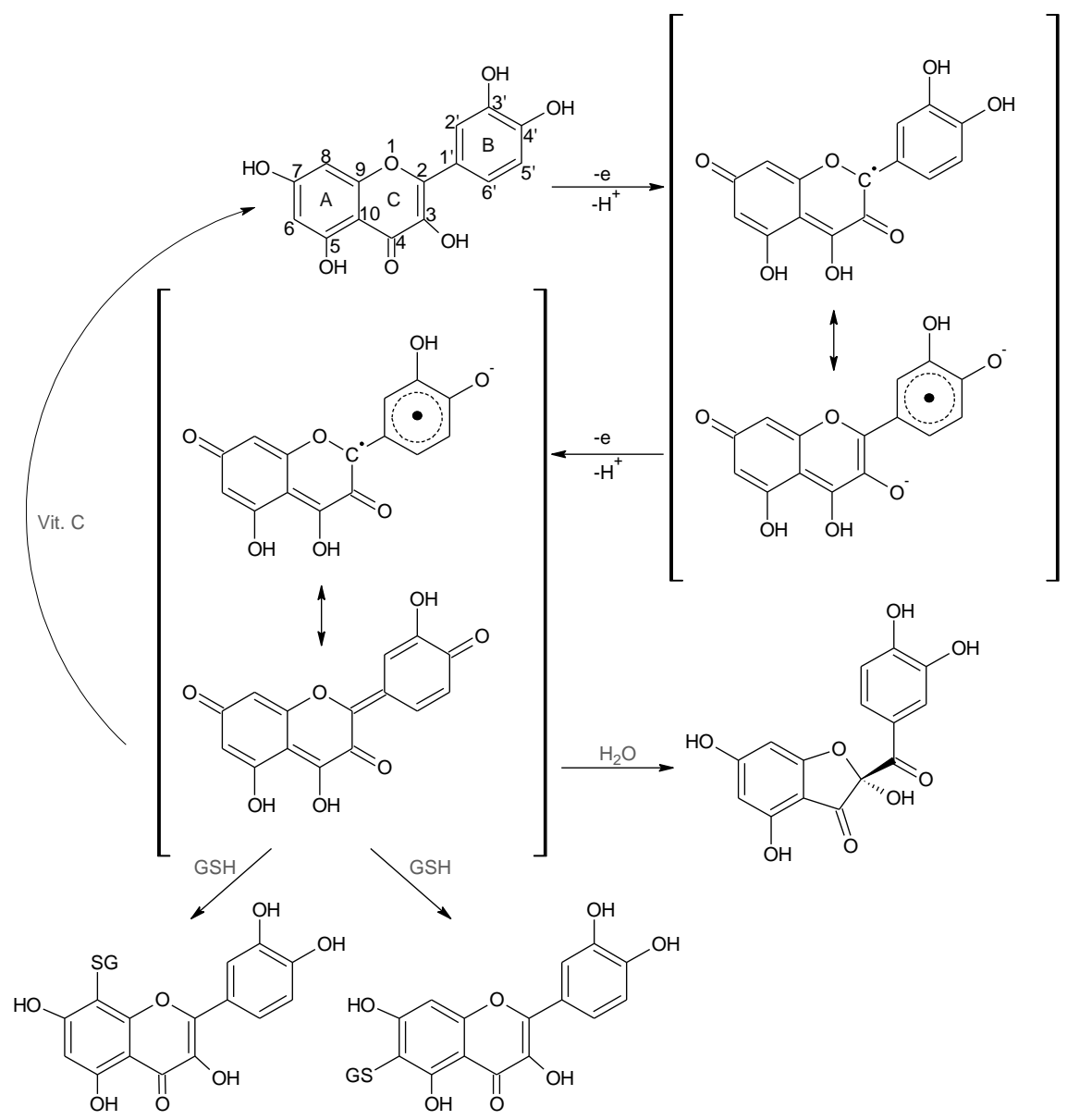

Figuur 4. Schematische weergave van de verschillende stappen die betrokken zijn in het anti-oxidant mechanisme van quercetine.

In Hoofdstuk 6 wordt de interactie tussen het anti-oxidant netwerk en de quinonen van $\mathbf{Q}$ en zijn gemethyleerde metabolieten beschreven. We hebben in figuur 4 de drie belangrijkste reacties geïllustreerd, die een quinone methide van $\mathbf{Q}(\mathbf{o x Q})$ kan ondergaan; i) oxQ kan reageren met water, ii) oxQ kan reageren met GSH om een GSH-adduct te vormen en iii) oxQ kan geregenereerd worden naar $\mathbf{Q}$ door vitamine C. Onze resultaten tonen aan dat $\mathbf{0 x Q}$ veel sneller reageert met thiolen dan met vitamine C. De relatief hoge thiol reactiviteit van oxQ kan 


\section{Samenvatting}

nadelig zijn in vivo omdat het de werking van essentiële thiol-houdende eiwitten kan belemmeren. Om de thiol toxiciteit te voorkomen, was onze strategie om $\mathbf{Q}$ derivaten te identificeren die sneller met vitamine $\mathrm{C}$ reageren dan met thiolen. Een extra voordeel van de reactie met vitamine $\mathrm{C}$ is dat het flavonoid gerecycled wordt, hetgeen leidt tot een versterking van de anti-oxidant activiteit van het flavonoid. Verder kan het geoxideerde vitamine $\mathrm{C}$ geregenereerd worden in vivo met het enzym dehydroascorbate reductase (DHR) die nicotinamide adenine dinucleotide (NADH) gebruikt als cofactor. Dit leidt tot een complete en zelfherstellende anti-oxidant cyclus.

Tamarixetine, 4'O-methylquercetin (4'MQ), bleek de meest effectieve derivaat te zijn met een oxidatie product (ox4'MQ) die 350 keer lager thiol reactiviteit vertoont dan oxQ. Waarschijnlijk is de endogene metabolisme van $\mathbf{Q}$ naar 4'MQ een fysiologische manier om veilig gebruik te maken van de potentie van $\mathbf{Q}$. 


\section{Conclusie en relevantie}




\section{Conclusie en relevantie}

\section{Conclusie}

In dit proefschrift ligt de nadruk op anti-oxidanten die vrije radicalen onschadelijk maken door er direct mee te reageren. Een anti-oxidant wordt gepositioneerd als een stof die de gevaarlijke reactiviteit van ROS veilig in het anti-oxidant netwerk van het lichaam kan leiden. Vanuit deze definitie zijn er drie belangrijke eisen voor een goede anti-oxidant afgeleid: (i) de anti-oxidant moet relatief snel kunnen reageren met radicalen, (ii) vervolgens moet de geoxideerde anti-oxidant een relatief stabiel product vormen, (iii) en uiteindelijk moet de geoxideerde anti-oxidant veilig geregenereerd kunnen worden in het anti-oxidant netwerk van het lichaam. We hebben de invloed van mono methylering van $\mathbf{Q}$ op elke van de drie eisen onderzocht, met het oog om de structuur elementen te identificeren die belangrijk zijn voor elke eis.

\section{Eerste eis}

Onze bevindingen geven aan dat de AC-ring van $\mathbf{Q}$ het meest geneigd is om het eerste elektron te doneren. Dat komt doordat het geconjugeerde $\pi$-systeem van de AC-ring, de elektronendichtheid gedoneerd door de hydroxylgroepen kan concentreren op één $\mathrm{C}$-atoom, namelijk de $\mathrm{C} 2$. Dit leidt tot een relatief hoge concentratie van de HOMO, het moleculaire orbitaal dat het makkelijkste elektronen kan doneren, op de C2. Dus voor de eerste eis is het belangrijk om zoveel mogelijke elektrondonoren te hebben, die een $\pi-\pi$ interactie hebben met een geconjugeerd $\pi$-systeem dat de elektronendichtheid kan concentreren op één $\mathrm{C}$-atoom in het molecuul. Met andere woorden, een anti-oxidant moet een relatieve hoog en geconcentreerd HOMO energie hebben om snel een elektron te kunnen doneren.

\section{Tweede eis}

$\mathrm{Na}$ het doneren van het eerste elektron door de AC-ring van $\mathbf{Q}$ via de $\mathrm{C} 2$ ontstaat er een radicaal met een ongepaarde elektron op de C2. Het ongepaarde elektron wordt direct opgevangen door de B-ring via intra-moleculaire elektrondonering. De potentie van de B-ring komt door de elektrondonering van de zuurstof op de 
4' positie, en het geconjugeerde $\pi$-systeem die de elektronendichtheid kan concentreren op de $\mathrm{C} 1$ '. Deze reactie is relatief snel omdat de $\mathrm{C} 1$ ' naast het ongepaarde elektron op de C2 staat. Vervolgens kan het ongepaarde elektron gestabiliseerd worden in het geconjugeerde $\pi$-systeem van de B-ring door de elektrondonoren (de AC-ring en de zuurstoffen op 3' en 4' positie) in $\mathbf{Q}^{*}$. Dus voor de tweede eis is het belangrijk om een geconjugeerd $\pi$-systeem te hebben dat het ongepaarde elektron kan delokaliseren, plus elektron donoren die op de ortho en/of para positie zitten om de verminderde elektronendichtheid in het $\pi$ systeem te compenseren.

\section{Derde eis}

Wanneer het ongepaarde elektron eenmaal veilig opgevangen is in het geconjugeerde $\pi$-systeem van de B-ring en de potentie van de AC-ring van $\mathbf{Q}^{\bullet}$ hersteld is, kan de AC-ring nog een elektron doneren. $\mathrm{Na}$ de donatie van het tweede elektron, ontstaat er een nieuwe ongepaard elektron op C2 in de AC-ring die snel combineert met het ongepaarde elektron in de B-ring. Dit leidt tot de vorming van een quinon methide (oxQ) die essentiële functies van thiolhoudende eiwitten kan belemmeren. Er zijn twee anti-oxidanten, GSH en vitamine $\mathrm{C}$, in het anti-oxidant netwerk die kunnen beschermen tegen quinon toxiciteit. Deze twee anti-oxidanten beschermen tegen quinon toxiciteit op verschillende manieren; vitamine $\mathrm{C}$ regenereert quinonen tot de originele flavonoïde, terwijl de reactie met GSH tot een GSH-flavonoïde adduct leidt. Echter, GSH-Q adducten kunnen nog steeds snel met eiwit thiolen reageren onder fysiologische condities, wat leidt tot de spreiding van de toxiciteit over de cellen. Dus voor de derde eis is het belangrijk dat de geoxideerde anti-oxidant sneller reageert met vitamine $\mathrm{C}$ dan met thiolen. Het blijkt dat de laagste niet bezette orbitaal, namelijk de LUMO, van geoxideerde flavonoïde als indicator gebruikt kan worden voor de neiging om met vitamine $\mathrm{C}$ te reageren. Onze bevindingen tonen aan dat geoxideerd tamarixetin (ox4'MQ) de hoogste LUMO energie van de mono gemethyleerde derivaten bevat, met als gevolg dat ox4'MQ het snelste met vitamine $\mathrm{C}$ reageert. Eigenlijk is de thiol reactiviteit van ox4'MQ 


\section{Conclusie en relevantie}

meer dan 350x lager dan oxQ. Dus voor de derde eis zou $\mathbf{Q}$ gemethyleerd moeten worden op de 4'O, wat zou leiden tot een verhoging van de LUMO energie van zijn quinone methide.

In conclusie, onze studie toont aan dat $O$-methylering op de 4' positie van $\mathbf{Q}$ de meest effectieve manier is om de negatieve effecten van $\mathbf{Q}$ te verminderen met behoud van genoeg anti-oxidant potentie. De anti-oxidant potentie van 4'MQ is ongeveer 2x lager dan die van $\mathbf{Q}$ (Hoofdstuk 3 \& 5), maar is nog steeds hoger dan bekende anti-oxidanten zoals vitamine $\mathrm{C}$ en vitamine $\mathrm{E}$. De hogere cellulaire opname van 4'MQ ten opzichte van $\mathbf{Q}$ kan de relatief lagere potentie van 4'MQ compenseren.

\section{Relevantie}

Het anti-oxidant mechanisme dat beschreven is in dit proefschrift vormt het fundament voor het verklaren en het voorspellen van de gezondheidseffecten van $\mathbf{Q}$ en zijn analogen. Dit kan leiden tot de ontwikkeling van een nieuwe klasse anti-oxidanten die ons arsenaal tegen zuurstof toxiciteit kunnen versterken. Toekomstig onderzoek zou gericht kunnen worden om de kennis die in dit proefschrift is vergaard te implementeren in complexere systemen, en uiteindelijk in de mens. 


\section{Acknowledgements}




\section{Acknowledgements}

\section{Acknowledgements}

All praises belong to Allah the sustainer of everything. It has been a great journey and I have always felt like a drop of water in an ocean full of blessings. I thank Allah for blessing me with great parents, great family, great mentors, great friends, great colleagues, strong faith, good health and the knowledge to finish this thesis.

Specifically for this thesis, I would like to express my gratitude for the support of my promotor Prof.dr. Aalt Bast, copromotors Dr. Guido RMM Haenen, Gino PF van Strijdonck, Dr. Geja Hageman and Prof.dr. Paul Borm.

Dear Aalt, I thank you for being my mentor and guiding me through this $\mathrm{PhD}$ with your kind and friendly smile. You had a way of turning every situation just a little bit better with the power of your smile. You started each meeting with a smile and ended each meeting with a smile. Not only on your face but also on ours. So here is a special thanks to your SMILE!

Dear Guido, I thank you for guiding me in a kind and friendly manner with every aspect of my $\mathrm{PhD}$. Your door was always open for me and you were always eager and enthusiastic to help me with your knowledge and wisdom. You taught me to think outside the box of chemistry. Your creativity is not only in your work but also in your jokes that are always rightly balanced. Without your jokes, my $\mathrm{PhD}$ project wouldn't have nearly been as much fun. So especial thanks to your JOKES!

Dear Gino, I thank you not only for guiding me through my $\mathrm{PhD}$ but also for getting me a job which is literally CHILL. You have exposed me to a work-place with many diversity and taught me to think outside the box of science. You have taught me to combine the innocence of science with the maturity of business. Watching you closely has showed me that even in business, it is always possible to find a win-win situation. So thank you for being such a CHILL guy!

Dear Geja, I thank you for being the first supervisor in Maastricht to take me under her care. You had the task of teaching a chemist on working extremely 
clean with cells, and you also taught me to be nurturing and have patience with "my" cells. This couldn't have been easy. So I thank you not only for your guidance but also for your patience.

Dear Paul, I thank you not only for motivating me in crucial moments in my $\mathrm{PhD}$ trajectory but also for teaching me there is life after $\mathrm{PhD}$. You have encouraged me to think and plan for that life. You are the one who first made me realize there are a lot of options out there. You even sent me to symposiums in and outside the Netherlands just to open my eyes to the possibilities. In the process, you have also awakened the entrepreneur in me. Thank you!

Truly, during my PhD I was sitting on the shoulders of Giants!

I would also like to thank the members of the commission for their effort and time in reviewing my thesis.

I would like to thank Marie-Claire van de Voort for helping me with the administration and arrangements for the defense of my thesis. I would also like to thank my paranymphs Kristien Lemmens and Erik Ruijters for agreeing to stand by my side on June the $11^{\text {th }}$. Thank you guys for helping me with the final parts of my promotion.

My sincere appreciations go to all the students I had to "sacrifice" for my $\mathrm{PhD}$ research: Zakaria Brdid, Misha Vrolijk, Linda Herfs, Ingrid Frissen, Maud Beckers, Trees S.Y. von Domburg, Maniyal Radhakrishnan, Marcha Verheijen, Jonathan Cremers, Simone Hendrikse, Gaston Richelle, Jody Lugger, Melissa Cremers. Together, they have taught me more than I could have ever taught them. May they rest in PEACE!

I would also like to thank my father Hussein Moalin Mursal, my uncles Ibrahim Moalin Mursal and Abukar Moalin Mursal. They have always encouraged me to be patient, seek knowledge and always be the best that I can be. Besides their encouragements, they were also the best role models a young man could have ever wished for. 


\section{Acknowledgements}

Special gratitude and appreciation to my mother Fadumo Aweis Abati! Words cannot describe the love that I have for her. Through my $\mathrm{PhD}$, and through life in general, she guarded my sanity by always keeping in touch with me and always keeping me in her prayers. Her love and encouragement has always been a great source of strength. May Allah bestow his mercy on her!

To be honest, I would have to write a book larger than this thesis to express my gratitude for the people in my life. Nevertheless, I hope that they can accept this small but sincere gratitude for everything they have done for me.

Many thanks \& love to everybody!! 


\section{Curriculum vitae}




\section{Curriculum vitae}

\section{Curriculum vitae}

Mohamed Moalin was born in 1983 on April the $18^{\text {th }}$ in Mogadishu, Somalia. In September 2003, he started his study of chemistry at the Radboud University in Nijmegen. He did his master internship in the Department of Physical-Organic and Supramolecular chemistry at the Radboud University in Nijmegen, where he synthesized macrocyclic host-guest molecules with the aim to investigate the kinetics and thermodynamics behind their supramolecular binding behavior. In 2008, he graduated as a Master of Science. In October 2008, he started his PhD project at the department of Toxicology in Maastricht University and at the Research Centre for Material Sciences in Zuyd University of Applied Sciences in Heerlen, which lead to the present thesis. The research described in this thesis was directly supervised by Prof.dr. A. Bast, Dr. G.R.M.M. Haenen and Dr. G.P.F. van Strijdonck, and occasionally supported by Dr. G. Hageman and Prof.dr. P. Borm. Since February 2012, he is an employer of Zuyd University of Applied Sciences in Heerlen and is detached as a supervisor at the Chemelot Innovation and Learning Labs (CHILL) in Geleen.

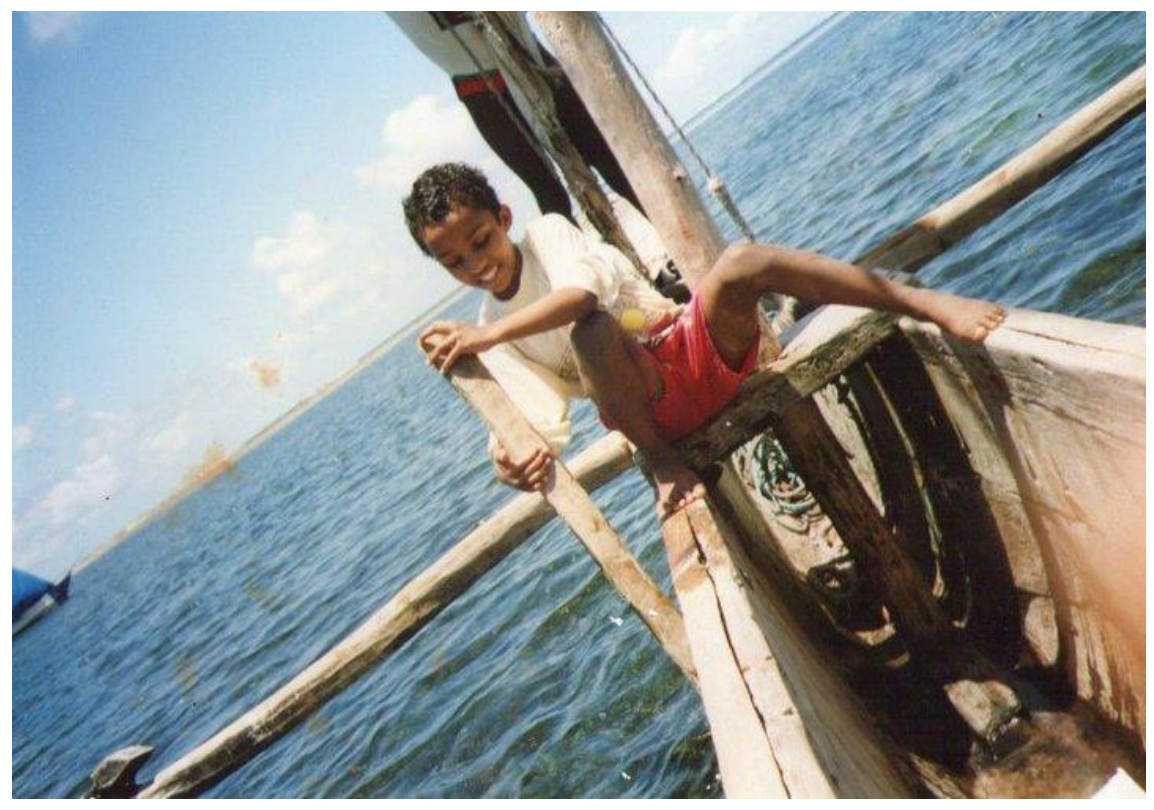


List of publications 


\section{List of publications}

\section{List of publications}

Moalin M, van Strijdonck GPF, Beckers M, Hageman G, Borm P, Bast A and Haenen GRMM. A planar conformation and the hydroxyl groups in the B and C ring play a pivotal role in the antioxidant capacity of quercetin and quercetin derivatives. Molecules. 16, 9636-9650 (2011).

Moalin M, van Strijdonck GPF, Bast A and Haenen GRMM. Competition between ascorbate and glutathione for the oxidized form of methylated quercetin metabolites and analogues: Tamarixetin, 4'O-Methylquercetin, has the Lowest Thiol Reactivity. J. Agric. and Food Chem. 60, 9292-7 (2012).

Deutman ABC, Monnereau C, Moalin M, Coumans RGE, Veling N, Coenen M, Smits JMM, de Gelder R, Elemans JAAW, Ercolani G, Nolte RJM, and Rowan AE. Squaring cooperative binding circles. PNAS. 106, 10471-10476 (2009).

Jacobs H, van der Vijgh WJ, Koek GH, Draaisma GJ, Moalin M, van Strijdonck GPF, Bast A, Haenen GRMM. Characterization of the glutathione conjugate of the semisynthetic flavonoid monoHER. Free Radic. Biol. Med. 46, 1567-1573 (2009).

Jacobs H, Moalin M, Bast A, van der Vijgh WJ, Haenen GRMM. An essential difference between the flavonoids MonoHER and quercetin in their interplay with the endogenous antioxidant network. PLoS One. 5, e13880: 1-9 (2010).

Jacobs H, Moalin M, van Gisbergen M, Bast A, van der Vijgh WJF, Haenen GRMM. An essential difference in the reactivity of the glutathione adducts of the structurally closely related flavonoids monoHER and quercetin. Free Radic. Biol. Med. 51, 2118-2123 (2011).

Jacobs H, Koek GH, Peters R, Moalin M, Tack J, van der Vijgh WJF, Bast A, Haenen GRMM. Differences in pharmacological activities of the antioxidant 
flavonoid monoHER in humans and mice are caused by variations in its metabolic profile. Clin. Pharmacol. Ther. 90, 852-859 (2011).

Moalin M, Hageman G, van Strijdonck GPF, Bast A, Haenen GRMM. Quercetin metabolites in humans. To be submitted

Moalin M, Haenen GRMM, Bast A, van Strijdonck GPF. Protection of the catechol moiety of quercetin through micro-reactor technology. To be submitted

Moalin M, van Strijdonck GPF, Bast A, Haenen GRMM. Quercetin radical's unpaired electron is delocalized in conjugated $\pi$-system of its B-ring. To be submitted

Moalin M, van Strijdonck GPF, Bast A, Haenen GRMM. Peroxynitrite scavenging of quercetin and structural analogues: The AC-ring of quercetin donates the first electron, the B-ring scavenges the AC-ring and safely cages the unpaired electron in the quercetin radical. To be submitted 